Aus der Abteilung Palliativmedizin

(Prof. Dr. med. F. Nauck)

im Zentrum Anaesthesiologie, Rettungs- und Intensivmedizin der Medizinischen Fakultät der Universität Göttingen

\title{
Tumorspezifische Therapien in der Palliativmedizin
}

\section{Indikation, Häufigkeit des therapeutischen Einsatzes und Standpunkte bei der Therapieentscheidung}

\author{
INAUGURAL-DISSERTATION \\ zur Erlangung des Doktorgrades \\ der Medizinischen Fakultät \\ der Georg-August-Universität zu Göttingen \\ vorgelegt von \\ Sabrina Pache \\ aus \\ Nordhorn
}


Dekan: Prof. Dr. med. C. Frömmel

I. Berichterstatter: Prof. Dr. med. F. Nauck

II. Berichterstatter/in: Prof. Dr. med. Binder

III. Berichterstatter/in: Prof. Dr. med. Oppermann

Tag der mündlichen Prüfung: 23.11.2010 


\section{Inhaltsverzeichnis}

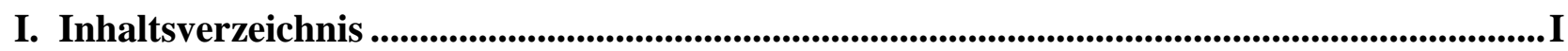

II. Abbildungs- und Tabellenverzeichnis ..........................................................................III

III. Abkürzungsverzeichnis ................................................................................................

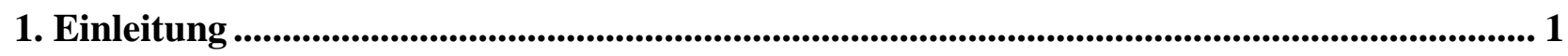

1.1. Zur Entwicklung der Palliativmedizin .......................................................................... 1

1.2. Zur Entwicklung in der Onkologie.......................................................................... 1

1.3. Wissenschaftlicher Hintergrund .............................................................................. 2

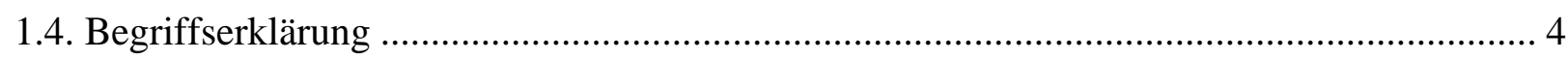

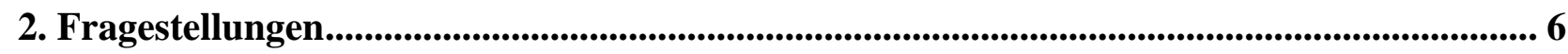

3. Untersuchung und Methodik .............................................................................................. 7

3.1. Hospiz- und Palliativerhebung (HOPE) ...................................................................... 7

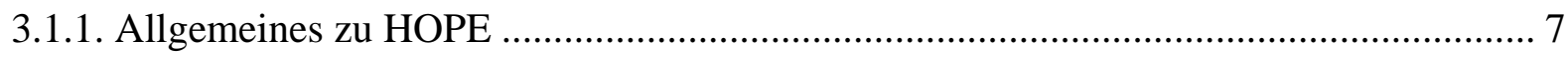

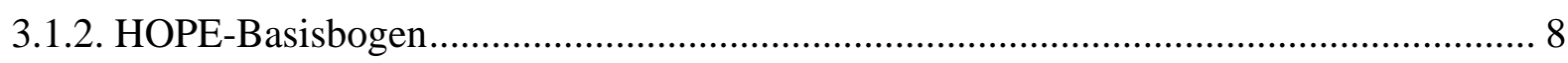

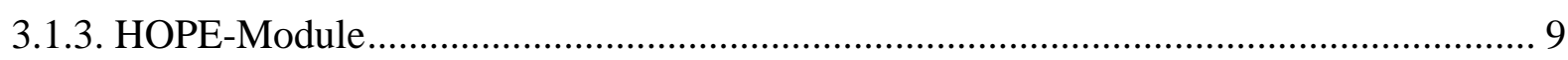

3.1.4. Zusatzmodul: Tumorspezifische Therapien in der Palliativmedizin........................... 10

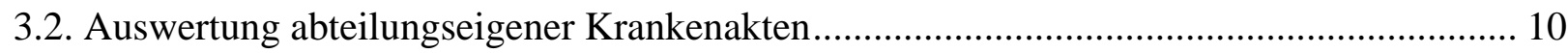

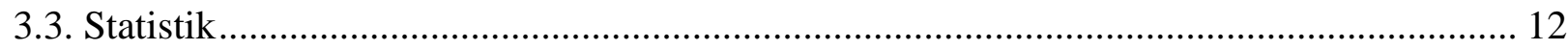

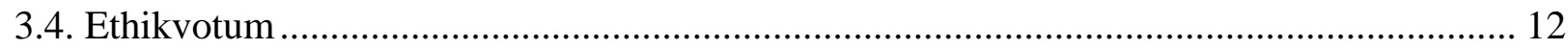

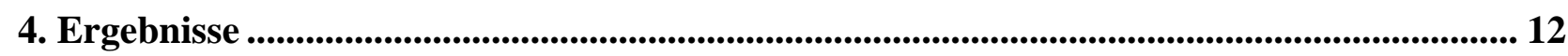

4.1. Behandlungsverläufe der Göttinger Palliativstation ..................................................... 12

4.2. Ergebnisse der Hospiz- und Palliativerhebung 2007 ....................................................... 21

4.2.1. Teilnehmende Einrichtungen und Anzahl der dokumentierten Patienten.................... 21

4.2.2. Demographische Daten der Patientenkollektive ........................................................ 22

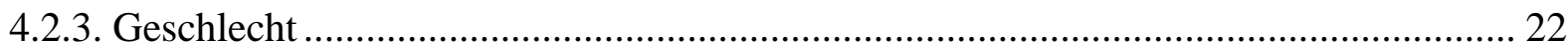

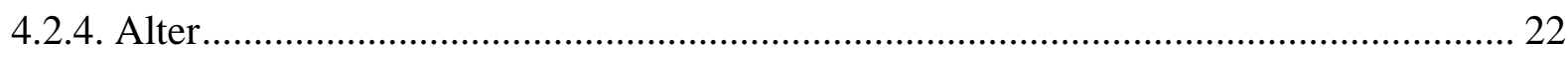

4.2.5. Verweildauer und Versterben innerhalb des Dokumentationszeitraumes .................... 23

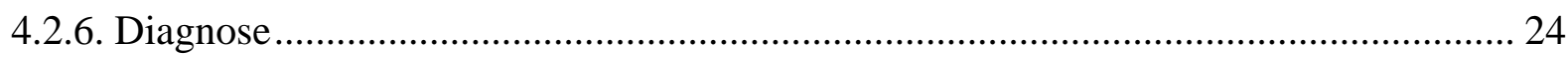

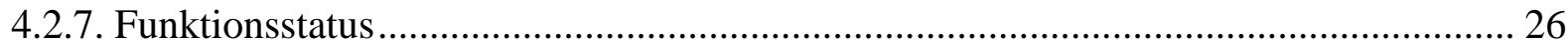




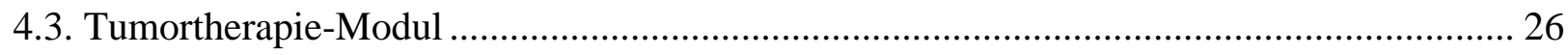

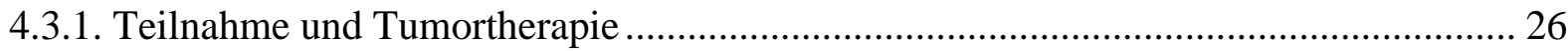

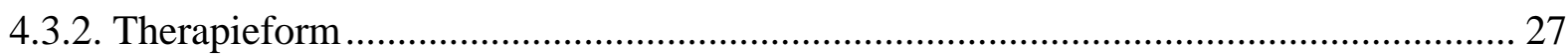

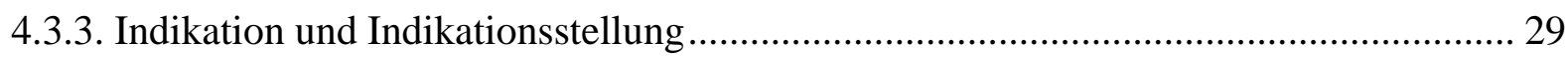

4.3.4. Standpunkte bei der Therapieentscheidung........................................................... 32

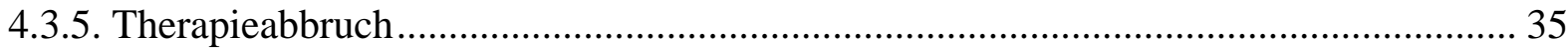

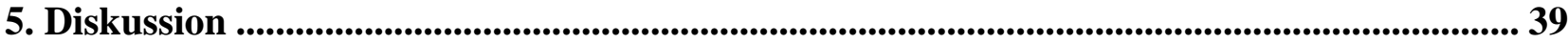

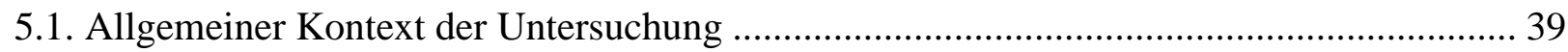

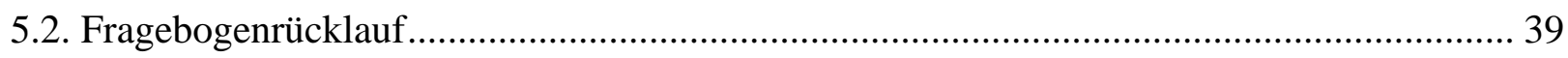

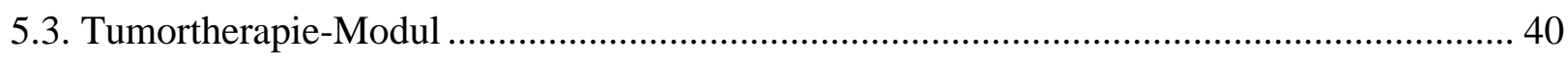

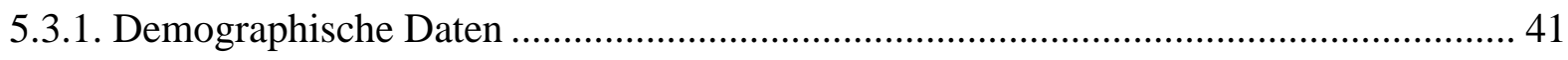

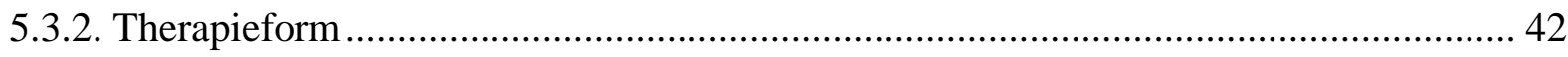

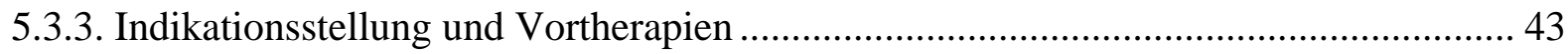

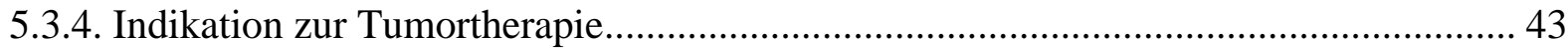

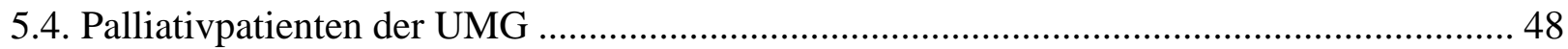

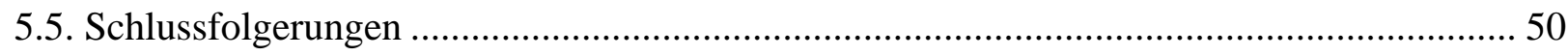

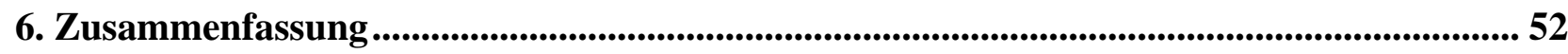

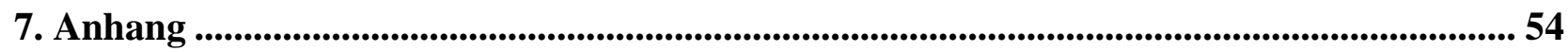

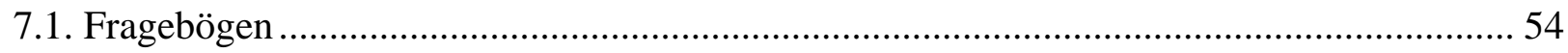

7.1.1. Hospiz- und Palliativerhebung (HOPE) Basisbogen ................................................ 54

7.1.2. Hospiz- und Palliativerhebung (HOPE) Modul Tumortherapie .................................. 55

7.2. Hospiz- und Palliativerhebung (HOPE) Patienteninformation und

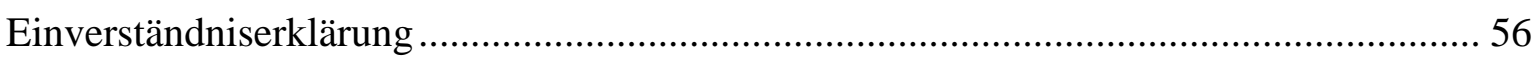

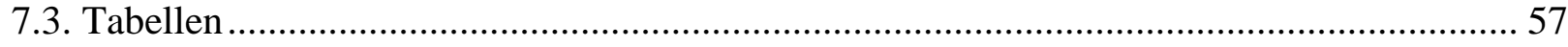

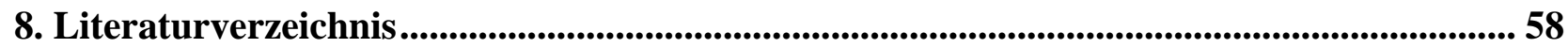

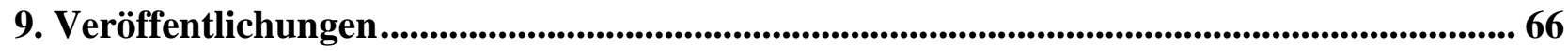




\section{Abbildungs- und Tabellenverzeichnis}

Abbildung 1: Fallzahlen der Palliativstation und chemotherapeutisch behandelter Patienten ....... 13

Tabelle 1: Übersicht der Therapieverläufe zytostatisch behandelter Palliativpatienten ................ 20

Tabelle 2: Teilnehmende Einrichtungen und Patienten HOPE 2007 .......................................... 21

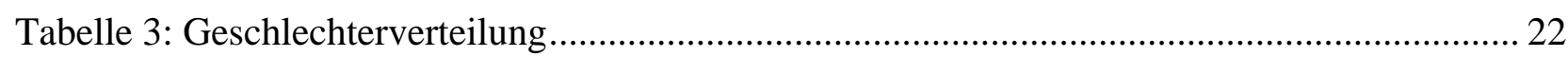

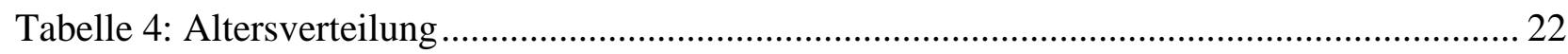

Tabelle 5: Verweildauer und Anzahl der verstorbenen Patienten am Therapieende ...................... 23

Abbildung 2: Anteil der verstorbenen Patienten am Therapieende ............................................. 24

Tabelle 6: Häufigkeit maligner Grunderkrankungen des HOPE-Kollektivs ................................ 25

Tabelle 7: Hauptdiagnosespektrum des Tumortherapie-Kollektivs ............................................. 25

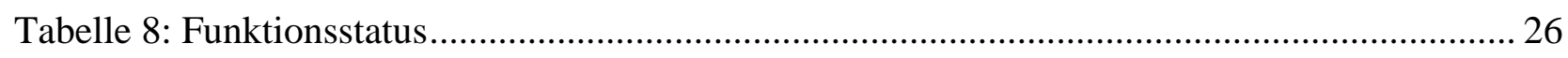

Tabelle 9: Teilnahme am Modul Tumortherapie ..................................................................... 27

Tabelle 10: Therapieform der 467 Tumortherapie-dokumentierten Patienten............................... 28

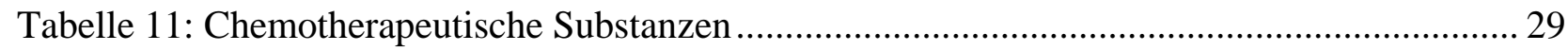

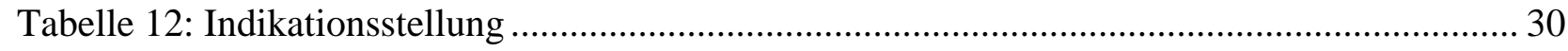

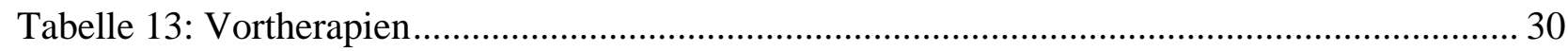

Tabelle 14: Teilnehmende Einrichtungen und Indikation zur Tumortherapie .............................. 31

Tabelle 15: Zugrundeliegende Symptome als Indikation zur Tumortherapie................................ 32

Tabelle 16: Symptomkontrolle oder Tumorgrößenreduktion als Indikation zur Tumortherapie.... 33

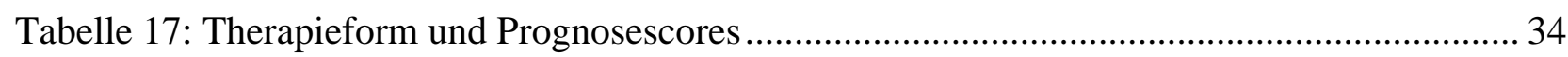

Abbildung 3: Erfolgsbeurteilung der TT nach dem „Schulnotenprinzip“ .................................... 35

Tabelle 18: Vorzeitiger Therapieabbruch …................................................................................. 35

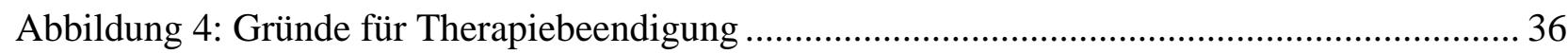

Tabelle 19: Therapieabbruch in Zusammenhang mit der zugrundeliegenden Therapieindikation. 37

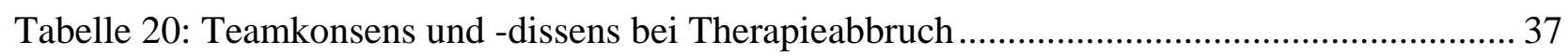

Tabelle 21: Dokumentation des Tumortherapie-Moduls .......................................................... 38

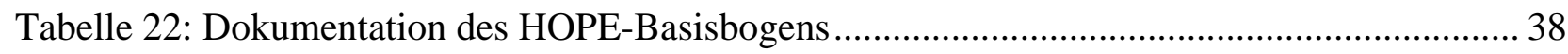

Tabelle 23: Teilnehmende Einrichtungen und Anzahl der dokumentierten Patienten zwischen 1999

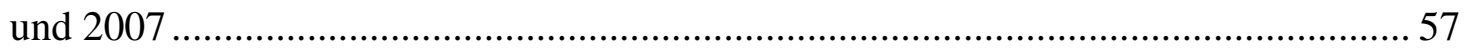




\section{Abkürzungsverzeichnis}

- AA

- Abb.

- abstr

- AP

- BAG

- BSC

- BWS

- bzw.

- ca.

- CLARA

- CUP

- DGHO

- DGP

- d.h.

- DHPV

- DIA

- DK

- DKG

- Dr. med.

- EAPC

- ECF

- ECOG

- ED

- ER

- evtl.

- FOLFOX

- fortg.

- $\mathrm{G}$

- $\mathrm{H}$

- HOPE

- ICD 10

- IKO

- i.th.

- i.v.

- KPS

- LCP

- $\mathrm{m}$

- $\mathrm{M}$

- MIDOS

- mind.

- $\mathrm{N}$

- NSCLC

- o. A.

- ÖGHO

- OS

- PaP-score
Ambulanter Arzt

Abbildung

abstract

Ambulante Pflege

Bundesarbeitsgemeinschaft Hospiz

best supportive care

Brustwirbelsäule

beziehungsweise

circa

Clinical Analysis, Research and Application

cancer of unknown primary

Deutsche Gesellschaft für Hämatologie und Onkologie

Deutsche Gesellschaft für Palliativmedizin

das heißt

Deutscher Hospiz- und Palliativ-Verband

Diagnostik

Dauerkatheter

Deutsche Krebsgesellschaft

Doktor der Medizin

European Association for Palliative Care

Epirubicin, Cisplatin, 5-Fluorouracil

Eastern Cooperative Oncology Group

Erstdiagnose

estrogen receptor

eventuell

Folinsäure, 5-Fluorouracil, Oxaliplatin

fortgesetzt

geriatrische Station

stationäres Hospiz

Hospiz- und Palliativerhebung

International Classification of Disease Version 10

Interdisziplinäre Kurzzeitonkologie

intrathekal

intravenös

Karnofsky Performance Status

Liverpool Care Pathway

männlich

Metastase

Minimales Dokumentationssystem

mindestens

Nod(ul)us

non small cell lung cancer

ohne Angabe(n)

Östereichische Gesellschaft für Hämatologie und Onkologie

Onkologische Station

Palliative Prognostic Score 
- Pat.

- PoBado

- POS

- PPI

- PPS

- Prof.

- PS

- QoL

- $\mathrm{R}$

- RKI

- S.C.

- SCLC

- SGMO

- sog.

- sonst.

- SPSS

- S.

- St.

- St

- s.u.

- $\mathrm{T}$

- Tab.

- TT

- UMG

- u.s.w.

- u.ä.

- V.a.

- vgl.

- VICE

- VIPE

- VS

- WHO

- $\mathrm{W}$

- z.B

- ZNS

- ZVK
Patienten

Psychoonkologische Basisdokumentation

Palliative Care Outcome scale

Palliative Prognostic Index

Palliative Performance Score

Professor

Palliativstation

Quality of Life

Resttumor

Robert-Koch-Institut

subkutan

small cell lung cancer

Schweizerische Gesellschaft für Medizinische Onkologie

so genannte $(\mathrm{r} / \mathrm{s})$

sonstige(r/s)

Statistik-Programm-System für Sozialwissenschaften

Seite

Saint

Station

siehe unten

Tumor

Tabelle

Tumor(spezifische) Therapie

Universitätsmedizin Göttingen

und so weiter

und ähnliche(r/s)

Verdacht auf

vergleiche

Etoposid, Ifosfamid, Carboplatin, Epirubicin

Etoposid, Ifosfamid, Cisplatin, Epirubicin

versus

World Health Organization

weiblich

zum Beispiel

zentrales Nervensystem

zentraler Venenkatheter 


\section{Einleitung}

\subsection{Zur Entwicklung der Palliativmedizin}

Die Palliativmedizin hat sich in jüngster Zeit rasant entwickelt. Dennoch gilt sie in der Literatur nicht als eine „junge Disziplin der Medizin“ (Klaschik und Husebo 1997, Hartenstein 2002). So gehen die institutionellen Anfänge der Palliativmedizin (palliative care) auf das Jahr 1967 zurück, als das St. Christopher’s Hospice in Großbritannien durch Cicely Saunders (1918-2005) errichtet wurde. Sie gilt mit ihrer Arbeit als Begründerin der modernen Hospizbewegung und der Palliativmedizin. In Deutschland entstand die erste Palliativstation 16 Jahre später (1983) in Köln. Im Jahre 2000 existierten bereits 62 deutsche Palliativstationen, davon waren fünf an Universitätskliniken angegliedert (Klaschik et al. 2000, Sabatowski et al. 2001 und 2005). Zum Untersuchungszeitpunkt der vorliegenden Studie, im Jahr 2007, gab es bundesweit 142 Palliativstationen (Deutsche Gesellschaft für Palliativmedizin (DGP), Stand 2/2007). Diese beeindruckende Zunahme palliativmedizinischer stationärer Einrichtungen in Deutschland (Radbruch et al. 2002) und die Implementierung von einheitlichen Dokumentations- und Qualitätssicherungssystemen (z.B. HOPE) sowie eine Intensivierung der Forschung verdeutlichen die rasante Entwicklung und den Fortschritt in der Palliativmedizin. Deutliche - wenn auch nicht hinreichende Entwicklungen sind auch hinsichtlich der palliativmedizinischen Ausbildung und Lehre zu verzeichnen (Ostgathe et al. 2007, Klinkhammer 2007, Laske et al. 2008).

\subsection{Zur Entwicklung in der Onkologie}

Rasante Entwicklungen finden sich auch in der Onkologie. Diese zeigen sich unter anderem in der Ausweitung onkologischer Therapieoptionen bis in den späten Krankheitsverlauf, z.B. durch verbesserte Nebenwirkungsprofile der eingesetzten antineoplastischen Substanzen, durch verbesserte Supportivtherapie, kontinuierliche Applikationsschemata und zunehmend oral verfügbare Applikationen (Reck et al. 2005). Während die Strahlentherapie zur Symptomkontrolle als schmerztherapeutische Option bereits anerkannt und durchgeführt wird (Portenoy und Lesage 1999), war noch bis vor wenigen Jahren „die Indikation für eine Chemotherapie unter der Zielsetzung einer analgetischen Symptomkontrolle nur wenig gesichert“ (Hanekop et al. 2000, S. 635). In klinischen Anwendungsuntersuchungen mit Chemotherapeutika gewinnen allerdings Symptomkontrolle und Lebensqualität als primäres und sekundäres Zielkriterium an Bedeutung (Anderson H et al. 2000, Gralla et al. 2003, 
Maughan et al. 2003, Gridelli et al. 2003, Bezjak et al. 2006, Motzer et al. 2007). Die Aussage „It matters not how long we live, but how“ spiegelt die Relevanz der Lebensqualität auch unter Inkaufnahme einer verkürzten Lebensdauer wider (Festus, Philip James Bailey zitiert von Cardoso et al. 2002, S. 197). Nicht nur für die neueren, sondern auch für eine Vielzahl älterer Chemotherapeutika wurden mittlerweile symptomkontrollierende und andere lebensqualitativ relevante Wirkungen bei Patienten mit fortgeschrittener Erkrankung beschrieben, während die Wirkung auf konventionelle tumorgrößenbezogene (onkologische) Zielkriterien, z.B. objektive response rate, partielle oder komplette Remission, Fünfjahresüberleben u.s.w. weniger eindrücklich ausfällt (Adelstein 1995, Ellis et al. 1995, Tummarello et al. 1995, Burris und Storniolo 1997, Fukuoka et al. 2003, Fuster und Sander 2004). Durch die symptomkontrollierenden Wirkungen beginnen sich die Therapieziele der palliativen Onkologie und diejenigen der Palliativmedizin in stärkerem Maße als bisher zu überschneiden. Insofern können tumorspezifische Therapien mit dem Ziel einer verbesserten Symptomkontrolle ein Bindeglied zwischen Palliativmedizin und Onkologie darstellen und palliativmedizinische Behandlungsmöglichkeiten erweitern (Alt-Epping und Nauck 2007).

Eine (palliative) Chemotherapie kann in palliativmedizinischen Versorgungsbereichen dann indiziert sein, wenn dadurch die Möglichkeit besteht, die Lebensqualität des Patienten zu verbessern (Pott 2007, Klaschik et al. 1998). Dennoch stellen Chemotherapien auf Palliativstationen eine Ausnahme dar (Klaschik et al. 2000). Sowohl Aspekte ärztlicher Weiterbildung und infrastrukturelle Faktoren als auch das palliativmedizinische Selbstverständnis beeinflussen die entscheidungsbegründende Haltung für oder gegen den Einsatz tumorspezifischer Therapien (Alt-Epping et al. 2006). So finden Chemotherapien auf anästhesiologisch-schmerztherapeutisch geprägten Palliativstationen seltener Anwendung als auf Palliativstationen mit onkologischem Hintergrund (Radbruch et al. 2002).

\subsection{Wissenschaftlicher Hintergrund}

Tumorerkrankungen stellen nach den Herz-Kreislauferkrankungen in Deutschland die zweithäufigste Todesursache dar (Statistisches Bundesamt 2007). Patienten mit weit fortgeschrittenen und inkurablen Tumorerkrankungen leiden in den letzten Wochen und Tagen ihres Lebens häufig an tumorassoziierten Schmerzen und / oder an anderen belastenden Symptomen (Strumpf et al. 1996, Radbruch et al. 2003). Die Linderung, bestenfalls die Kontrolle der Schmerzen und damit einhergehend eine Verbesserung der Lebensqualität für 
den Patienten und seine Angehörigen stehen im Mittelpunkt der palliativmedizinischen Behandlungsintention. Nicht nur der Umstand, dass die Mehrzahl der palliativmedizinisch betreuten Erkrankten Tumorpatienten sind und Tumorerkrankungen eine der häufigsten Todesursachen darstellen, sondern auch die Möglichkeit des Einsatzes von Tumortherapien (TT) unter der Zielsetzung einer Symptomkontrolle, verdeutlicht die Überschneidung von Onkologie und Palliativmedizin und die Notwendigkeit der Interdisziplinarität innerhalb der Palliativmedizin. Hartenstein fordert in diesem Zusammenhang eine Kooperation von Onkologie und Palliativmedizin und verweist auf die Notwendigkeit der „Palliativmedizin in der Onkologie“ (Hartenstein 2002, S. 60). Davon abzugrenzen sei der irreführende Begriff „onkologische Palliativtherapie“, welche eine antineoplastische Behandlung bei fehlender kurativer Behandlungsintention mit dem Ziel einer partiellen Tumorregression und, wenn möglich, einer Lebensverlängerung darstellt. Ob und inwieweit auch onkologische Therapiekonzepte palliativmedizinische Optionen erweitern können, also eine „Onkologie in der Palliativmedizin“ möglich und sinnvoll ist, soll in dieser Arbeit am Beispiel der TT zur Symptomkontrolle verdeutlicht werden.

Symptomkontrolle, Lebensqualität und clinical benefit werden in diversen Studien als primäre oder sekundäre Erfolgskriterien genannt. Bei verschiedenen soliden Tumoren konnten symptomkontrollierende und andere lebensqualitative Effekte, die durch unterschiedliche tumorspezifische Substanzen hervorgerufen wurden, nachgewiesen werden. Hier sei auf die Arbeiten von Alt-Epping et al. (2007), Alt- Epping et al. (2006), Klastersky und Paesmans (2001), Reck et al. (2005) und Steele und Klabatsa (2005) verwiesen, die verschiedene Studien zusammenfassen. Auch Kris et al. (2002), Middleton et al. (1998), Pawel et al. (1999) und Shepherd et al. (2005) untersuchten den symptomkontrollierenden Effekt von Chemotherapeutika. Als Beispiel hierfür ist das Studienergebnis von Berry et al. (2006) zu nennen: bei Patienten mit fortgeschrittenem Prostatakarzinom konnten tumorassoziierte Schmerzen sowohl durch die Kombination von Prednison und Mitoxantron als auch durch Docetaxel kombiniert mit Estramustin mit positiver Auswirkung auf die Lebensqualität gelindert werden. Ähnliche Ergebnisse zeigt die Studie von Tannock et al. (2004).

Des Weiteren finden sich Beispiele dafür, dass Chemotherapeutika eine relevante Wirkung auf tumorassoziierte Symptome nach sich ziehen können - unabhängig von einem nachweislichen nennenswerten Effekt auf die Tumorgröße (Natale et al. 2002). Daher kann in der Literatur von einer symptombezogenen Indikation zur Chemotherapie gesprochen werden. Kris et al. stellt 2003 sogar symptomkontrollierende Effekte durch Chemotherapie unter Tumorprogression fest. 


\subsection{Begriffserklärung}

Der Begriff „palliativ“ leitet sich vom lateinischen „pallium“, der Mantel, und „palliare“, lindern, ab. Trotz gleichen Wortstammes ist es notwendig, die palliative Therapie von der Palliativmedizin bzw. palliativmedizinischen Behandlung inhaltlich abzugrenzen (Klaschik et al. 2000, Aichmüller-Lietzmann 1998).

Es wird beispielsweise zwischen einer „Palliativmedizin in der Onkologie“ und einer „Onkologie in der Palliativmedizin“ bzw. einer „onkologischen Palliativmedizin“ unterschieden, aber auch auf Überschneidungen hingewiesen (Hartenstein 2002, Alt-Epping, Nauck 2007). Im Folgenden werden die Begrifflichkeiten kurz erörtert.

\section{Palliativmedizin:}

Der Begriff „pallium“ beschreibt das primäre Anliegen der Palliativmedizin: den Patienten wie durch einen schützenden Mantel, abgeschirmt von belastenden Beschwerden seiner Erkrankung durch die letzte Zeit seines Lebens zu führen (Aichmüller-Lietzmann 1998). Die „umhüllende“, d.h. die ganzheitliche Betreuung und Behandlung von sterbenskranken Patienten (DGP 2003, Klaschik et al. 2001) bedeutet zum einen Interdisziplinarität und Multiprofessionalität, also eine fächerübergreifende Kooperation von Ärzten verschiedener Fachdisziplinen und anderer Berufsgruppen, z.B. Pflegepersonal, Psychologen und Seelsorger (Radbruch et al. 2002). Dies bedeutet, dass interdisziplinäre, z.B. chirurgische, strahlentherapeutische, medikamentöse und nicht medikamentöse therapeutische Verfahren in die Palliativmedizin mit eingeschlossen werden. Zum anderen ist mit „Ganzheitlichkeit“ eine umfassende Betrachtung des Patienten hinsichtlich der physischen, psychischen, sozialen und spirituellen Dimensionen der Betreuung und Behandlung gemeint. Unter Berücksichtigung des Zusammenwirkens verschiedener Einflussfaktoren, z.B. auf das Schmerzerleben, werden Symptome innerhalb eines palliativmedizinischen Gesamtkonzeptes therapiert (Beck D und Kettler 2001, Hanekop et al. 2000). Nach der Definition der WHO ist das Ziel der Palliativmedizin, durch Erkennen, Vorbeugen und Lindern belastender Beschwerden die Lebensqualität Schwerstkranker und Sterbender zu verbessern und deren Autonomie und Würde zu erhalten (Sepulveda et al. 2002). Die Auseinandersetzung mit ethischen und rechtlichen Fragen spielt dabei ebenso eine Rolle (Klaschik et al. 2000).

Nicht eine Verlängerung der Lebenszeit um jeden Preis, sondern eine Verbesserung der Lebensqualität ist das Behandlungsziel. Die Aussage „You can add life to days, even when you cannot add days to life” (Herkunft unbekannt) fasst dieses Konzept treffend zusammen. 
Der Tod soll weder hinausgezögert noch beschleunigt werden. Palliativmedizin wird als „aktive Lebenshilfe“ verstanden (Klaschik et al. 2001, S.71, Hiddemann 2000). Die palliativmedizinische (symptomatische) Therapie befasst sich daher mit der Linderung belastender, häufig tumorassoziierter Symptome. Schmerzen, Dyspnoe, Übelkeit, Erbrechen und Obstipation sind die häufigsten Symptome, welche die Lebensqualität erheblich einschränken können (Radbruch et al. 2003).

Der „Palliativpatient“:

„Palliativpatienten“ haben eine begrenzte Lebenserwartung und leiden an den Symptomen einer inkurablen, progredienten und weit fortgeschrittenen Erkrankung. Dies ist die Definition der Deutschen Gesellschaft für Palliativmedizin (DGP 2003) und der European Association for Palliative Care (EAPC) in Anlehnung an die Definition der Weltgesundheitsorganisation (WHO 1990). Die Mehrzahl der Palliativpatienten leidet unter fortgeschrittenen Tumorerkrankungen, aber auch Patienten mit unheilbaren neurologischen und chronisch internistischen Erkrankungen werden palliativmedizinisch betreut.

Palliative (Tumor-) Therapie und Supportivtherapie:

Die palliative Therapie umfasst in der Onkologie tumorspezifische Behandlungen, welche das Leben verlängern und zu einer Verbesserung der Lebensqualität beitragen können, wenn eine kurative Therapie nicht mehr möglich ist. $\mathrm{Zu}$ den tumorspezifischen Therapien zählen Chemotherapie, Strahlentherapie, Hormontherapie und operative Interventionen. Sie können im Rahmen einer kausalen Therapie durch einen „direkten Tumoreffekt“, z.B. das Zurückdrängen von Tumormassen, Symptomen vorbeugen bzw. diese reduzieren. Die medikamentöse Tumortherapie beinhaltet in der Regel den Einsatz chemisch definierter, intravenös oder per oral zyklisch oder kontinuierlich applizierter zytotoxischer Substanzen („Chemotherapeutika“), die unspezifisch und somit nebenwirkungsträchtig Zellproliferationsprozesse hemmen. Supportive Maßnahmen sollen hier die Nebenwirkungen der Tumortherapie möglichst gering halten. Daneben kommen in der Onkologie neuere Substanzen zum Einsatz, die größtenteils nicht-zytotoxische tumormodifizierende Wirkungen zeigen, sog. targeted therapies. Dazu zählen tumorspezifische Antikörper und small molecules (sog. „Designermoleküle“), die z.B. über die Hemmung membranständiger oder intrazellulärer Tyrosinkinasen wirken (Junker 2002, Beck C und Kneba 2004, Fölsch und Schreiber 2004, Jochims et al. 2006) und die bereits im Zusammenhang mit fortgeschrittenen 
Erkrankungen klinisch untersucht wurden (Saltz et al. 2004, Hurwitz et al. 2004, Kabbinavar et al. 2005, Lin et al. 2006, Geyer et al. 2006, Schöffski et al. 2006, Escudier et al. 2007).

Zusammenfassend lässt sich sagen, dass sog. palliativen Therapien typische onkologische Zielkriterien zugrunde liegen, die sich am tumormetrischen Ansprechen orientieren, während in der Palliativmedizin die Symptomlinderung und - damit einhergehend - die Lebensqualität im Vordergrund der Behandlungsintention stehen.

\section{Fragestellungen}

Aus den oben genannten wissenschaftlichen Voraussetzungen ergibt sich die Frage, ob und mit welcher Indikation tumorspezifische Therapien in den unterschiedlichen palliativmedizinischen Versorgungsstrukturen tatsächlich zum Einsatz kommen. Diese Fragestellung soll in der vorliegenden Studie beantwortet werden. Ein weiterer Schwerpunkt dieser Arbeit ist die Untersuchung der Standpunkte bei der Therapieentscheidung und die Haltung im Palliativteam gegenüber dem Einsatz von Tumortherapien bei Palliativpatienten. Dabei wird der Fokus auf die palliativmedizinische Situation gelegt, um Unterschiede bzw. Gemeinsamkeiten zwischen stationärer Onkologie und stationärer Palliativversorgung aufzuzeigen.

Im Einzelnen sollen insbesondere folgende Fragen beantwortet werden:

- In welchen palliativmedizinischen Versorgungsstrukturen werden Tumortherapien eingesetzt?

- Wie viele Palliativpatienten werden auch chemotherapeutisch behandelt?

- Welche Tumorentitäten und welche Symptome stehen dabei im Vordergrund?

- Mit welcher Indikation kommen Tumortherapien im palliativmedizinischen Setting zum Einsatz?

- Welche demographischen Charakteristika weisen die Palliativpatienten auf, die gleichzeitig chemotherapeutisch behandelt wurden?

- Lässt sich ein bestimmter Standpunkt bei der Therapieentscheidung innerhalb des Teams gegenüber dem Einsatz von tumorspezifischen Therapien erkennen?

Durch die Beantwortung dieser Fragen soll ein Zustandsbericht des bisherigen Einsatzes tumorspezifischer Therapien in palliativmedizinischen Versorgungsbereichen gegeben werden, um daraus Möglichkeiten zur Verbesserung der Behandlung von Palliativpatienten 
abzuleiten. Dabei wird mit Hilfe einer quantitativen Datenerfassung erstmalig der besondere Aspekt der Symptomkontrolle durch Tumortherapien innerhalb der Palliativmedizin beleuchtet.

\section{Untersuchung und Methodik}

\subsection{Hospiz- und Palliativerhebung (HOPE)}

\subsubsection{Allgemeines zu HOPE}

Zur Beantwortung der in der Einleitung dargestellten Fragestellungen wird auf die Datenbank der Hospiz- und Palliativerhebung (HOPE, s.u.) zurückgegriffen.

Die Hospiz- und Palliativerhebung (HOPE) erfasst seit 1999 jährlich bundesweit personen-, krankheits- und therapiebezogene Daten in Einrichtungen, die palliativmedizinische Patienten betreuen. Vom Bundesgesundheitsministerium 1996 initiiert, entwickelte eine multidisziplinäre Arbeitsgruppe - bestehend aus Vertretern mehrerer Palliativstationen (PS), der Deutschen Krebsgesellschaft (DKG) und der DGP - ein Instrument zur Evaluierung von Konzepten und Prozeduren in der Palliativmedizin. HOPE dient der Qualitätssicherung, da die erhobenen Daten Aufschluss über die betreuten Patienten, Therapiemaßnahmen und -erfolge geben und einen Vergleich zwischen den teilnehmenden Einrichtungen analog eines Benchmarkingprozesses ermöglichen.

Seit 1999 werden jährlich deutschlandweit alle Einrichtungen, die Palliativpatienten betreuen, zur Teilnahme an der HOPE-Dokumentation eingeladen. Die Fragebögen wurden seither mehrfach angepasst und erweitert. Zwischen 1999 und 2002 beteiligten sich an der Dokumentation lediglich Palliativstationen (PS), seit 2002 auch onkologische Stationen (OS), stationäre Hospize (H), ambulant tätige Ärzte (AA) und ambulante Pflegedienste (AP). 2002 nahmen außerdem zwei geriatrische Stationen (G) an der HOPE-Dokumentation teil (vgl. Anhang 7.3., Tabelle 26). HOPE wurde bereits in der Vergangenheit zu wissenschaftlichen Fragestellungen herangezogen (Bausewein et al. 2005, Radbruch et al. 2000, Nauck et al. 2004) und bietet damit eine Grundlage für Forschung in der Palliativmedizin. Gefördert wurde HOPE 2007 durch die DKG, die DGP, den Deutschen Hospiz- und Palliativ-Verband (DHPV, früher: Bundesarbeitsgemeinschaft Hospiz (BAG)) und die Firma Mundipharma Limburg, wobei ein Interessenkonflikt zwischen Pharmaunternehmen und der HOPEDokumentation ausgeschlossen werden kann. Eine Koordinationsgruppe, bestehend aus Vertretern von DGP, DKG, DHPV und dem Institut CLARA (Clinical Analysis, Research and Application) ist für die Vorbereitung der Studie, die Datensammlung und für die 
Auswertung der Basisdaten der so genannten Kerndokumentation zuständig. 2007 wurden zum achten Mal palliativmedizinische Einrichtungen (Palliativstationen, stationäre Hospize, palliativärztliche und- pflegerische Ambulanzen sowie onkologische Stationen) identifiziert, über das Projekt in einem Anschreiben informiert und zur Teilnahme eingeladen. Jede teilnehmende Einrichtung ernannte eine Kontaktperson, die an einem Vorbereitungstreffen zur Schulung und Abstimmung teilnahm und die Datenerhebung in ihrer Einrichtung koordinierte. Eine Anmeldung zur online-Dokumentation war ebenso möglich, wie eine Anmeldung zur handschriftlichen Dokumentation. Die HOPE-Dokumente konnten über das Internet (www.dgpalliativmedizin.de, www.palliativmedizin.ukaachen.de, www.hopeclara.de) angefordert werden.

In einem Dokumentationszeitraum von drei Monaten sollten konsekutiv möglichst dreißig neu aufgenommene Patienten unselektiert erfasst werden, d.h. es lagen keine gesonderten Einund Ausschlusskriterien für die teilnehmenden Einrichtungen vor. Die Patienten wurden von Ärzten oder dem Pflegepersonal über die Studie informiert und gaben schriftlich ihre Zustimmung zur Erhebung und Speicherung der Daten (siehe Anhang 7.2.). Eine Dokumentation der Daten erfolgte online mit einer zu diesem Zweck eingerichteten Datenbank (www.hope-clara.de) oder handschriftlich auf den angeforderten und ausgedruckten Fragebögen. Der über ein Kennwort und einen Zugangscode geschützte onlineZugang war über den gesamten Dokumentationszeitraum eingerichtet, die Daten konnten eingesehen und ggf. korrigiert werden. Die Dokumentationsbögen sollten bis zum 30.06.2007 online in die Datenbank eingetragen oder auf Papier ausgefüllt und per Post versandt werden. Dokumentationsbögen, die nach dem 30.06.2007 eintrafen, wurden nicht mehr in die Auswertung einbezogen. Patienten, die während der Dokumentationsphase entlassen worden sind, durften bei einer Wiedervorstellung nicht erneut in die Dokumentation aufgenommen werden.

\subsubsection{HOPE-Basisbogen}

HOPE umfasst einen zweiseitigen Basisbogen (Basisdaten der so genannten Kerndokumentation), der nummeriert und einem Patienten zugeordnet ist, sowie die von den jeweiligen Einrichtungen ausgewählten Module (vgl. Abschnitt 3.1.3.). Auf allen für diesen Patienten dokumentierten Fragebögen ist die Patientennummer als Methode der Pseudonymisierung einheitlich eingetragen. Der Basisbogen soll für alle Patienten in der dreimonatigen Dokumentationsphase zu Beginn und am Ende einer Betreuung, sowie 
möglichst einmal im Verlauf ausgefüllt werden. Zu jedem dokumentierten Patienten sollen demnach mindestens zwei Basisbögen ausgefüllt werden. Dadurch können demografische Daten, die vorliegende Grunderkrankung, eine mögliche Metastasierung, Begleiterkrankungen, Einweisungsumstände und der Funktionsstatus erfasst werden. Außerdem werden Angaben zu den Symptomen und deren Stärke (Fremdbeurteilung), zur Medikation, zu laufenden Therapien, zu medizinischen Hilfsmitteln und zur Pflegebedürftigkeit des Patienten erhoben.

\subsubsection{HOPE-Module}

Die Beteiligung an den Modulen ist den Einrichtungen freigestellt. Das Modul MIDOS („Minimales Dokumentationssystem“) dient der Erfassung von Symptomen, Schmerzen und des Allgemeinzustandes unmittelbar durch den Patienten (Selbsteinschätzung) und ist als einziges Zusatzmodul bisher in allen Dokumentationsjahren beibehalten worden. Die übrigen Module wechseln nach aktuellem Informationsbedarf. In der Dokumentationsphase 2007 konnten neben MIDOS als Selbsteinschätzungsinstrument der Patienten folgende Module verwendet werden:

- Modul DIA: Erweiterte Diagnostik in der Palliativmedizin

- Modul LCP: palliative Betreuung am Lebensende nach dem Liverpool Care Pathway of the Dying (Ellershaw 2002 und 2007, Grossenbacher-Gschwend und Eychmüller 2007)

- Modul TT: tumorspezifische Therapien in der Palliativmedizin.

Neben dem Basisbogen, der patienten- und krankheitsbezogene Daten erfragt, stellt der Fragebogen des Zusatzmoduls „Tumorspezifische Therapien in der Palliativmedizin“, der von der Untersucherin entwickelt und mit den Mitgliedern der HOPE Koordinationsgruppe weiter ausgearbeitet wurde, die wesentliche Datenquelle dieser Arbeit dar. 


\subsubsection{Zusatzmodul: Tumorspezifische Therapien in der Palliativmedizin}

Alle Patienten, die bundesweit in einer der teilnehmenden palliativmedizinischen Einrichtungen während der Dokumentationsphase zwischen dem 15. März und dem 15. Juni 2007 mit HOPE erfasst wurden, sollten auf den Einsatz einer Tumortherapie (TT) überprüft werden.

Der dazugehörige eine Seite umfassende Fragebogen wurde vor Studienbeginn von den Mitarbeitern der palliativmedizinischen Abteilung der UMG im Rahmen eines Pre-Tests auf Anwendbarkeit überprüft. Er ist in zwei Themenkomplexe unterteilt:

Der erste Teil des TT-Bogens beinhaltet Fragen zur Therapieform, zur Vortherapie, zur Indikation, zur verwendeten tumortherapeutischen Substanz, zur Zuständigkeit der Indikationsstellung, zur Prognose und zu den Standpunkten bei der Therapieentscheidung sowie zur Haltung im Palliativteam gegenüber der Fortsetzung oder Einleitung der Tumortherapie. Im Falle einer neu begonnenen Tumortherapie wurde der Bogen zum Zeitpunkt der Therapieeinleitung, bei einer fortgesetzten Vortherapie bei Aufnahme des Patienten ausgefüllt. Der zweite Teil des Fragebogens bezieht sich auf eine eventuelle Beendigung der Tumortherapie und beinhaltet Fragen zum subjektiven Erfolg der Tumortherapie und zu einem eventuellen vorzeitigen Therapieabbruch. Abschließend wurde dokumentiert, wer für das Ausfüllen des Bogens verantwortlich war. Die Fragen 9-12 , die sich auf einen eventuellen Abbruch der Tumortherapie beziehen, sollten nach Abschluss der Therapie beantwortet werden. Es sollte also - anders als beim Basisbogen - nur ein TTFragebogen im Behandlungsverlauf pro Patient ausgefüllt werden. Die Beantwortung der Fragen wurde sowohl durch Ankreuzen einer oder mehrerer Alternativen aus vorgegebenen Möglichkeiten (multiple choice) als auch als Freitextangabe erbeten. Jedem Tumortherapiebogen wurde mit Hilfe der Patientennummer ein Basisbogen zugeordnet. Dadurch konnten zugehörige und für die Fragestellung relevante Informationen vom Basisbogen ergänzend gewonnen werden. Die Daten wurden somit durch Verwendung von Patientennummern bereits zum Zeitpunkt der Dokumentation pseudonymisiert.

Die für diese Arbeit relevanten Fragebögen sind in Anhang 7.1. vollständig wiedergegeben.

\subsection{Auswertung abteilungseigener Krankenakten}

Zusätzlich zur prospektiven Datenerhebung mittels der Hospiz- und Palliativerhebung wurden retrospektiv Daten zum Symptomverlauf und zur Symptomkontrolle der zwischen 1999 bis 
einschließlich 2006 chemotherapeutisch behandelten Patienten der Göttinger Palliativstation anhand der Patientenakten ausgewertet. Diese klinischen Daten wurden mit der bundesweiten HOPE-Erhebung abgeglichen.

Der Zeitraum von 1999 bis einschließlich 2006 wurde aus folgenden Gründen gewählt: Nach ihrer Gründung 1991 war die Göttinger Palliativstation zunächst im Evangelischen Krankenhaus Göttingen-Weende untergebracht und zog 1999 in das Universitätsklinikum Göttingen um. Hier konnten bis zu sieben Patienten von einem Anästhesisten / Palliativmediziner, einem Psychologen und insgesamt neun Pflegekräften betreut werden. Die Palliativstation wurde zu diesem Zeitpunkt konsiliarisch durch die Abteilung Hämatologie / Onkologie mitbetreut. Aus Gründen der Vergleichbarkeit wurde der Zeitraum vor dem Wechsel der Stationsinfrastruktur 1999 nicht in die Datenerhebung einbezogen. Das Ende des Untersuchungszeitraumes wurde auf Ende 2006 gelegt, da zu diesem Zeitpunkt eine erneute Abteilungsumstrukturierung stattfand, die durch einen räumlichen und interdisziplinärpersonellen Zuwachs gekennzeichnet war. Außerdem begann Anfang 2007 eine weitere prospektive Studie, die Patienten einschloss, welche auf der Palliativstation chemotherapeutisch behandelt wurden. Zum Untersuchungszeitpunkt (2007) war die Göttinger Palliativstation eine von fünf universitären bzw. eine von 142 bundesweiten Palliativstationen (DGP, Stand 2007).

Über die Mitarbeiter der Klinikapotheke der Universitätsmedizin Göttingen wurden alle Patienten der Palliativstation Göttingen ermittelt, die zwischen dem 01.01.1999 und dem 31.12.2006 stationär chemotherapeutisch behandelt wurden.

Seitens der Apotheke wurden weitere Informationen über die applizierte Substanz, Dosierung und Applikationsform bereitgestellt. Anhand der dazugehörigen Patientenakten, die zur Einsicht über die Palliativstation vom Zentralarchiv angefordert worden sind, wurden weitere Daten zum Therapieverlauf der behandelten Patienten ermittelt. Die Krankenakte beinhaltet neben Anamnesebögen auch Dokumentationen durch das Pflegeteam und durch die Ärzte zum körperlichen und psychischen Zustand des Patienten, Laborberichte, Medikationen und sonstige ärztliche Anordnungen. Zudem sind ärztliche Konsile und Abschlussberichte früherer Krankenhausaufenthalte sowie Entlassungs- und Abschlussberichte enthalten.

Bei der Bearbeitung der Akten wurde insbesondere auf die Dokumentation von Symptomen im Zusammenhang mit onkologisch-therapeutischen Verfahren geachtet. Neben der Patientenanamnese wurde das Beschwerdebild zum Zeitpunkt und nach der Chemotherapie und der weitere Krankheitsverlauf anhand der Akten epikritisch erhoben und zusammengefasst. Die Erhebung der Daten aus den vorliegenden Akten orientierte sich an 
den Fragestellungen des HOPE-Tumortherapie-Moduls. Die Untersuchung liefert somit Hinweise auf die Qualität der therapeutischen palliativmedizinischen Vorgehensweise in den betrachteten Fällen.

\subsection{Statistik}

Die Übertragung der Rohdaten von der online Datenbank in das Kalkulationsprogramm Microsoft office excel (2003) für windows sowie die statistische Auswertung mit Hilfe des Statistik-Programm-Systems für Sozialwissenschaften (SPSS) Version 8.0 für windows erfolgte durch das datenverarbeitende Institut CLARA und durch die Autorin. Die Daten wurden mit Mitteln der deskriptiven und analytischen Statistik ausgewertet. Mittelwerte und prozentuale Anteile wurden errechnet. Angaben in Prozent wurden auf die erste Nachkommastelle gerundet. Signifikanzen werden mit Hilfe des Chi-Quadrat (Vierfelder)Tests bestimmt, um einen Vergleich von Merkmalen zwischen den Patienten onkologischer Stationen und den Patienten der Palliativstationen leisten zu können. Die statistische Signifikanz wird mit einem p-Wert kleiner 5\% $(0,05)$ festgelegt. Die Auswertungen der eigenen Behandlungsverläufe wurden anhand der Patientenakten deskriptiv zusammengefasst und als Fallberichte beschrieben.

\subsection{Ethikvotum}

Die Studie wurde von der Ethikkommission der Medizinischen Fakultät Göttingen in der Sitzung vom 20.09.2007 zustimmend bewertet.

\section{Ergebnisse}

\subsection{Behandlungsverläufe der Göttinger Palliativstation}

Insgesamt konnten anhand der verfügbaren Patientenakten elf Krankheitsverläufe rekonstruiert werden (Tab. 1), die eine chemotherapeutische (bzw. hormontherapeutische) Mitbehandlung auf der Palliativstation einschlossen (sechs Patienten und fünf Patientinnen). Dies entspricht einem Anteil von 1,4\% der 808 zwischen 1999 und einschließlich 2006 behandelten Patienten (Abb. 1). Das durchschnittliche Alter der elf Patienten mit Chemotherapie beträgt 51 Jahre. 
Abbildung 1: Fallzahlen der Palliativstation und chemotherapeutisch behandelter Patienten

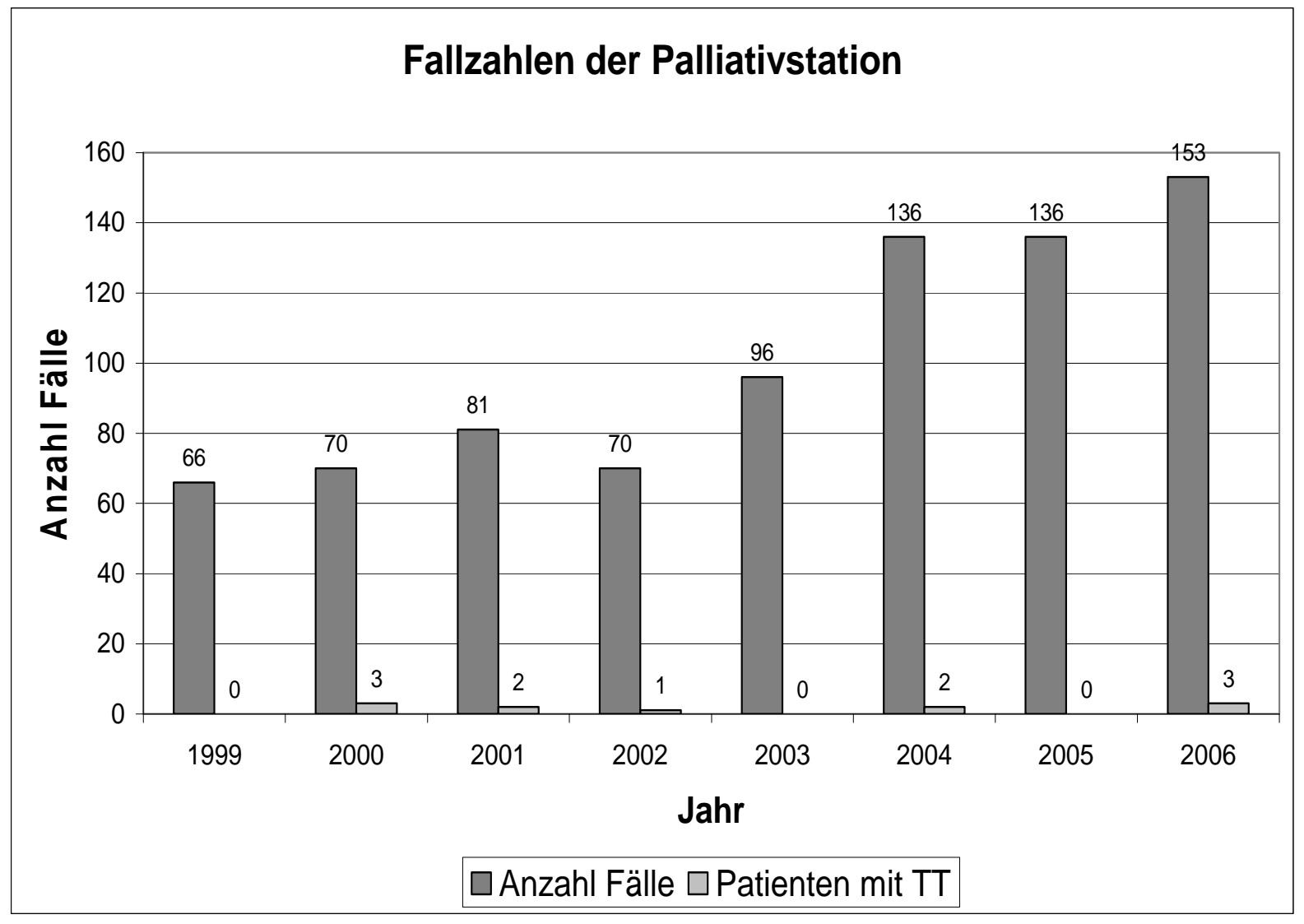

Patient 1

Ein 56-jähriger männlicher Patient mit hepatisch metastasiertem Ösophaguskarzinom (ED 6/99; T4 N2 M1) erhält bei Dysphagie 7/99 eine Implantation eines Ösophagusstents, der jedoch disloziert. Es wird mit einer total parenteralen Ernährung begonnen. Ebenfalls 7/99: Einleitung einer palliativen Chemotherapie nach ECF- Schema (Epirubicin, Cisplatin, 5Fluorouracil) bei ausgeprägtem Therapiewunsch. 11/99 wird eine Besserung der Dysphagie dokumentiert, weshalb die totale parenterale Ernährung versuchsweise ausgesetzt wird. Eine Flüssigkeits- und Nahrungsaufnahme ist über drei Monate möglich. 1/00 wurde der Patient auf die Palliativstation wegen Schmerzen, Erbrechen, Schwäche und Obstipation aufgenommen. Der Patient wünscht hier eine Fortsetzung der Chemotherapie aufgrund seines Appetitmangels. Während des weiteren Aufenthalts: Anämie und Übelkeit. Der Patient kann schließlich symptomkontrolliert nach Hause entlassen werden. 2/00 erfolgt die stationäre Aufnahme durch die Gastroenterologie der Universitätsmedizin Göttingen wegen Reduktion des Allgemein- und Ernährungszustandes, sowie Luftnot und Übelkeit. Eine total parenterale Ernährung - unter Fortsetzung der Chemotherapie - wird erneut begonnen. 3/00 wird der Patient wegen zunehmender Schmerzen und Schwäche auf die Palliativstation verlegt. Dort wird die Chemotherapie auf Wunsch des Patienten zunächst weitergeführt, dann aber wegen 
zunehmender Schwäche und Leukozytopenie abgebrochen. Im weiteren Verlauf entwickelt der Patient Temperaturen und eine Niereninsuffizienz. Er verstirbt drei Wochen nach der letzten Chemotherapiegabe auf der Palliativstation.

\section{Patient 2}

Ein 52-jähriger männlicher Patient mit 4/99 erstdiagnostiziertem kleinzelligen Bronchialkarzinom (SCLC) Stadium IIIa erhält 4-5/99 drei Zyklen VIPE Induktion mit Stammzellsupport und Hochdosischemotherapie (VICE) mit autologer Stammzellrückgabe. 8/99 erfolgt die Pneumektomie mit Lymphadenektomie (R0 Resektion). Nach Radiatio des zentralen Nervensystems und des Mediastinums wird eine komplette Remission dokumentiert.

Bei ossärer Tumormetastase (der Brustwirbelsäule) und intraspinalem Tumorrezidiv mit inkompletter Querschnittssymptomatik wird der Patient 8/00 laminektomiert. Im Anschluss erfolgt die lokale palliative Radiatio der Brustwirbelsäule und es wird mit dem ersten Zyklus der Chemotherapie mit Topotecan (dosisreduziert aufgrund der gleichzeitig laufenden Strahlentherapie) mit nachfolgender Panzytopenie begonnen. 10/00 erfolgt auf Wunsch des Patienten die Fortführung der Chemotherapie auf der Palliativstation wegen Tumorprogress. Dort erhält der Patient den zweiten dosisreduzierten Zyklus der Chemotherapie mit Topotecan unter Rücksprache und Mitbetreuung der Abteilung Hämatologie / Onkologie der UMG. Darunter kommt es zur Aplasie mit nachfolgender therapierefraktärer Pneumonie. Der Patient verstirbt ca. drei Wochen nach der letzten Chemotherapie.

\section{Patient 3}

Ein 57-jähriger männlicher Patient mit nicht-kleinzelligem Bronchialkarzinom (NSCLC) Stadium IV, ED 2/99 (T4 N2 M1, ossär) wird wie folgt therapiert: Pneumektomie (R1), Radiatio des Mediastinums, palliative Radiatio multipler Skelettmetastasen und Bisphosphonattherapie. 2/00 entscheidet sich der Patient gegen eine Chemotherapie. Als Grund gibt er seine psychische Labilität an. 3/00 erfolgt die Aufnahme des Patienten auf die Palliativstation. Hier besteht der Wunsch des Patienten nach weiterer onkologisch-palliativer Therapie und Schmerzlinderung. Bei Aufnahme klagt der Patient über thorakale Schmerzen, Übelkeit, Obstipation, Dysphagie, Anorexie, Atembehinderung und über eine Reduktion des Allgemeinzustandes. Laut strahlentherapeutischem Konsil besteht aufgrund der Vorbehandlung am Myelon keine weitere suffiziente strahlentherapeutische Option. Auf Patientenwunsch wird 4/00 auf der Palliativstation eine Chemotherapie mit Vinorelbin und 
Gemcitabin in Rücksprache mit der Abteilung Hämatologie / Onkologie eingeleitet. Nach Applikation der Zytostatika wird von dem Patienten Panik, Angst, Atemnot und Übelkeit beklagt. Bei erhöhter Temperatur und Entzündungsparametern sowie röntgenologischem Nachweis von pneumonischen Lungeninfiltrationen wird eine antibiotische Therapie (Imipenem plus Cilastatin) begonnen. Im weiteren Verlauf wird bei dem Patient ein paralytischer Ileus festgestellt. Der Patient verstirbt fünf Tage nach letzter ChemotherapieGabe. Als Todesursache wird angegeben: Pneumonie, Lungenembolie, Darmparalyse.

\section{Patient 4}

Eine 39-jährige Patientin mit 9/01 erstdiagnostiziertem NSCLC Stadium IV, T3 N2 M1 (mediastinale Lymphknotenmetastasen, ossäre Metastasen mit Tumoreinbruch in den Spinalkanal) wird 11/01 auf die Palliativstation aufgenommen. Die Patientin klagt während des stationären Aufenthaltes über Knochenschmerz, Übelkeit und Diarrhoen. Von der Palliativstation wird folgendes diagnostische und therapeutische Prozedere initiiert: Radiatio der Brustwirbelsäule, Komplettierung des Staging sowie Planung einer Chemotherapie in Rücksprache mit der Interdisziplinären Kurzzeitonkologie (ambulante Vorstellung). Die palliative Chemotherapie mit Vinorelbin und Cisplatin wird während des stationären Aufenthaltes auf der Palliativstation begonnen. Begleitend erhält die Patientin Bisphosphonate. Die Patientin wird symptomkontrolliert nach Hause entlassen und erhält ambulant den zweiten Zyklus der Chemotherapie. Vor Beginn des dritten Zyklus erfolgt 1/02 ein Restaging, aus dem sich ein Tumorprogress ergibt. Der dritte Zyklus wird daher nicht gegeben. Die Patientin verstirbt 17 Tage nach Applikation der letzten ambulanten Chemotherapie nach einer Pneumonie auf der Palliativstation, wo sie zuvor wegen akuter Schmerzen notfallmäßig aufgenommen wurde.

\section{Patient 5}

Bei einer 62-jährigen Patientin mit ossär metastasiertem Rektumkarzinom (ED 2/99) und neurologischen Ausfällen erfolgt zunächst eine Rektumexstirpation und eine Radiochemotherapie. Ein Rezidiv des Rektumkarzinoms wird 9/99 diagnostiziert. 7/02 erfolgt die stationäre Aufnahme der Patientin auf die Palliativstation wegen Schmerzen, welche zuvor mit Opioiden behandelt wurden, und rezidivierender Subileussymptomatik. Stationär wird eine Chemotherapie mit Irinotecan und 5-Fluorouracil fortgesetzt. Die Patientin kann symptomkontrolliert nach Hause entlassen werden. Anamnestisch waren zwischen 8/02 und 12/02 keine stationären oder ambulanten Krankenhausaufenthalte erforderlich. In dieser Zeit 
bestanden jedoch weiterhin Schmerzen, Schlafstörungen, Fatigue und Unruhe. 12/02 stellte sich die Patientin erneut mit Subileussymptomatik, Schmerzen, Unterschenkelödemen bei Tumorinfiltration der Harnblase und assoziierter Hydronephrose auf der Palliativstation vor. Die Patientin konnte in ein Pflegeheim entlassen werden. Der weitere Krankheitsverlauf ist unbekannt.

\section{Patient 6}

2/05 wird bei einer Hysterektomie einer 40-jährigen Patientin mit rezidivierenden Unterbauchbeschwerden als Zufallsbefund ein Ovarialkarzinom festgestellt. Es erfolgt die Adnexektomie beidseits sowie eine Omentektomie mit histologischem Nachweis einer Peritonealkarzinose: pT3a R2 G2. 3-4/05 wird eine Chemotherapie mit liposomalem Doxorubicin eingeleitet. Hierunter kommt es zum zeitweiligen Ansprechen, dann jedoch zum Progress der Peritonealkarzinose. 5/05 erfolgt eine retroperitoneale Lymphadenektomie. Zwischen März und Juli 2005 erhält die Patientin Carboplatin und Paclitaxel und zwischen Dezember 2005 und September 2006 Doxorubicin. Die Chemotherapie wird jedoch bei Progress abgebrochen. Im Verlauf der Therapie zwischen 12/05 und 9/06: portassoziierte Subklaviathrombose, rezidivierende Lungenarterienembolie bei Beckenvenenthrombose, rezidivierender Aszites, Harnleiterkompression (durch abgekapselten Aszites) sowie Pleuraergüsse beidseits. 10/06 wird die Patientin notfallmäßig mit V.a. Exsikkose auf die Palliativstation aufgenommen. Hier erfolgt die einmalige Gabe von Methotrexat intrathekal bei leptomeningealer Tumoraussaat (meningeosis carcinomatosa / polytope leptomeningeale und kortikale Herde) und zunehmender Desorientiertheit sowie Bewusstseinsstörungen der Patientin. Es wird „keine Befundbesserung“ dokumentiert. Im weiteren Verlauf kommt es zur Verschlechterung der vorbestehenden gastrointestinalen Problematik (Diarrhoen, Übelkeit, Erbrechen) bei intraabdominellem Tumorprogress und beginnendem Nierenversagen. Die Patientin wird eine Woche nach der intrathekalen Methotrexat-Gabe nach Hause entlassen. Der weitere Krankheitsverlauf ist nicht bekannt.

\section{Patient 7}

Eine 66-jährige Patientin mit disseminierten Lebermetastasen (ED 11/05) bei unbekanntem Primärtumor (Cancer of unknown primary, CUP), vermutlich ein cholangiozelluläres Karzinom, erhält eine palliative Chemotherapie mit Gemcitabin. 11/05 wird eine (paraneoplastische) Unterschenkelvenenthrombose diagnostiziert. Die Aufnahme der Patientin auf die Palliativstation erfolgt 1/06 nach Übernahme aus der hausärztlichen 
Betreuung wegen Aszites, Übelkeit, Erbrechen, Schmerzen, Subileussymptomatik und tumorassoziierter Fatigue. Bisher wurde die Patientin ambulant chemotherapiert. Darunter besserten sich die Leberwerte bei objektiver Reduktion des Allgemeinzustandes. Auf der Palliativstation erfolgt die Komplettierung des dritten Zyklus der palliativen Chemotherapie mit Gemcitabin in Rücksprache mit der Abteilung Hämatologie / Onkologie. Es wird eine zunehmende Fatigue festgestellt. Die Patientin wird zur Pflege in der letzen Lebensphase nach Hause entlassen. Der weitere Krankheitsverlauf ist nicht bekannt.

\section{Patient 8}

Eine 37-jährige Patientin erhält 12/01 die Erstdiagnose eines Mammakarzinoms (initial T1 N0 Mx, G2, ER+). Es folgt eine operative Tumorentfernung mit anschließender Radiatio bis 4/02 sowie eine adjuvante Hormontherapie mit Goserelin und Tamoxifen. Außerdem erhält die Patientin im Verlauf eine adjuvante Chemotherapie mit Epirubicin / Cyclophosphamid. 8/03 kommt es zur Exulzeration axillärer Lymphknoten und zur Diagnose disseminierter Lungenfiliae eines Mammakarzinomrezidivs. Zwischen September und November 2003 erfolgt die Umstellung der Hormontherapie auf Exemestan und die Einleitung einer palliativen Erstlinienchemotherapie mit 5-Fluoruracil, Folinsäure und Vinorelbin sowie eine Radiatio. 11-12/03 wird ein Tumorprogress festgestellt. Es zeigt sich eine Zunahme der Lungenfiliae. Außerdem werden erstmalig zerebrale Filiae diagnostiziert. Im November 2003 erhält die Patientin erstmalig eine palliative Zweitlinienchemotherapie mit Paclitaxel. Während des stationären Aufenthaltes der Patientin auf der Palliativstation zwischen Januar und März 2004 äußert die Patientin den Wunsch nach Fortsetzung der Chemotherapie bei Übelkeit, Erbrechen, Dyspnoe, neurologischen Ausfällen, exulzerierendem Tumor und Stauungsdermatitis. Die Chemotherapie wird in reduzierter Dosis unter gleichzeitig stattfindender Strahlentherapie zunächst fortgesetzt, dann jedoch nach drei Gaben Paclitaxel wegen Tumorprogress und weiterer Reduktion des Allgemeinzustandes im Februar 2004 abgebrochen. Zwischen den einzelnen Gaben der Chemotherapie (jeweils eine Woche) wird eine kurzzeitige Verbesserung des Allgemeinzustandes und eine Besserung der zuvor betehenden Stauungsdermatitis aber auch Übelkeit, Erbrechen und Schwäche dokumentiert.

Die Patientin verstirbt ca. vier Wochen nach der letzten Chemotherapie im Multiorganversagen. 


\section{Patient 9}

Bei einem 56-jährigen männlichen Patienten wird im Februar 2004 ein polytop ossär, hepatisch, retroperitoneal, lymphogen und mediastinal metastasiertes Bronchialkarzinom (T2 N3 M1) erstdiagnostiziert. Außerdem wird eine begleitende massive obere Einflussstauung bei Ummauerung der mediastinalen Gefäße beschrieben. Der Patient erhält eine Radiatio des Mediastinums und der ossären Metastasen, Bisphosphonate sowie eine palliative Chemotherapie mit Carboplatin und Gemcitabin. 5-6/04 erfolgt die Aufnahme des Patienten auf die Palliativstation wegen Schmerzen und zur Fortführung der palliativen Chemotherapie. Der Patient erhält zwei Gaben in einwöchigem Abstand. Nach der ersten Applikation der Zytostatika tritt Atemnot auf, die sich jedoch unter Furosemid bessert. Im weiteren Verlauf zeigt sich eine Panzytopenie bei Knochenmarksaplasie mit Aufschub der zweiten Chemotherapie auf der Palliativstation um einen Tag. Nach Rücksprache mit der Abteilung Hämatologie / Onkologie erhält der Patient Gemcitabin in halbierter Dosis. Auch nach der zweiten, dosisreduzierten Chemotherapie tritt Luftnot auf. Diese wird jedoch als anhaltender und intensiver als nach der ersten Chemotherapiegabe beschrieben. Unter Morphin s.c. bessert sich die Luftnot. Der Allgemeinzustand des Patienten reduziert sich im Verlauf. Er verstirbt zwölf Tage nach der letzten dosisreduzierten Chemotherapie in Folge eines Multiorganversagens auf der Palliativstation.

\section{Patient 10}

Im Juli 2006 wird bei einem 39-jährigen männlichen Patienten ein Rektumkarzinom (T3 Nx M1) mit polytopen ossären Metastasen diagnostiziert. Im selben Monat wird eine Chemotherapie nach dem FOLFOX-Schema eingeleitet. 8/06 erfolgt eine Thorakolumbalorthese sowie eine Radiatio der ossären vertebralen Metastasen. 8/06 beschließt die interdisziplinäre Tumorkonferenz, dass eine palliative Chemotherapie mit Vinorelbin oder Gemcitabin möglich sei. Im selben Monat: Aufnahme des Patienten auf die Palliativstation wegen thorakaler Schmerzen. Hier wird die im Juli initiierte Chemotherapie mit Folinsäure, 5-Fluorourocil und Oxaliplatin (FOLFOX) fortgesetzt. Die letzte Gabe dort erfolgt am 12.09.2006. Zwischen 10-11/06 finden sich Dokumentationen zu wiederholten Krankenhausaufenthalten wegen Pleuraergüssen, Anämie, Pneumonie und einem Harnwegsinfekt unter laufender ambulanter (unbekannter) Chemotherapie in der Interdisziplinären Kurzzeitonkologie (IKO). 10/06 wird diese Therapie dort wegen neu aufgetretener ossärer Metastasenherde abgebrochen. Der weitere Krankheitsverlauf ist unbekannt. 


\section{Patient 11}

Bei einem 62-jährigen männlichen Patienten mit 1995 erstdiagnostiziertem lymphogen metastasiertem Prostatakarzinom (danach subtotale Prostatektomie und sekundäre Lymphadenektomie sowie Androgendeprivation) werden 8/01 erstmalig ossäre Metastasen des Prostatakarzinoms diagnostiziert. Im September 2001 zeigt sich bei diffuser Infiltration des Knochenmarks eine Thrombozytopenie sowie eine Anämie. Eine Radiatio über 14 Tage wird 10/01 nach Gabe von Thrombozytenkonzentraten begonnen. Von einer Chemotherapie mit Estramustin und Docetaxel wird aufgrund des knochenmarktoxischen Nebenwirkungsprofils der Chemotherapie abgeraten. Im November 2001 erfolgte die Aufnahme des Patienten auf die Palliativstation. Hier wird die zuvor initiierte Hormontherapie mit Fosfestrol (Östrogen) über mehrere Tage fortgesetzt. Im weiteren Verlauf entwickelt der Patient neurologische Ausfälle und zeigt eine erhöhte Blutungsneigung (Epitaxis). Vier Wochen nach der letzten Fosfestrolgabe verstirbt der Patient auf der Palliativstation. Als Todesursache wird eine intrazerebrale Massenblutung angegeben. 
Tabelle 1: Übersicht der Therapieverläufe zytostatisch behandelter Palliativpatienten

\begin{tabular}{|c|c|c|c|c|c|c|}
\hline Patient & Geschlecht & Alter & Tumorentität & Metastasen & $\begin{array}{c}\text { Applizierte Substanz } \\
\text { auf der } \\
\text { Palliativstation } \\
\end{array}$ & $\begin{array}{c}\text { Zeitraum letzte } \\
\text { Chemogabe bis } \\
\text { Versterben }\end{array}$ \\
\hline 1 & $\mathrm{~m}$ & 56 & $\begin{array}{l}\text { Ösophagus- } \\
\text { karzinom }\end{array}$ & hepatisch & $\begin{array}{l}\text { ECF-Schema } \\
\text { (Epirubicin, Cisplatin, } \\
\text { 5-Fluorouracil) }\end{array}$ & ca. drei Wochen \\
\hline 2 & $\mathrm{~m}$ & 52 & $\begin{array}{l}\text { Bronchial- } \\
\text { karzinom }\end{array}$ & $\begin{array}{l}\text { lymphogen, } \\
\text { ossär }\end{array}$ & Topotecan & ca. drei Wochen \\
\hline 3 & $\mathrm{~m}$ & 57 & $\begin{array}{l}\text { Bronchial- } \\
\text { karzinom }\end{array}$ & ossär & $\begin{array}{l}\text { Vinorelbin und } \\
\text { Gemcitabin }\end{array}$ & ca. eine Woche \\
\hline 4 & $\mathrm{~W}$ & 39 & $\begin{array}{l}\text { Bronchial- } \\
\text { karzinom }\end{array}$ & $\begin{array}{l}\text { lymphogen, } \\
\text { ossär }\end{array}$ & $\begin{array}{l}\text { Cisplatin und } \\
\text { Vinorelbin, Radiatio } \\
\text { der BWS } \\
\text { Bisphosphonat }\end{array}$ & ca. zwei Wochen \\
\hline 5 & $\mathrm{~W}$ & 62 & $\begin{array}{l}\text { Rektum- } \\
\text { karzinom }\end{array}$ & ossär & $\begin{array}{l}\text { Irinotecan und } \\
\text { 5-Fluorouracil }\end{array}$ & $\begin{array}{l}\text { unbekannt, } \\
\text { Entlassung in die } \\
\text { häusliche } \\
\text { Umgebung }\end{array}$ \\
\hline 6 & $\mathrm{~W}$ & 40 & $\begin{array}{l}\text { Ovarial- } \\
\text { karzinom }\end{array}$ & $\begin{array}{l}\text { Peritoneal- } \\
\text { karzinose, } \\
\text { Meningeosis } \\
\text { carcinomatosa }\end{array}$ & Methotrexat i.th. & $\begin{array}{l}\text { unbekannt, } \\
\text { Entlassung in die } \\
\text { häusliche } \\
\text { Umgebung }\end{array}$ \\
\hline 7 & $\mathrm{~W}$ & 66 & CUP & hepatisch & Gemcitabin & $\begin{array}{l}\text { unbekannt, } \\
\text { Entlassung in die } \\
\text { häusliche } \\
\text { Umgebung }\end{array}$ \\
\hline 8 & $\mathrm{~W}$ & 37 & $\begin{array}{l}\text { Mamma- } \\
\text { karzinom }\end{array}$ & $\begin{array}{l}\text { lymphogen, } \\
\text { pulmonal, } \\
\text { zerebral }\end{array}$ & Paclitaxel & ca. vier Wochen \\
\hline 9 & $\mathrm{~m}$ & 56 & $\begin{array}{l}\text { Bronchial- } \\
\text { karzinom }\end{array}$ & $\begin{array}{l}\text { polytop ossär, } \\
\text { hepatisch, } \\
\text { retroperitoneal, } \\
\text { lymphogen, } \\
\text { mediastinal }\end{array}$ & $\begin{array}{l}\text { Carboplatin und } \\
\text { Gemcitabin }\end{array}$ & ca. zwei Wochen \\
\hline 10 & $\mathrm{~m}$ & 39 & $\begin{array}{l}\text { Rektum- } \\
\text { karzinom }\end{array}$ & ossär & $\begin{array}{l}\text { Folinsäure, } \\
\text { 5-Fluorouracil und } \\
\text { Oxaliplatin }\end{array}$ & $\begin{array}{l}\text { unbekannt, } \\
\text { Entlassung in die } \\
\text { häusliche } \\
\text { Umgebung }\end{array}$ \\
\hline 11 & $\mathrm{~m}$ & 62 & $\begin{array}{l}\text { Prostata- } \\
\text { karzinom }\end{array}$ & $\begin{array}{l}\text { lymphogen, } \\
\text { ossär }\end{array}$ & Fosfestrol & ca. vier Wochen \\
\hline
\end{tabular}

\section{Legende:}

m: männlich; w: weiblich; BWS: Brustwirbelsäule; i.th.: intrathekal: CUP: cancer of unknown primary 


\subsection{Ergebnisse der Hospiz- und Palliativerhebung 2007}

\subsubsection{Teilnehmende Einrichtungen und Anzahl der dokumentierten Patienten}

2007 beteiligten sich insgesamt 149 Einrichtungen an der HOPE-Dokumentation, darunter 67 Palliativstationen (PS). Diese Zahl entspricht in etwa der Hälfte (47,2\%) der zum Untersuchungszeitpunkt (2007) bundesweit existierenden Palliativstationen (PS, 142). Neben den 67 teilnehmenden PS füllten auch ambulant tätige Ärzte (AA, 28), stationäre Hospize (H, 24), ambulante Pflegedienste (AP, 22) und onkologische Stationen (OS, 8) den HOPEBasisbogen für insgesamt 3.184 Palliativpatienten aus.

Die Teilnahme an der modulbezogenen Dokumentation stand jeder dieser Einrichtungen frei. Mit Ausnahme der stationären Hospize beteiligten sich alle palliativmedizinischen Versorgungsbereiche an der TT-Dokumentation. Bei 467 Patienten, 14,7\% aller dokumentierten HOPE-Patienten (bei einer Gesamtzahl von 3.184), wurde ein Tumortherapiebogen von 38 Einrichtungen ausgefüllt (Tab. 2). Idealerweise sollten pro teilnehmender Einrichtung 30 Patienten dokumentiert werden. Im Durchschnitt wurden jedoch 21,4 Therapieverläufe pro Einrichtung durch den HOPE-Basisbogen sowie 12,3 Therapieverläufe pro TT-dokumentierender Einrichtung mit dem TT-Modul erfasst.

Tabelle 2: Teilnehmende Einrichtungen und Patienten HOPE 2007

\begin{tabular}{|l|l|r|r|r|r|r|r|}
\hline \multicolumn{1}{|l|}{} & Gesamt & \multicolumn{1}{|c|}{ PS } & \multicolumn{1}{|c|}{ OS } & H & AA & AP \\
\hline Patienten mit TT & Anzahl & 467 & 352 & 23 & 0 & 59 & 33 \\
\hline $\begin{array}{l}\text { Patienten mit } \\
\text { dokumentierter TT }\end{array}$ & Anzahl & 205 & 128 & 20 & 0 & 48 & 9 \\
\hline Patienten mit HOPE & Anzahl & 3184 & 1663 & 143 & 498 & 435 & 445 \\
\hline TT-Patienten / alle & $\begin{array}{l}\text { Anteil } \\
\text { (in \%) }\end{array}$ & 14,7 & 21,2 & 16,1 & 0 & 13,6 & 7,4 \\
\hline Einrichtungen mit TT & Anzahl & 38 & 27 & 2 & 0 & 6 & 3 \\
\hline $\begin{array}{l}\text { Einrichtungen mit } \\
\text { HOPE }\end{array}$ & Anzahl & 149 & 67 & 8 & 24 & 28 & 22 \\
\hline TT-Einrichtung / alle & $\begin{array}{l}\text { Anteil } \\
\text { (in \%) }\end{array}$ & 25,5 & 40,3 & 25 & 0 & 21,4 & 13,6 \\
\hline
\end{tabular}




\subsubsection{Demographische Daten der Patientenkollektive}

Ein besonderes Augenmerk wird im Folgenden auf die stationären Einrichtungen gelegt, um einen Vergleich zwischen Palliativstationen und onkologischen Stationen zu ermöglichen.

\subsubsection{Geschlecht}

Tabelle 3: Geschlechterverteilung

\begin{tabular}{|l|l|r|r|r|r|r|r|}
\hline & Geschlecht & Gesamt & \multicolumn{1}{c|}{ PS } & \multicolumn{1}{c|}{ OS } & H & AA & \multicolumn{1}{c|}{ AP } \\
\hline TT & weiblich & $58,0 \%$ & $60,0 \%$ & $45,5 \%$ & - & $50,9 \%$ & $57,6 \%$ \\
\hline TT & männlich & $42,0 \%$ & $40,0 \%$ & $54,5 \%$ & - & $49,1 \%$ & $42,4 \%$ \\
\hline HOPE & weiblich & $51,7 \%$ & $52,7 \%$ & $49,7 \%$ & $53,8 \%$ & $49,9 \%$ & $47,6 \%$ \\
\hline HOPE & männlich & $46,8 \%$ & $45,9 \%$ & $48,3 \%$ & $43,6 \%$ & $47,8 \%$ & $52,4 \%$ \\
\hline
\end{tabular}

51,7\% der Patienten, die mit HOPE dokumentiert wurden, waren Frauen, 46,8\% waren Männer. Außerdem fanden sich 1,5\% der HOPE-Bögen ohne Angaben zum Geschlecht. Mit der TT-Dokumentation wurden 58\% Frauen und 42\% Männer erfasst. Tabelle 3 zeigt, dass für weibliche Patienten in allen Einrichtungen (mit Ausnahme der onkologischen Stationen) etwas häufiger als für männliche Patienten ein Tumortherapiebogen bzw. Basisbogen ausgefüllt wurde.

\subsubsection{Alter}

Patienten, für die ein TT-Modul dokumentiert wurde, sind im Mittel nicht wesentlich jünger (67,5 Jahre) als das durch HOPE dokumentierte Gesamtkollektiv (67,8 Jahre).

Tabelle 4: Altersverteilung

\begin{tabular}{|c|c|c|c|c|c|c|c|}
\hline & & \multicolumn{6}{|c|}{ Alter in Jahren } \\
\hline & & Gesamt & PS & OS & $\mathbf{H}$ & $\mathbf{A A}$ & $\mathbf{A P}$ \\
\hline TT & Mittelwert & 67,5 & 67,4 & 69,4 & - & 66,1 & 70,6 \\
\hline HOPE & Mittelwert & 67,8 & 67,2 & 66,3 & 70,1 & 67,3 & 68,5 \\
\hline
\end{tabular}




\subsubsection{Verweildauer und Versterben innerhalb des Dokumentationszeitraumes}

Bei etwas längerer Verweildauer der TT-Patienten (20,5 Tage) gegenüber der Gesamtgruppe von HOPE (18,2 Tage) ist der Gesamt-Anteil verstorbener TT-Patienten (22,3\%) geringer als der des HOPE-Gesamtkollektivs (31,1\%). Der Anteil verstorbener Patienten der Palliativstationen ohne TT-Dokumentation (32,8\%) ist höher als der Anteil mit TTDokumentation (24,4\%). Die onkologischen Stationen dokumentierten 18 verstorbene Patienten im HOPE-Gesamtkollektiv (12,6\%) und zwei verstorbene Patienten (8,7\%) mit TTModul (Tab. 5). Der Anteil verstorbener Patienten auf Palliativstationen unterscheidet sich signifikant vom Anteil derjenigen Patienten, die auf onkologischen Stationen im Dokumentationszeitraum verstarben (HOPE-Gesamtkollektiv PS vs OS; p < 0,05; (Abb. 2)).

Tabelle 5: Verweildauer und Anzahl der verstorbenen Patienten am Therapieende

\begin{tabular}{|l|l|r|r|r|r|r|r|}
\hline \multicolumn{1}{|l|}{} & Gesamt & \multicolumn{1}{|c|}{ PS } & \multicolumn{1}{|c|}{ OS } & H & AA & AP \\
\hline Verweildauer TT & Mittelwert & 20,5 & 13,8 & 12,7 & - & 48,5 & 33,4 \\
\hline $\begin{array}{l}\text { Verweildauer } \\
\text { HOPE }\end{array}$ & Mittelwert & 18,2 & 13,1 & 13,6 & 19,6 & 31,1 & 27,4 \\
\hline $\begin{array}{l}\text { Therapieende } \\
\text { verstorben TT }\end{array}$ & Anzahl & 104 & 86 & 2 & - & 7 & 9 \\
\hline $\begin{array}{l}\text { Therapieende } \\
\text { verstorben HOPE }\end{array}$ & Anzahl & 990 & 545 & 18 & 183 & 82 & 162 \\
\hline
\end{tabular}


Abbildung 2: Anteil der verstorbenen Patienten am Therapieende

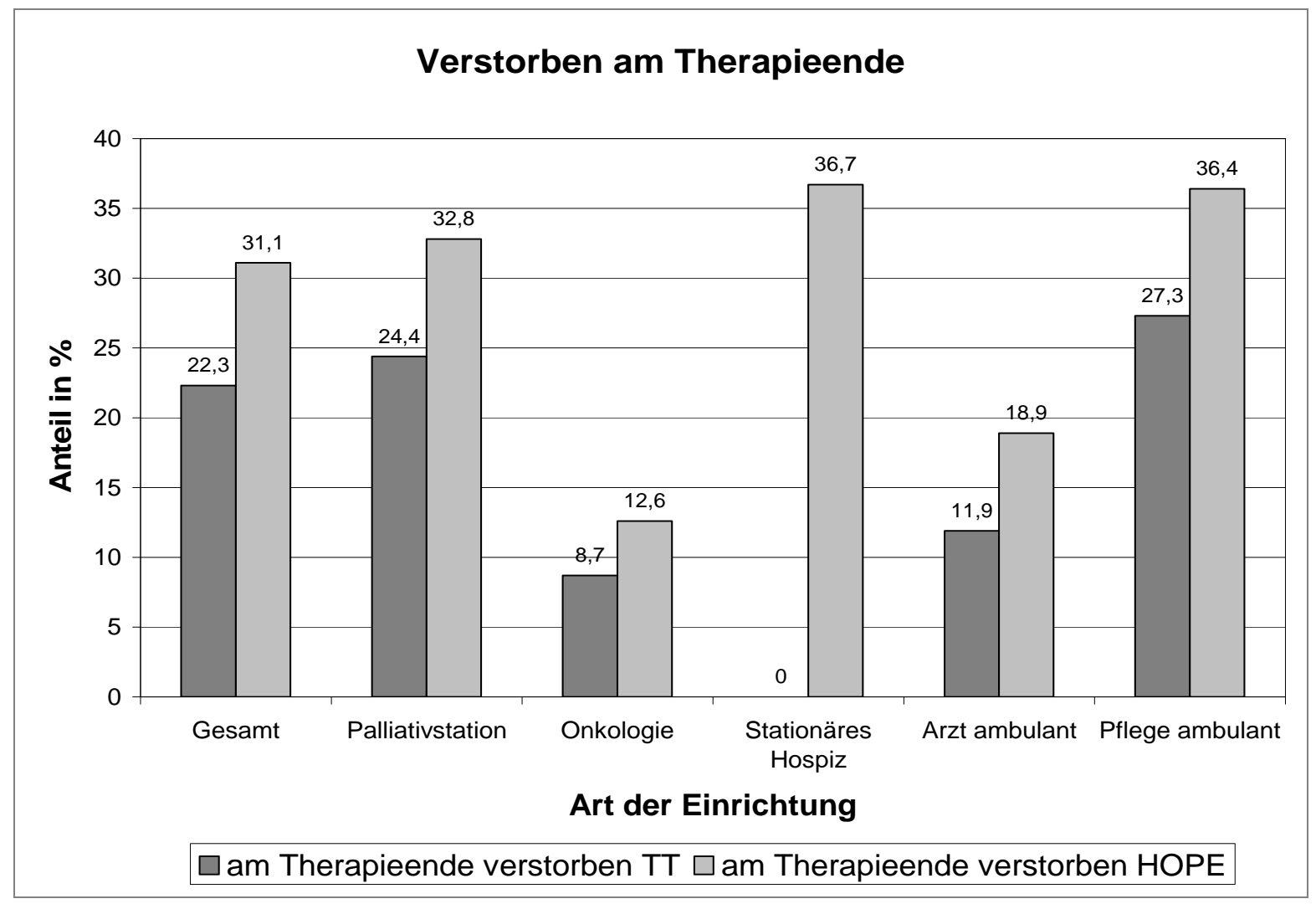

104 Patienten (22,3\% des TT-Kollektivs: 467) mit TT-Dokumentation verstarben am Therapieende (Abb. 2). Im HOPE-Kollektiv verstarben 990 Patienten (31,1\% des HOPEGesamtkollektivs: 3.184). PS-Patienten, die mit dem TT-Modul dokumentiert wurden, verstarben zwar seltener als andere PS-Patienten, dennoch verstarben PS-Patienten mit dokumentierter TT nicht signifikant häufiger ( $\mathrm{p}>0,05(0,085))$ als onkologische Patienten mit dokumentierter TT. Auf Palliativstationen und in der ambulanten Pflege verstarben mehr Patienten als in onkologischen Therapiebereichen mit oder ohne TT-Dokumentation (24,4\% PS bzw. 27,3\% AP vs 8,7\% OS bzw. 11,9\% AA).

\subsubsection{Diagnose}

Die Diagnose konnte durch Freitext oder ICD-10-verschlüsselt (international classification of diseases Version 10) dokumentiert werden. Mehrfachnennungen waren möglich. Bösartige Neubildungen nahmen mit 91,3\% den Schwerpunkt aller Diagnosegruppen der HOPEdokumentierten Patienten ein (95,1\% auf onkologischen Stationen versus 89,7 \% auf Palliativstationen, $\mathrm{p}<0,05(0,0381))$.

Bei der Mehrzahl dieser Patienten (88\%) waren zum Aufnahmezeitpunkt Metastasen bekannt (91,4\% bei PS, 92,6\% bei onkologischen Palliativpatienten) (Tab. 6). 
Tabelle 6: Häufigkeit maligner Grunderkrankungen des HOPE-Kollektivs (Mehrfachnennungen waren möglich)

\begin{tabular}{|l|r|r|r|r|r|r|}
\hline \multicolumn{1}{|c|}{ Diagnose (in \%) } & Gesamt & \multicolumn{1}{|c|}{ PS } & \multicolumn{1}{c|}{ OS } & \multicolumn{1}{c|}{ H } & \multicolumn{1}{|c|}{ AA } & \multicolumn{1}{|c|}{ AP } \\
\hline bösartige Neubildung & 91,3 & 89,7 & 95,1 & 90,5 & 92,1 & 96,4 \\
\hline $\begin{array}{l}\text { davon mit } \\
\text { dokumentierten } \\
\text { Metastasen }\end{array}$ & 88,0 & 91,4 & 92,6 & 79,6 & 87,2 & 84,2 \\
\hline
\end{tabular}

Auch bei denjenigen Patienten, für die das TT-Modul dokumentiert wurde, dominieren maligne Erkrankungen unter den Hauptdiagnosen (91,2\%) als Erstnennung, während für 7,7\% der TT-Patienten eine nicht-neoplastische Erkrankung als Hauptdiagnose dokumentiert wurde. Bei 1,1\% der Patienten erfolgte keine Angabe zur Diagnose. Bei den Tumorerkrankungen der 467 dokumentierten TT-Patienten überwogen Tumore des Gastrointestinaltraktes, gefolgt von Tumoren des Respirationstraktes und der Brust (Tab. 7).

Tabelle 7: Hauptdiagnosespektrum des Tumortherapie-Kollektivs

\begin{tabular}{|c|c|c|c|}
\hline ICD- 10 & Diagnosen & Patienten (Anzahl) & $\begin{array}{c}\text { Patienten } \\
\text { (Anteil in \%) }\end{array}$ \\
\hline C00- C14 & Mund und Pharynx & 11 & 2,4 \\
\hline C15- C26 & Gastrointestinaltrakt & 126 & 27,0 \\
\hline C30- C39 & Respirationstrakt & 69 & 14,8 \\
\hline C40- C41 & skelettales System & 1 & 0,2 \\
\hline C43- C44 & Haut & 9 & 1,9 \\
\hline C45- C49 & Weichteilgewebe & 7 & 1,5 \\
\hline C50 & Brust & 67 & 14,3 \\
\hline C51- C58 & weiblicher Genitaltrakt & 31 & 6,6 \\
\hline C60- C63 & männlicher Genitaltrakt & 27 & 5,8 \\
\hline C64- C68 & harnableitende Wege & 28 & 6,0 \\
\hline C69- C72 & Auge und ZNS & 11 & 2,4 \\
\hline C73- C75 & endokrine Drüsen & 1 & 0,2 \\
\hline C76- C80 & $\begin{array}{l}\text { undefinierter primärer oder } \\
\text { sekundärer Tumor }\end{array}$ & 13 & 2,8 \\
\hline \multirow[t]{2}{*}{ C81- C96 } & Lymphome, Leukämie & 16 & 3,4 \\
\hline & sonst. maligne Erkrankungen & 9 & 1,9 \\
\hline Gesamt & alle malignen Erkrankungen & 426 & 91,2 \\
\hline Gesamt & nicht dokumentiert / o. A. & 5 & 1,1 \\
\hline Gesamt & $\begin{array}{l}\text { nicht-neoplastische } \\
\text { Erkrankungen }\end{array}$ & 36 & 7,7 \\
\hline Gesamt & Hauptdiagnosen & 467 & $100 \%$ \\
\hline
\end{tabular}




\subsubsection{Funktionsstatus}

Der Funktionsstatus der dokumentierten Patienten wurde mit ECOG (Eastern Cooperative Oncology Group) erfasst. Dieser stellt eine Weiterentwicklung der Karnofsky Performance Status Scale (von maximal 100 Prozent (keinerlei Einschränkungen) bis zu 0 Prozent (Tod)) in Hinblick auf die Pflegebedürftigkeit und Chemotherapiefähigkeit des Patienten dar und reicht von ECOG 0 (normale Aktivität) bis ECOG 4 (permanent bettlägerig) (Tab. 8).

Tabelle 8: Funktionsstatus

\begin{tabular}{|l|r|r|r|r|r|r|}
\hline & Gesamt & \multicolumn{1}{|c|}{ PS } & \multicolumn{1}{|c|}{ OS } & H & AA & AP \\
\hline $\begin{array}{l}\text { Funktionsstatus (ECOG) bei } \\
\text { Aufnahme }\end{array}$ & 3,0 & 3,1 & 2,4 & 3,5 & 2,3 & 2,9 \\
\hline $\begin{array}{l}\text { Anteil Patienten mit ECOG 3 } \\
\text { oder 4 bei Aufnahme (in \%) }\end{array}$ & 72,6 & 78,3 & 48,2 & 90,1 & 47,7 & 67,7 \\
\hline
\end{tabular}

Die dokumentierten Patienten wurden mit einem durchschnittlichen ECOG-Wert von 3,0 aufgenommen. Der Funktionsstatus der Patienten einer Palliativstation wurde höher bewertet $(3,1)$ und war somit schlechter, als derjenige der Patienten onkologischer Stationen $(2,4)$. So finden sich auch anteilig mehr Patienten mit einem ECOG von 3 oder 4 bei Aufnahme einer Palliativstation (78,3\%) als Patienten einer onkologischen Station (48,2\%).

\subsection{Tumortherapie-Modul}

\subsubsection{Teilnahme und Tumortherapie}

Abgesehen von stationären Hospizen $(\mathrm{H})$ beteiligten sich alle übrigen Einrichtungen am TTModul (Tab. 9). Um die Anschaulichkeit der Tabellen und Grafiken zu vereinfachen, werden die Stationären Hospize im Folgenden nicht weiter aufgeführt. 
Tabelle 9: Teilnahme am Modul Tumortherapie

\begin{tabular}{|c|c|c|c|c|c|}
\hline Patienten & Gesamt & PS & OS & AA & AP \\
\hline mit TT-Modul & 467 & 352 & 23 & 59 & 33 \\
\hline $\begin{array}{l}\text { mind. eine TT } \\
\text { fortgesetzt }\end{array}$ & 91 & 57 & 5 & 25 & 4 \\
\hline $\begin{array}{l}\text { mind. eine TT } \\
\text { neu }\end{array}$ & 120 & $\begin{array}{r}75 \\
\text { (7,2\% aller } \\
\text { PS-Pat.) }\end{array}$ & $\begin{array}{r}17 \\
\text { (11,9\% aller } \\
\text { OS-Pat.) }\end{array}$ & $\begin{array}{r}23 \\
\text { (5,3\% aller } \\
\text { AA-Pat.) }\end{array}$ & $\begin{array}{r}5 \\
\text { (1,1\% aller } \\
\text { AP-Pat.) }\end{array}$ \\
\hline keine TT & 262 & 224 & 3 & 11 & 24 \\
\hline eine TT & 205 & 128 & 20 & 48 & 9 \\
\hline TT abgebrochen & 93 & 74 & 7 & 10 & 2 \\
\hline
\end{tabular}

Insgesamt wurden 467 TT-Bögen eingereicht, wobei sich anteilig mehr Palliativstationen (75,4\%) beteiligten als onkologische Stationen (4,9\%). Die Vorlage des TT-Bogens bedeutete jedoch nicht, dass auch eine Tumortherapie fortgesetzt oder begonnen wurde. Daher wurde nach einer Fortsetzung oder Initiierung einer TT gefragt: Auf 205 (128 PS vs 20 OS) Therapiebögen wurden insgesamt 211 Tumortherapien dokumentiert, entweder als fortgesetzte (91) oder als neu begonnene (120) TT. Das entspricht 6,4\% des HOPEGesamtkollektivs. Auf 6 TT-Bögen wurden demnach zwei verschiedene TT dokumentiert. Bei 262 (56,1\%; entsprechend der Gesamtzahl aller zurückgesendeten TT-Bögen (467) minus der Bögen mit dokumentierter TT (205)) der Patienten mit einem Tumortherapiebogen wurde dokumentiert, dass keine Tumortherapie fortgesetzt oder begonnen wurde. In 50 dieser Bögen (entspricht 19,1\%) wurde angegeben, dass eine Tumortherapie vorzeitig abgebrochen worden sei. 15 weitere verneinten dies. 50 von 262 ohne TT dokumentierten demnach TT-Abbrüche ohne Angabe einer evtl. Vortherapie. An dieser Stelle ist unklar, auf welche TT Bezug genommen wurde. Insofern kann davon ausgegangen werden, dass neben den 205 Patienten, für die eindeutig eine Tumortherapie dokumentiert wurde, weitere Tumortherapien bei bis zu 50 Patienten durchgeführt wurden, die jedoch nicht eindeutig dokumentiert wurden.

\subsubsection{Therapieform}

Insgesamt 247 Therapien wurden bei den 205 Patienten mit Angaben zur Tumortherapie dokumentiert, darunter sowohl neu initiierte als auch fortgesetzte Tumortherapien. In 43,7\% aller TT wurden zytotoxische i.v. Chemotherapien appliziert. 
Tabelle 10: Therapieform der 467 Tumortherapie-dokumentierten Patienten (Mehrfachnennungen waren möglich)

\begin{tabular}{|l|r|r|r|r|r|r|r|r|r|r|r|r|}
\hline & \multicolumn{1}{|c|}{} & $\mathbf{0 1}$ & $\mathbf{0 2}$ & $\mathbf{0 3}$ & $\mathbf{0 4}$ & $\mathbf{0 5}$ & $\mathbf{0 6}$ & $\mathbf{0 7}$ & $\mathbf{0 8}$ & $\mathbf{0 9}$ & $\mathbf{1 0}$ Total \\
\hline neu & 61 & 10 & 3 & 10 & 2 & 33 & 10 & 0 & 8 & 9 & 146 \\
\hline fortg. & 47 & 13 & 4 & 19 & 5 & 10 & 1 & 0 & 0 & 2 & 101 \\
\hline $\begin{array}{l}\text { Gesamt } \\
\text { (neu + } \\
\text { fortg.) }\end{array}$ & 108 & 23 & 7 & 29 & 7 & 43 & 11 & 0 & 8 & 11 & $\mathbf{2 4 7}$ \\
\hline o. A. & 359 & 444 & 460 & 438 & 460 & 424 & 456 & 467 & 459 & 456 & 467 \\
\hline
\end{tabular}

TTF01: intravenöse, zyklische oder kontinuierliche zytotoxische Chemotherapie TTF02: per orale, zyklische oder kontinuierliche zytotoxische Chemotherapie TTF03: tumorspezifischer Antikörper TTF04: Hormontherapie TTF05: per orale Tyrosinkinasehemmer oder andere „targeted therapy“ TTF06: Strahlentherapie TTF07: endoskopische Intervention TTF08: nuklearmedizinische Therapie TTF09: operative Intervention TTF10: andere Verfahren

Bei der Frage nach den applizierten Substanzen / Regimen / Modi bestand die Möglichkeit zu einer Freitextangabe. Es zeigte sich, dass die Mehrzahl der TT-dokumentierten Patienten mit Angaben zur verwendeten Substanz eine Monotherapie mit einem Zytostatikum (68) erhielten. Die folgende Tabelle gibt Auskunft über die verwendeten Substanzen der 68 Chemotherapien mit jeweils einer Substanz. Es zeigte sich, dass unter den verwendeten Chemomonotherapiesubstanzen insbesondere Antimetabolite (41,2\%) und darunter die Pyrimidinanaloga Gemcitabin und Capecitabin am häufigsten zum Einsatz kamen. 
Tabelle 11: Chemotherapeutische Substanzen (Freitexteingabe)

\begin{tabular}{|c|c|c|c|c|}
\hline $\begin{array}{l}\text { Zytostatika- } \\
\text { Gruppe }\end{array}$ & Wirkstoff & Anzahl & insgesamt & $\begin{array}{l}\text { Anteil der Gruppe } \\
\text { (in \%) }\end{array}$ \\
\hline \multirow[t]{4}{*}{ Antimetabolit } & Gemcitabin & 13 & & \\
\hline & Capecitabin & 11 & & \\
\hline & 5-Fluorouracil & 3 & & \\
\hline & Pemetrexed & 1 & 28 & 41,2 \\
\hline \multirow[t]{2}{*}{ Taxan } & Paclitaxel & 3 & & \\
\hline & Docetaxel & 8 & 11 & 16,2 \\
\hline \multirow[t]{2}{*}{ Alkaloid } & Vinorelbin & 6 & & \\
\hline & Vinblastin & 1 & 7 & 10,3 \\
\hline \multirow[t]{5}{*}{ Alkylans } & Bendamustin & 3 & & \\
\hline & Temozolomid & 3 & & \\
\hline & Trofosfamid & 2 & & \\
\hline & Fortemustin & 1 & & \\
\hline & Cyclophosphamid & 1 & 10 & 14,7 \\
\hline \multirow{2}{*}{$\begin{array}{l}\text { Topoisomerase- } \\
\text { Hemmer }\end{array}$} & Topotecan & 3 & & \\
\hline & Mitoxantron & 1 & 4 & 5,9 \\
\hline \multirow[t]{2}{*}{ Anthracyclin } & Doxorubicin & 3 & & \\
\hline & Epirubicin & 2 & 5 & 7,4 \\
\hline Platinkomplex & Carboplatin & 1 & 1 & 1,5 \\
\hline \multirow[t]{2}{*}{ sonst. } & $\begin{array}{l}\text { DTIC (Dimethyl-trizeno- } \\
\text { imidazol-carboxamid) }\end{array}$ & 1 & & \\
\hline & Hydroxycarbamid & 1 & 2 & 2,9 \\
\hline Gesamt & & 68 & 68 & 100 \\
\hline
\end{tabular}

\subsubsection{Indikation und Indikationsstellung}

Auch Angaben zur Indikationsstellung wurden erfragt. Mehrfachnennungen waren möglich. Die Indikation zur Tumortherapie auf der Palliativstation wurde eher durch die Vorbehandelnden (114 Angaben) als durch die eigene Abteilung (44 Angaben) gestellt. Bei 34 Patienten fanden aber auch Tumortherapien unter eigener Indikationsstellung in Rücksprache mit anderen Fachdisziplinen statt (Tab. 12). Auf onkologischen Stationen wurde die Indikation zur TT häufiger selbst getroffen. 
Tabelle 12: Indikationsstellung (Mehrfachnennungen waren möglich)

\begin{tabular}{|c|c|c|c|c|c|}
\hline & Gesamt & PS & OS & AA & AP \\
\hline 1= vorbehandelnde Abteilung & 129 & 115 & 1 & 7 & 6 \\
\hline $\begin{array}{l}\text { 2= eigene Indikationsstellung } \\
\text { nach Rücksprache mit } \\
\text { anderen Fachdisziplinen }\end{array}$ & 63 & 34 & 4 & 25 & 0 \\
\hline 3= eigene Indikationsstellung & 73 & 44 & 15 & 14 & 0 \\
\hline $1+2$ & 1 & 1 & 0 & 0 & 0 \\
\hline $2+3$ & 1 & 1 & 0 & 0 & 0 \\
\hline o. A. & 200 & 157 & 3 & 13 & 27 \\
\hline Gesamt & 467 & 352 & 23 & 59 & 33 \\
\hline
\end{tabular}

Bei der Frage nach in Vortherapien gegebenen Chemotherapien und Hormonbehandlungen wurden bei den insgesamt 467 eingereichten TT-Bögen 214 Angaben gemacht. Es wurden insgesamt 325 Chemotherapien bei einer Anzahl von 146 Angaben und 68 Hormontherapien bei 52 Angaben in der Vortherapie dokumentiert. Die folgende Tabelle (Tabelle 13) gibt Auskunft über die durchschnittliche Anzahl der jeweiligen Vortherapien der Patienten einzelner palliativmedizinischer Einrichtungen. Patienten der Palliativstation wurden demnach durchschnittlich häufiger chemotherapeutisch vorbehandelt als Patienten onkologischer Stationen.

Tabelle 13: Vortherapien (Angabe in Summe der Therapieanzahl / Anzahl der Angaben, Mehrfachnennungen waren möglich)

\begin{tabular}{|l|r|r|r|r|}
\hline \multicolumn{1}{|c|}{ PS } & \multicolumn{1}{|c|}{ OS } & AA & \multicolumn{1}{c|}{ AP } \\
\hline $\begin{array}{l}\text { Vortherapie: } \\
\text { Chemotherapie }\end{array}$ & $254 / 109=\mathbf{2 , 3}$ & $14 / 8=\mathbf{1 , 7 5}$ & $52 / 28=\mathbf{1 , 9}$ & $5 / 1=\mathbf{5}$ \\
\hline $\begin{array}{l}\text { Vortherapie: } \\
\text { Hormontherapie }\end{array}$ & $50 / 41=\mathbf{1 , 2}$ & $2 / 2=\mathbf{1 , 0}$ & $16 / 9=\mathbf{1 , 8}$ & $0 / 0=\mathbf{0}$ \\
\hline
\end{tabular}


Zu den 255 dokumentierten Patienten mit TT wurde nach der Indikation zur TT gefragt. Mehrfachnennungen waren möglich.

Tabelle 14: Teilnehmende Einrichtungen und Indikation zur Tumortherapie (Mehrfachnennungen waren möglich)

\begin{tabular}{|l|l|r|r|r|r|r|}
\hline & & Gesamt & \multicolumn{1}{|c|}{ PS } & \multicolumn{1}{|c|}{ OS } & AA & AP \\
\hline \multirow{2}{*}{ Gesamt } & Anzahl & 255 & 175 & 21 & 50 & 9 \\
\hline \multirow{2}{*}{ o. A. } & Anzahl & 29 & 24 & 1 & 3 & 1 \\
\cline { 2 - 8 } & in \% & 11,4 & 13,7 & 4,8 & 6,0 & 11,1 \\
\hline \multirow{2}{*}{$\begin{array}{l}\text { Tumorgrößen- } \\
\text { reduktion }\end{array}$} & Anzahl & 95 & 42 & 8 & 43 & 2 \\
\hline \multirow{2}{*}{ beides } & in \% & 37,3 & 24,0 & 38,1 & 86,0 & 22,2 \\
\hline \multirow{2}{*}{ Symptomkontrolle } & Anzahl & 52 & 42 & 6 & 3 & 1 \\
\cline { 2 - 8 } & in \% & 20,4 & 24,0 & 28,6 & 6,0 & 11,1 \\
\hline & in \% & 31,0 & 38,3 & 28,6 & 2,0 & 55,6 \\
\hline
\end{tabular}

24\% aller TT wurden auf Palliativstationen mit dem Ziel einer Tumorgrößenreduktion induziert, 38,3\% der TT mit dem Ziel der Symptomkontrolle. Auf onkologischen Stationen findet sich ein umgekehrtes Verhältnis mit 38,1\% (Tumorgrößenreduktion) bzw. 28,6\% (Symptomkontrolle). Hinsichtlich der Symptomkontrolle als Indikation zur TT konnten Angaben zur Art der Symptome gemacht werden. Auch hier waren Mehrfachnennungen möglich. 
Tabelle 15: Zugrundeliegende Symptome als Indikation zur Tumortherapie (Mehrfachnennungen waren möglich)

\begin{tabular}{|l|r|r|r|r|r|}
\hline & Gesamt & PS & OS & AA & AP \\
\hline $\begin{array}{l}\text { neurologische } \\
\text { Kompression }\end{array}$ & 20 & 17 & 3 & 0 & 0 \\
\hline Schmerzen & 60 & 49 & 6 & 2 & 3 \\
\hline Luftnot & 26 & 19 & 3 & 2 & 2 \\
\hline gastrointestinale & 13 & 12 & 0 & 1 & 0 \\
Kompression & 6 & 5 & 0 & 0 & 1 \\
\hline sonst. & 29 & 26 & 3 & 0 & 0 \\
\hline o. A. & 131 & 109 & 12 & 4 & 6 \\
\hline Gesamt & & & & & \\
\hline
\end{tabular}

Es bestand außerdem die Möglichkeit zu einer Freitextangabe zur Dokumentation von anderen Symptomen. Hier fanden sich in absteigender Häufigkeit folgende Indikationen: Dysphagie, Behandlungswunsch, Tumorblutung, initial kurative- dann palliative Therapie, neuropathische Schmerzen bei Plexusinfiltration.

\subsubsection{Standpunkte bei der Therapieentscheidung}

Bei der Frage nach der Entscheidung zur Fortsetzung oder Initiierung einer TT wird deutlich, dass die meisten Therapieentscheidungen innerhalb des Teams im Konsens gefällt wurden (147 Entscheidungen im „klaren Konsens“ sowie 40 „eher im Konsens“ vs 11 klare Dissensentscheidungen). Dies zeigt sich insbesondere im Falle der Tumorgrößenreduktion als Indikation für eine TT. Die wenigen Dissensentscheidungen kumulieren hingegen im Zusammenhang mit der Indikation „Symptomkontrolle“ (54,5\%) (Abb. 16). 
Tabelle 16: Symptomkontrolle oder Tumorgrößenreduktion als Indikation zur Tumortherapie (Einfachnennung erbeten)

\begin{tabular}{|c|c|c|c|c|c|c|c|c|c|c|}
\hline & \multicolumn{2}{|c|}{ Gesamt } & \multicolumn{2}{|c|}{ o. A. } & \multicolumn{2}{|c|}{ klarer Dissens } & \multicolumn{2}{|c|}{ eher Konsens } & \multicolumn{2}{|c|}{ klarer Konsens } \\
\hline & Anzahl & $\%$ & Anzahl & $\%$ & Anzahl & $\%$ & Anzahl & $\%$ & Anzahl & $\%$ \\
\hline o. A. & 29 & 11,4 & 18 & 31,6 & 0 & 0 & 3 & 7,5 & 8 & 5,4 \\
\hline $\begin{array}{r}\text { Tumor- } \\
\text { größen- } \\
\text { reduktion }\end{array}$ & 95 & 37,3 & 18 & 31,6 & 2 & 18,2 & 10 & 25 & 65 & 44,2 \\
\hline beides & 52 & 20,4 & 8 & 14 & 3 & 27,3 & 10 & 25 & 31 & 21,1 \\
\hline $\begin{array}{r}\text { Symptom- } \\
\text { kontrolle }\end{array}$ & 79 & 31 & 13 & 22,8 & 6 & 54,5 & 17 & 42,5 & 43 & 29,3 \\
\hline Gesamt & 255 & 100 & 57 & 100 & 11 & 100 & 40 & 100 & 147 & 100 \\
\hline
\end{tabular}

Die Entscheidung zur Tumortherapie richtet sich neben der Indikation und Haltung auch nach der Prognose der Patienten mit fortgeschrittener Erkrankung. Dazu war im TT-Modul sowohl nach dem Palliativen Performance Score (PPS, eine Erweiterung des Karnofsky Performance Status (KPS) zur Einschätzung körperlicher Funktionen und der Prognose von Palliativpatienten (Anderson F et al. 1996) sowie nach dem Palliative Prognostic Index (PPI) gefragt worden (Tab. 17). Der PPI berücksichtigt als nicht-invasives Messinstrument neben dem PPS außerdem folgende Symptome: orale (Nahrungs-) Zufuhr bzw. Appetitlosigkeit, Ödeme, Ruhedyspnoe und Delirium (Morita et al. 1999). Der PPI und der PPS bieten damit eine Hilfe bei Behandlungsentscheidungen und der Untersuchung von Behandlungseffekten. 
Tabelle 17: Therapieform und Prognosescores

\begin{tabular}{|c|c|c|c|c|c|c|c|}
\hline & \multicolumn{3}{|c|}{ PPS } & \multicolumn{4}{|c|}{ PPI } \\
\hline & $\begin{array}{c}0 \\
\text { Punkte }\end{array}$ & $\begin{array}{c}2,5 \\
\text { Punkte\# }\end{array}$ & $\begin{array}{c}4 \\
\text { Punkte }\end{array}$ & o. A. & $\begin{array}{c}0 \\
\text { Punkte }\end{array}$ & $\begin{array}{c}1 \\
\text { Punkt* }\end{array}$ & $\begin{array}{c}2 \\
\text { Punkte** }\end{array}$ \\
\hline Tumortherapie & Anzahl & Anzahl & Anzahl & Anzahl & Anzahl & Anzahl & Anzahl \\
\hline keine fortgesetzt & 32 & 34 & 13 & 93 & 44 & 13 & 14 \\
\hline $\begin{array}{l}\text { mind. eine } \\
\text { fortgesetzt }\end{array}$ & 32 & 22 & 5 & 34 & 49 & 5 & 3 \\
\hline keine neu & 32 & 22 & 11 & 73 & 48 & 6 & 8 \\
\hline mind. eine neu & 32 & 34 & 7 & 54 & 45 & 12 & 9 \\
\hline eine TT & 62 & 52 & 12 & 88 & 89 & 16 & 12 \\
\hline Gesamt & 64 & 56 & 18 & 127 & 93 & 18 & 17 \\
\hline
\end{tabular}

\# 6-Monatsüberleben bei $10 \%$

* 6-Wochenüberleben bei $20 \%$

**3-Wochenüberleben bei $20 \%$

Eine höhere Punktzahl bedeutet jeweils eine schlechtere Prognose. Bei einigen Patienten (9) wurde trotz schlechter Prognose im PPI (PPI = 2) eine TT neu begonnen.

Im TT-Modul wurde außerdem nach dem subjektiven Erfolg der durchgeführten TT gefragt. Bei 33,6\% der insgesamt 467 TT-Dokumentationen fanden sich hierzu Angaben. Zur Beurteilung des Erfolgs konnten Bewertungen auf einer Skala zwischen 1 und 6 nach dem „Schulnotenprinzip“ gemacht werden (Abb. 3). Der Therapieverlauf wurde mit einer durchschnittlichen Note von 2,68 durch die dokumentierende Person eingeschätzt (310 ohne Angaben). 
Abbildung 3: Erfolgsbeurteilung der TT nach dem „Schulnotenprinzip“ (Einfachnennung)

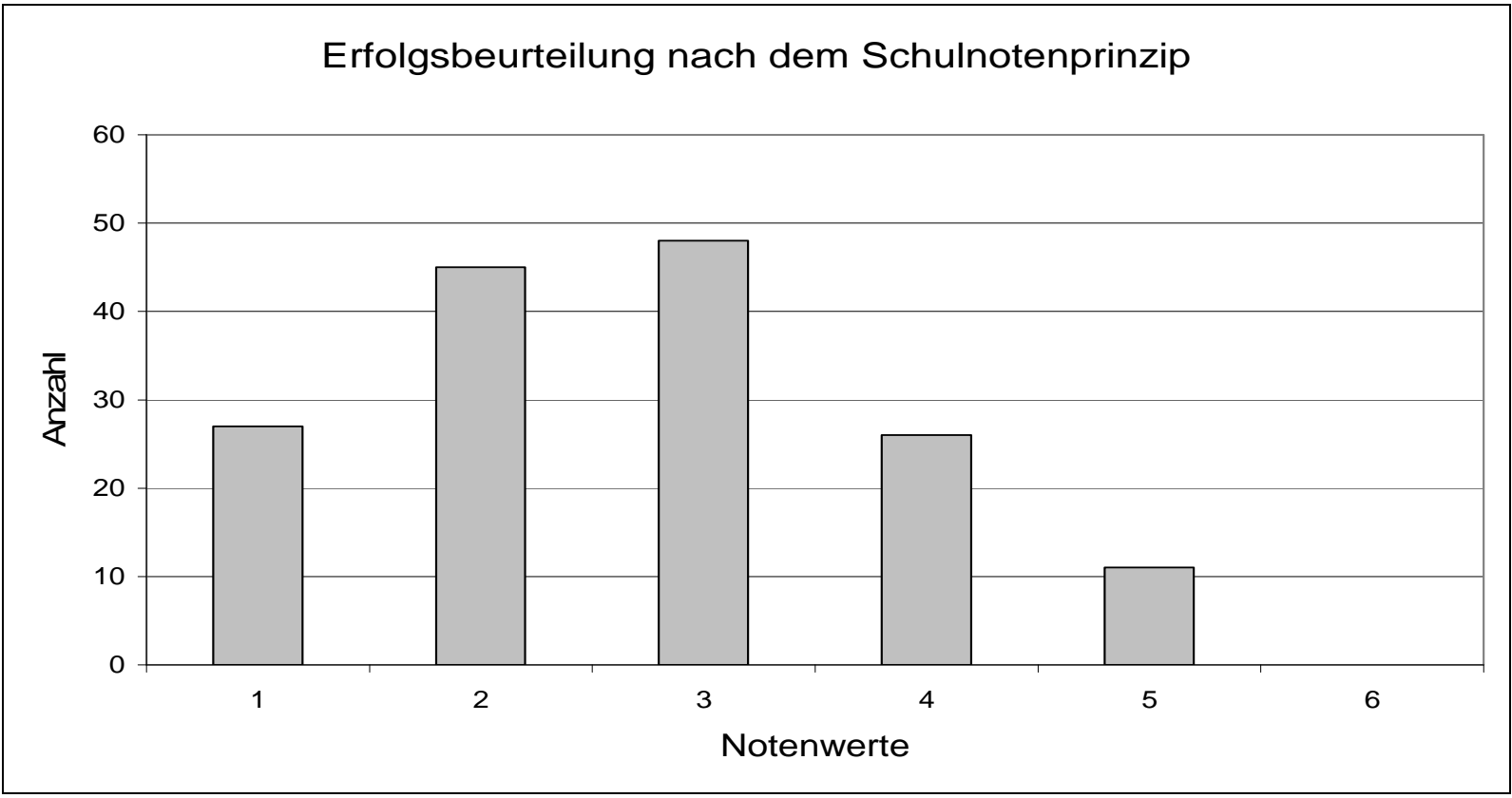

\subsubsection{Therapieabbruch}

Die Frage nach einem vorzeitigen Abbruch der Tumortherapie wurde bei 70 Fragebögen mit „Nein“ und bei 93 mit „Ja“ beantwortet (Tab. 18). Bei letzteren zeigt sich, dass insbesondere initial fortgesetzte TT abgebrochen wurden.

Tabelle 18: Vorzeitiger Therapieabbruch (Einfachnennung)

\begin{tabular}{|c|c|c|c|c|c|}
\hline & \multicolumn{4}{|c|}{ Tumortherapie vorzeitig abgebrochen? } \\
\hline & & o. A. & ja & nein & Gesamt \\
\hline & & Anzahl & Anzahl & Anzahl & Anzahl \\
\hline \multirow[t]{6}{*}{ Therapiefom } & o. A. & 197 & 50 & 15 & 262 \\
\hline & fortges. & 91 & 39 & 38 & 168 \\
\hline & neu & 12 & 3 & 14 & 29 \\
\hline & $>1$ fortges. & 4 & 1 & 1 & 6 \\
\hline & 1 fortges., 1 neu & 0 & 0 & 2 & 2 \\
\hline & Gesamt & 304 & 93 & 70 & 467 \\
\hline \multirow[t]{3}{*}{ Gesamt } & keine & 197 & 50 & 15 & 262 \\
\hline & eine TT & 107 & 43 & 55 & 205 \\
\hline & Gesamt & 304 & 93 & 70 & 467 \\
\hline
\end{tabular}

Im Anschluss wurde nach dem Grund des vorzeitigen Abbruchs gefragt, der bei allen 93 Fragebögen dokumentiert wurde. Mehrfachnennungen waren möglich, so dass insgesamt 150 Angaben zum Grund der Therapiebeendigung gemacht wurden (Abb. 4). 
Abbildung 4: Gründe für Therapiebeendigung (Mehrfachnennungen waren möglich)

\section{Angaben zur Therapiebeendigung}

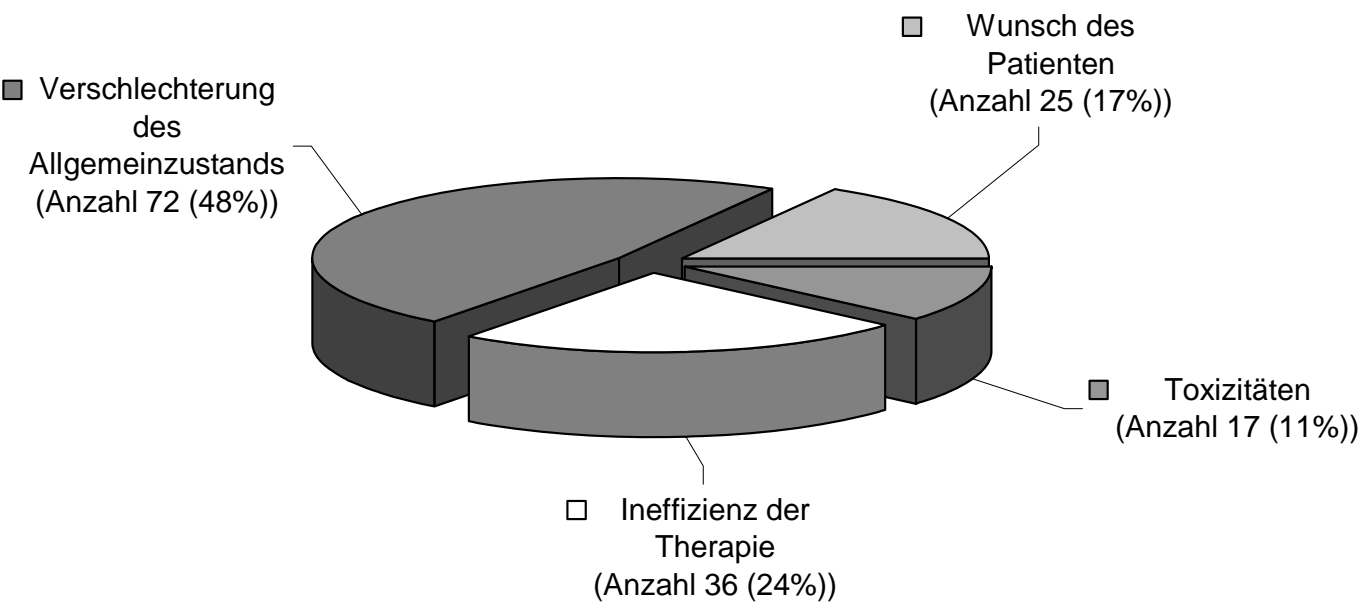

Die Art der Toxizitäten bzw. Nebenwirkungen der Tumortherapien, die zu einem Abbruch geführt haben, konnten als Freitexteingabe dokumentiert werden. Es wurden folgende Aussagen getroffen: Embolische Komplikation, Hämatotoxizität, Panzytopenie, Kachexie, Appetitmangel, Diarrhoe, Infektionen und Sepsis, Übelkeit, Erbrechen, Tumorprogress, psychomotorische Veränderung, Cholestase, akutes Nierenversagen, Patient verstorben.

Die folgende Tabelle (Tab. 22) zeigt den Bezug zwischen Abbruch und Indikationsstellung. Demnach wurden mehr TT abgebrochen, die initial zur Tumorgrößenreduktion eingeleitet oder fortgesetzt wurden, als solche, die zur Symptomkontrolle eingesetzt wurden. 
Tabelle 19: Therapieabbruch in Zusammenhang mit der zugrundeliegenden Therapieindikation (Einfachnennung erbeten)

\begin{tabular}{|c|c|c|c|c|c|c|}
\hline & & Gesamt & PS & OS & AA & AP \\
\hline Gesamt & Anzahl & 93 & 74 & 7 & 10 & 2 \\
\hline \multirow{2}{*}{ o. A. } & Anzahl & 22 & 18 & 1 & 2 & 1 \\
\hline & in \% & 23,7 & 24,3 & 14,3 & 20 & 50 \\
\hline \multirow{2}{*}{$\begin{array}{l}\text { Tumorgrößen- } \\
\text { reduktion }\end{array}$} & Anzahl & 50 & 38 & 3 & 8 & 1 \\
\hline & in \% & 53,8 & 51,4 & 42,9 & 80 & 50 \\
\hline \multirow{2}{*}{ beides } & Anzahl & 4 & 3 & 1 & 0 & 0 \\
\hline & in \% & 4,3 & 4,1 & 14,3 & 0 & 0 \\
\hline \multirow{2}{*}{$\begin{array}{l}\text { Symptom- } \\
\text { kontrolle }\end{array}$} & Anzahl & 17 & 15 & 2 & 0 & 0 \\
\hline & in \% & 18,3 & 20,3 & 28,6 & 0 & 0 \\
\hline
\end{tabular}

Außerdem wurde nach der Entscheidung zum Abbruch der Therapie gefragt (Tab. 20).

Hier zeigt sich, dass die Entscheidung zum Therapieabbruch unabhängig von der initialen Therapieindikation häufiger im Konsens getroffen wird, während die Entscheidung zur Fortsetzung oder zur Einleitung einer Tumortherapie insbesondere im Zusammenhang mit der Indikation zur Symptomkontrolle häufiger im Dissens getroffen wird (vgl. Tab. 16).

Tabelle 20: Teamkonsens und -dissens bei Therapieabbruch

\begin{tabular}{|c|c|c|c|c|c|c|c|c|c|c|}
\hline & \multirow{2}{*}{\multicolumn{2}{|c|}{$\begin{array}{c}\text { Gesamt } \\
\text { Anzahl in \% }\end{array}$}} & \multicolumn{2}{|c|}{ o. A. } & \multicolumn{2}{|c|}{ klarer Dissens } & \multicolumn{2}{|c|}{ eher Konsens } & \multicolumn{2}{|c|}{ klarer Konsens } \\
\hline & & & Anzahl & in $\%$ & Anzahl & in $\%$ & Anzahl & in $\%$ & Anzahl & in $\%$ \\
\hline o. A. & 22 & 23,7 & 4 & 44,4 & 0 & 0 & 0 & 0 & 18 & 23,1 \\
\hline $\begin{array}{l}\text { Tumor- } \\
\text { größen- } \\
\text { reduktion }\end{array}$ & 50 & 53,8 & 4 & 44,4 & 1 & 50 & 2 & 50 & 43 & 55,1 \\
\hline beides & 4 & 4,3 & 0 & 0 & 0 & 0 & 2 & 50 & 2 & 2,6 \\
\hline $\begin{array}{l}\text { Symptom- } \\
\text { kontrolle }\end{array}$ & 17 & 18,3 & 1 & 11,1 & 1 & 50 & 0 & 0 & 15 & 19,2 \\
\hline Gesamt & 93 & 100 & 9 & 100 & 2 & 100 & 4 & 100 & 78 & 100 \\
\hline
\end{tabular}


Abschließend konnten Angaben darüber gemacht werden, wer für das Ausfüllen des TTFragebogens verantwortlich war. Mehrfachnennungen waren möglich (Tab. 21). Demnach füllten anteilig mehr Ärzte (76,7\%) als Pflegekräfte (5,4\%) einen TT-Fragebogen aus. Ähnliche Angaben wurden auch bei der Frage nach der Dokumentation des HOPEFragebogens gemacht (Tab. 22). Insbesondere Ärzte der Hämatologie / Onkologie (30,4\%, vs Ärzte der Anästhesiologie mit 15,4\%) füllten einen TT-Fragebogen aus.

Tabelle 21: Dokumentation des Tumortherapie-Moduls (Mehrfachnennungen waren möglich)

\begin{tabular}{|l|r|r|r|r|r|}
\hline Bogen ausgefüllt (in \%) & Gesamt & \multicolumn{1}{|l|}{ PS } & \multicolumn{1}{|l|}{ OS } & AA & AP \\
\hline Pflege & 5,4 & 2,3 & 0 & 3,4 & 45,5 \\
\hline Arzt & 76,7 & 90,6 & 100 & 23,7 & 6,1 \\
\hline andere Mitarbeiter & 6,9 & 0 & 0 & 54,2 & 0 \\
\hline Innere & 35,1 & 42,3 & 65,2 & 0 & 0 \\
\hline Anästhesiologie & 15,4 & 19,0 & 0 & 5,1 & 6,1 \\
\hline Hämatologie / Onkologie & 30,4 & 34,1 & 78,3 & 6,8 & 0 \\
\hline sonstige & 9,0 & 11,1 & 8,7 & 1,7 & 0 \\
\hline
\end{tabular}

Tabelle 22: Dokumentation des HOPE-Basisbogens (Mehrfachnennungen waren möglich)

\begin{tabular}{|l|r|r|r|r|r|r|}
\hline Bogen ausgefüllt (in \%) & Gesamt & \multicolumn{1}{|c|}{ PS } & \multicolumn{1}{c|}{ OS } & \multicolumn{1}{c|}{ H } & \multicolumn{1}{c|}{ AA } & \multicolumn{1}{c|}{ AP } \\
\hline Pflege & 42,3 & 25,3 & 28,7 & 83,3 & 31,7 & 74,6 \\
\hline Arzt & 52,6 & 79,1 & 71,3 & 3,8 & 43,7 & 10,8 \\
\hline andere Mitarbeiter & 6,7 & 2,7 & 14,7 & 7,0 & 16,8 & 8,6 \\
\hline
\end{tabular}




\section{Diskussion}

\subsection{Allgemeiner Kontext der Untersuchung}

Die vorliegende Untersuchung fand vor dem Hintergrund weitreichender Veränderungen in der modernen Onkologie statt (vgl. Abschnitt 1.2.), die eine Ausweitung tumorspezifischer Therapien und eine Erweiterung tumortherapeutischer Indikationsspektren hin zu genuin palliativmedizinischen Zielen der Symptomkontrolle nahe legen. Gleichzeitig beschränkt sich die Palliativmedizin nach Definition der WHO (1990) nicht ausschließlich auf die Behandlung und Begleitung des Patienten in der letzten Lebensphase (Sepulveda et al. 2002). Das Ausmaß des Einsatzes von Tumortherapien in der Palliativmedizin ist bislang weder systematisch untersucht worden, noch können der Literatur Informationen zur Indikation, zu Standpunkten bei der Therapieentscheidung und zur Haltung bezüglich tumorspezifischer Therapien bei Palliativpatienten entnommen werden. Es ist also bisher nicht bekannt, ob und inwieweit tumorspezifische Therapien nicht aus einer tumorgerichteten „onkologischen“ Indikation, sondern aus einer primär symptomgeleiteten „palliativmedizinischen“ Indikationsstellung in der Vergangenheit bereits aufgegriffen und in primär palliativmedizinische Therapiekonzepte integriert wurden.

Mithilfe der vorliegenden prospektiven Studie konnten erstmalig entsprechende Daten zum systematischen Einsatz von Tumortherapien im palliativmedizinischen Setting gewonnen werden. Neben grundlegenden Erkenntnissen zur konkreten palliativmedizinischen Praxis wurden Aspekte palliativmedizinischer Grundhaltung, Indikationen und Standpunkte bei der Therapieentscheidung untersucht. Die Ergebnisse geben damit u.a. Auskunft über den Stellenwert tumorspezifischer Therapien zur Symptomkontrolle bei Palliativpatienten. Ein besonderes Augenmerk bei der Datenbewertung wurde auf die stationären, Palliativpatienten betreuenden Einrichtungen gelegt, um Charakteristika von onkologischen und palliativmedizinischen Versorgungseinrichtungen und Behandlungskonzepten zu vergleichen.

\subsection{Fragebogenrücklauf}

Die erhobenen Daten können als repräsentativ angesehen werden, da die im Jahre 2007 an HOPE teilnehmenden Palliativstationen etwa 50\% der zu diesem Zeitpunkt bundesweit bestehenden Palliativstationen ausmachen.

Die verschiedenen genannten Patientenkollektive (Gesamtkollektive, Patienten unter TT, Patienten auf OS oder PS) ähneln sich hinsichtlich ihrer Patientencharakteristika (u.a. 
fortgeschrittene Erkrankung, Lebensalter, Liegedauer) und ermöglichen daher einen Vergleich untereinander.

Bei der Interpretation der Untersuchungsergebnisse muss einschränkend berücksichtigt werden, dass sich HOPE primär an palliativmedizinische und hospizliche Versorgungseinrichtungen richtet und für diese auch konzipiert wurde. So stehen anteilig mehr Daten von diesen Einrichtungen als von onkologischen Stationen zur Verfügung. Letztere nahmen mit einer Anzahl von acht Einrichtungen gegenüber 67 Palliativstationen an der Dokumentation 2007 teil. Dieser Unterschied lässt sich dadurch erklären, dass die Behandlung und Begleitung von Palliativpatienten für onkologische Stationen nur einen Teilaufgabenbereich abbildet. Die geringe Anzahl teilnehmender onkologischer Einrichtungen kann möglicherweise zu Verzerrungen bei den Ergebnissen führen und ist bei deren Interpretation zu berücksichtigen. Des Weiteren ist $\mathrm{zu}$ bedenken, dass der Dokumentation keine Patientenauswahl in den unterschiedlichen palliativmedizinischen Einrichtungen vorausging, die Patienten demnach konsekutiv im Dokumentationszeitraum erfasst wurden.

Die Fortführung und Initiierung von Tumortherapien ist in allen palliativmedizinischen Versorgungsbereichen mit Ausnahme der stationären Hospize von Bedeutung. Stationäre Hospize begleiten als spezialisierte Einrichtungen Patienten pflegerisch, psychosozial und spirituell in ihrer letzten Lebensphase meist bis zum Tod. Die medizinische Betreuung wie Symptomkontrolle und medikamentöse Einstellungen obliegt in der Regel dem Hausarzt (Sabatowski und Graf 2007).

\subsection{Tumortherapie-Modul}

Im TT-Modul wurde erstmals explizit nach einer Fortsetzung oder Initiierung einzelner Tumortherapieformen gefragt. Es konnte gezeigt werden, dass lediglich 205 der eingereichten 467 TT-Bögen Auskünfte über eine Fortsetzung und / oder Einleitung der insgesamt 211 dokumentierten TT enthielten, wobei mehr TT neu initiiert (120) als fortgesetzt (91) wurden. Beim Kriterium „vorzeitiger Abbruch“ wurde offen gelassen, ob es sich um eine bereits zum Übernahmezeitpunkt oder im weiteren Verlauf abgesetzte Therapie handelt. An dieser Stelle bleibt der Fragebogen uneindeutig. So wurden 205 Patienten dokumentiert, bei denen eine TT begonnen oder fortgesetzt wurde. Hinzu kommen 50 Bögen von weiteren Patienten, die aussagen, dass eine TT vorzeitig abgebrochen wurde. In diesen Bögen wurden jedoch keine 
Angaben zu einer fortgesetzten oder begonnenen TT gemacht. Es muss folglich davon ausgegangen werden, dass insgesamt 255 Patienten eine TT erhielten.

Um dieses Missverständnis zukünftig auszuräumen, könnte im Rahmen von Folgeprojekten in das erste Fragenkapitel zur Therapieform die Antwortkategorie „Eine laufende TT wurde bei Aufnahme abgebrochenen / beendet“ aufgenommen werden. Dieses würde nicht nur das Verständnis erleichtern, sondern auch die Möglichkeit bieten, die Frage zu beantworten, ob möglicherweise eine laufende oder geplante TT einen Ausschlussgrund für die Aufnahme / Betreuung eines Patienten auf einer Palliativstation oder in der spezialisierten ambulanten Palliativversorgung darstellt.

\subsubsection{Demographische Daten}

Die Untersuchung der demographischen Daten zeigt, dass beim Einsatz von Tumortherapien in palliativmedizinischen Versorgungsbereichen nicht jüngere Patienten bevorzugt werden. An dieser Stelle darf jedoch nicht unerwähnt bleiben, dass sich das Alter in diesem Zusammenhang auf das Patientenkollektiv mit einem ausgefüllten TT-Fragebogen bezieht (467) und nicht die Patienten erfasst, für die eine Tumortherapie angegeben wurde (255). Es kann jedoch davon ausgegangen werden, dass die 467 Patienten, für die ein TT-Modul ausgefüllt wurde, jenes Patientenkollektiv widerspiegeln, für das eine TT diskutiert wurde. Dieser Umstand bezieht sich auch auf die Untersuchung des Geschlechts, der Liegedauer und des Anteils der verstorbenen Patienten.

Der Anteil der weiblichen Patienten, für die auf einer Palliativstation das TT-Modul ausgefüllt wurde, ist größer (60\%) als der männliche Anteil (40\%). Mit 95\%iger Sicherheit liegt der Anteil der Männer zwischen 32,6\% und 47,7\%, der Anteil der Frauen entsprechend zwischen 52,3\% und 67,3\%. Auch im HOPE-Gesamtkollektiv ist der weibliche Anteil größer als der männliche Anteil. Dieser Umstand könnte mit der zugrunde liegenden Erkrankung und der Tumorhäufigkeit zusammenhängen.

Die Diagnose der 3184 dokumentierten Patienten konnte dem Basisbogen in Form eines Freitextes oder ICD-10-verschlüsselt entnommen werden. Insbesondere Tumorerkrankungen dominieren bei den zur Aufnahme des Patienten dokumentierten Erkrankungen und spiegeln, wie eingangs erwähnt, die nach wie vor große Anzahl von Patienten mit Krebserkrankungen in der Palliativmedizin wider. Die Häufigkeit von Tumoren des Gastrointestinaltraktes und des Respirationstraktes, sowie der weiblichen Brust im TT-Kollektiv entsprechen näherungsweise der Häufigkeit der Krebsneuerkrankungen und -sterbefälle, die vom RobertKoch-Institut erfasst wurden (RKI 2004). 
Patienten der teilnehmenden Palliativstationen (PS) mit TT-Dokumentation verstarben zwar seltener als andere PS-Patienten, dennoch verstarben PS-Patienten mit einer TTDokumentation häufiger als onkologische Patienten mit eingereichtem TT-Modul. In der Patientengruppe mit TT-Dokumentation wurden weniger Sterbefälle als im HOPEGesamtkollektiv dokumentiert (22,3\% vs 31,8\%). Der Anteil verstorbener Patienten der Palliativstationen sowie der onkologischen Stationen mit TT-Dokumentation ist also geringer als der Anteil verstorbener Patienten ohne TT-Dokumentation. Ein Überlebensvorteil der PSPatienten mit TT darf an dieser Stelle so jedoch nicht schlussgefolgert werden. Dies kann dahingehend interpretiert werden, dass die wenigen Patienten, die auf Palliativstationen und in onkologischen Einrichtungen eine Tumortherapie erhielten, einen besseren Allgemeinzustand im Sinne einer Chemotherapiefähigkeit aufwiesen als Patienten ohne Tumortherapie.

Die Patienten wurden mit einem durchschnittlichen ECOG-Wert von 3,0 (in der Skala von 0, nicht beeinträchtigt bis 4, voll pflegebedürftig) behandelt. Hier gibt es jedoch deutliche Unterschiede zwischen den teilnehmenden Einrichtungsarten. Patienten stationärer Hospize und Palliativstationen werden demnach pflegebedürftiger eingeschätzt als Patienten onkologischer Stationen.

Es deutet sich an, dass sich Palliativpatienten in onkologischen Versorgungsstrukturen in Bezug auf klinische und versorgungsbezogene Kriterien von Palliativpatienten in palliativmedizinischen (und hospizlichen) Einrichtungen unterscheiden. Hier kann gemutmaßt werden, dass die Definition des Begriffes „Palliativpatient“, die sich im palliativmedizinischen Selbstverständnis an medizinischen, pflegerischen, psychosozialen und spirituellen Bedürfnissen des Patienten orientiert, in onkologischen bzw. palliativmedizinischen Arbeitsbereichen unterschiedlich verstanden wird.

\subsubsection{Therapieform}

Für die Entscheidungsfindung über eine Indikation zur Tumortherapie oder ihre Beendigung sind sowohl patienten- und krankheitsbezogene Voraussetzungen relevant als auch der Therapiemodus. Die Untersuchungsergebnisse zeigen, dass intravenöse, zyklische oder kontinuierliche zytostatische Chemotherapien den größten Anteil der dokumentierten Therapieformen der mit dem TT-Modul erfassten Palliativpatienten ausmachen (43,7\%), gefolgt von der Strahlentherapie (17,4\%) und der Hormontherapie (11,7\%). Bei der Freitexteingabe zur Frage nach der verwendeten Substanz / Regime / Modus zeigt sich bei der 
Datenauswertung, dass unter den verwendeten 68 Chemotherapie-Mono-Substanzen Antimetabolite, insbesondere das zu den Pyrimidinanaloga zählende Chemotherapeutikum Gemcitabin, aber auch Capecitabin, die größten Anteile einnehmen. Es konnte gezeigt werden, dass sog. targeted therapies hinsichtlich des postulierten Potentials für dieses fortgeschritten erkrankte Patientenkollektiv erstaunlich selten eingesetzt wurde. Der häufige Einsatz von zytostatischen Monotherapien kann als Vorzug etablierter, zugelassener Substanzen mit definiertem Toxizitätsprofil und dennoch als angemessen behutsame Vorgehensweise interpretiert werden.

\subsubsection{Indikationsstellung und Vortherapien}

Eine Indikation zur TT erfolgt auf der PS hauptsächlich durch die vorbehandelnde Abteilung. Es finden sich aber auch Angaben zur eigenen Indikation zur TT bei den dokumentierenden Palliativstationen. Seltener wird dort die Indikation zur Tumortherapie unter Rücksprache mit anderen Fachdisziplinen gestellt. Im Gegensatz dazu treffen onkologische Stationen häufiger selbst die Entscheidung zur TT.

Bei der Interpretation der Untersuchungsergebnisse hinsichtlich der Anzahl der Vortherapien stellt sich erneut die Frage, ob das Bild von einem „Palliativpatienten“ auf onkologischen Stationen vergleichbar ist mit demjenigen auf Palliativstationen. Die Daten zeigen, dass Patienten der PS im Vergleich zu denen onkologischer Stationen häufiger chemotherapeutisch vortherapiert sind und somit die Vermutung nahe liegt, dass sich die Tumorerkrankungen der PS-Patienten in einem fortgeschritteneren Stadium befinden.

\subsubsection{Indikation zur Tumortherapie}

Die in der Einleitung aufgestellte Hypothese, dass in der Onkologie eine primär tumorgrößenreduzierende Indikationsstellung im Vordergrund der Behandlungsintention steht, lässt sich anhand der Untersuchungsergebnisse bestätigen. Onkologische Einrichtungen benennen mit 38,1\% die Tumorgrößenkontrolle als Indikationsschwerpunkt - wobei der Aspekt der antizipierenden Symptombehandlung durch Tumorkontrolle nicht erfasst wurde während Palliativstationen die Symptomkontrolle als Indikationsschwerpunkt (38,3\%) für eine TT bei Palliativpatienten angeben.

$\mathrm{Zu}$ den im Zusammenhang mit der erwünschten Symptomkontrolle dokumentierten Symptomen zählen insbesondere Schmerzen und Luftnot. 
Die Frage nach einem teaminternen Konsens oder Dissens bei der Entscheidung zur oder gegen die Fortsetzung, Einleitung oder Beendigung einer Tumortherapie kann Rückschlüsse auf die unterschiedlichen Standpunkte bei der Therapieentscheidung und die Haltung gegenüber TT im palliativmedizinischen Setting liefern, ohne dabei Auskunft über Entscheidungsfindungsprozesse geben zu können. Während die Entscheidung zur Tumorgrößenkontrolle eher im Konsens fällt, wird die Symptomkontrolle als Indikation zur TT bei Palliativpatienten im Team deutlich kontroverser diskutiert als eine TT zur Tumorgrößenreduktion. Ob dieser Umstand eher ein Problem palliativmedizinischer oder onkologischer Indikationsstellung oder ein Hinweis auf Ambivalenzen innerhalb der Palliativmedizin darstellt, kann an dieser Stelle nicht ausreichend beantwortet werden und muss zukünftig genauer untersucht werden.

Der Literatur können keine Informationen über Standpunkte bei der Therapieentscheidung und zur Haltung gegenüber tumorspezifischen Therapien bei Palliativpatienten entnommen werden. Laut Frickhofen (2006) wird der Einsatz von Chemotherapeutika in der Palliativmedizin jedoch eher skeptisch beurteilt.

Es stellt sich die Frage, inwiefern die Haltung zur TT im Palliativteam die Entscheidung zur Einleitung bzw. Fortführung oder zum Abbruch einer TT beeinflusst und inwieweit Aspekte ärztlicher Weiterbildung und infrastrukturelle Faktoren bezüglich onkologischer Expertise vor Ort in die Therapieentscheidung hinein wirken.

Die Voraussetzung für die Gabe von Chemotherapeutika am Lebensende ist, dass der Nutzen durch die Chemotherapie den eventuell auftretenden Nebenwirkungen / Toxizitäten überwiegen muss (Frickhofen 2006).

Die beurteilte durchschnittliche subjektive Effektivität einer TT von 2,68 (auf einer Skala von 1-6) ist als befriedigend zu interpretieren. Allerdings zeigt die geringe Beantwortung dieser Frage (33,6\% der eingereichten TT-Bögen), dass eine Aussage zum subjektiven Erfolg einer TT bei Palliativpatienten zurückhaltend gemacht wird. Tendenziell ist jedoch eine positive Beurteilung des subjektiven Erfolgs zu verzeichnen. (Noten 1 oder 2: 72 Angaben vs Note 4 und schlechter: 37 Angaben). Bei der Interpretation dieser Daten muss berücksichtigt werden, dass die subjektive Beurteilung hinsichtlich des Erfolgs der durchgeführten Tumortherapie z.B. vom Standpunkt bei der Therapieentscheidung und der Haltung zur TT im palliativmedizinischen Setting oder der Art der Fachrichtung des dokumentierenden Arztes beeinflusst sein könnte. So waren für das Ausfüllen der TT-Bögen anteilig mehr Ärzte als Pflegekräfte verantwortlich, davon waren mit 30,4\% mehr Ärzte mit der Facharztbezeichnung Hämatologie / Onkologie vertreten, als mit anästhesiologischem Hintergrund (15,4\%). Dies 
wird durch Klaschiks erfahrungsbasierte Hypothese bestätigt, dass Chemotherapeutika selten auf Palliativstationen mit anästhesiologischem Hintergrund zum Einsatz kommen (Klaschik et al. 2000, zitiert auch von Radbruch et al. 2002).

$\mathrm{Zu}$ den Gründen für einen vorzeitigen Therapieabbruch, der bei 93 TT-Bögen bestätigt wurde, zählt neben der Reduktion des Allgemeinzustandes die Ineffizienz einer Therapie. Toxizitäten (z.B. Hämatotoxizität) als Grund für den vorzeitigen Therapieabbruch wurden mit 17 von 105 Angaben (16,2\%) vergleichsweise selten vermerkt. Es wurden anteilig mehr TT abgebrochen, die initial zur Tumorgrößenreduktion neu begonnen oder fortgesetzt wurden (50 von 95), was in $86 \%$ der Fälle mit einem klaren Konsens einherging. Verglichen damit wurden 17 der insgesamt 79 TT mit der Indikation zur Symptomkontrolle abgebrochen (21,5\%), auch hier eher im Konsens.

Der PPI (Morita et al. 1999) und der PPS (Anderson F et al. 1996) stellen Messinstrumente zur Prognosebeurteilung dar und bieten Hilfe bei einer Behandlungsentscheidung und bei der Untersuchung von Behandlungseffekten im palliativmedizinischen Setting. Der PPI berücksichtigt neben dem PPS auch klinische Symptome, wie Appetitlosigkeit, Ödeme, Ruhedyspnoe und delirante Zustände. Im palliativmedizinischen Setting kommt neben dem PPI und PPS außerdem der PaP-score (palliative prognostic score) zum Tragen. Dieser unterteilt terminal Kranke hinsichtlich ihrer Prognose in drei Risikogruppen und berücksichtigt als prädiktive Faktoren sowohl klinische als auch biochemische Parameter: KPS, klinische Überlebensvorhersage, weißes Blutbild, Lymphozyten, Dyspnoe und Anorexie (Maltoni et al. 1999, Pirovano et al. 1999). Es konnte gezeigt werden, dass bei einigen Patienten (9) trotz schlechter Prognose im PPI (PPI = 2, entspricht einem 3-Wochenüberleben von 20\%) eine Tumortherapie neu begonnen wurde.

Die Standpunkte bei der Entscheidung für oder gegen eine Tumortherapie bei Palliativpatienten werden beeinflusst durch die oben genannten Aspekte, z.B. durch das Selbstverständnis der Palliativmedizin, durch die behandelnde Fachgruppe auf der Palliativstation und durch die Prognose des Patienten. In der Literatur finden sich weitere wichtige Einflussgrößen, die bei der Entscheidung für oder gegen eine TT bei Palliativpatienten berücksichtigt werden müssen.

Laut Pott (2007) und Klaschik et al. (1998) kann eine Chemotherapie am Lebensende indiziert sein, wenn sie zu einer Verbesserung der Lebensqualität beitragen kann. Die Linderung von krankheits-, insbesondere tumorbedingten Symptomen wie Schmerzen und Luftnot ist stark mit der Lebensqualität der Patienten assoziiert. Bei Tumorpatienten stößt die Lebensqualität der Patienten als Outcome Parameter auch in der Hämatologie / Onkologie auf 
zunehmendes Interesse, wie diverse Studien mit quality of life (QoL) als primäres oder sekundäres Endziel zeigen. Die Messung der QoL wird von einigen Autoren als sinnvoll und notwendig bezeichnet (Taylor et al. 1997, Kornblith 2001), da das Wissen um die QoL des Patienten beispielsweise bei der Therapieentscheidung aber auch bei der Evaluierung des palliativen Effekts einer Therapie von Bedeutung sein kann. Es werden jedoch auch Schwierigkeiten bei der Messung beobachtet. So ist die Evaluierung des Befindens mittels Selbsteinschätzung - minimales Dokumentationssystem (MIDOS; Radbruch et al. 2000), Palliative Care Outcome Scale (POS; Bausewein et al. 2005, Hearn und Higginson 1999) und Fremdeinschätzung (z.B. psychoonkologische Basisdokumentation (PO-Bado; Herschbach et al. 2004)) bei Patienten mit fortgeschrittenen Erkrankungen bzw. in schlechtem psychischen und / oder physischen Zustand nur erschwert möglich (Krumm et al. 2008, Hearn und Higginson 1999). Außerdem würde mit dem subjektiven Empfinden nicht das gesamte Spektrum der QoL erfasst werden können. Die Studie von Shepherd et al. im Jahr 2000 zeigt, dass die Lebensqualität unter best supportive care (BSC) allein schlechter bewertet wird als in Kombination oder im Vergleich mit einer Chemotherapie. Dies wird durch Untersuchungen von O’Brien et al. (2005 und 2006) bestätigt. Die Haltung zur Lebensqualität als klinischer Parameter, sowie zur QoL-Messmethode selbst ist entscheidend für die Bereitschaft QoLInformationen in die klinische Arbeit einzubeziehen (Taylor et al. 1997). Laut einer Studie von Bezjak et al. im Jahr 2001 sind Ärzte dazu bereit, QoL-Informationen für die Entscheidungsfindung zu nutzen. Eine Untersuchung von Detmar et al. (2002) kommt hingegen zu dem Schluss, dass die QoL nur eine untergeordnete Rolle bei der Entscheidung zur Chemotherapie, deren Modifikation oder deren Abbruch spielt.

In der Studie von Doyle werden die Patientenerwartungen und -vorstellungen vom Benefit bzw. Wert einer Chemotherapie und die QoL durch den Patienten bewertet (Doyle et al. 2001). Hier zeigt sich eine durch den Patienten evaluierte Linderung von Symptomen sowie eine Besserung der QoL und der emotionalen Funktion nach Applikation einer Chemotherapie trotz geringem Tumoransprechen bzw. objektivierbarem Nutzen. Doyle verweist aber auch auf die unrealistischen Vorstellungen und Erwartungen der Patienten hinsichtlich der Heilungschancen bei palliativer Chemotherapie. Diese wünschen laut Koedoot et al. (2003) eher eine Chemotherapie als BSC allein. Der Wunsch nach einer Chemotherapie wird durch den Patienten mit dem Aspekt der Lebenszeitverlängerung, weniger mit der Verbesserung oder dem Erhalten der Lebensqualität begründet. BSC wird durch den Patienten häufig als „Nichtstun“ interpretiert (Koedoot et al. 2003). Husebo erklärt sich das Verhalten von Tumorpatienten damit, dass diese „fast jeden Strohhalm greifen würden“ (Husebo und 
Klaschik 2003, S.297). Er bezieht sich auf eine Studie, bei der sowohl Tumorpatienten als auch das Pflegepersonal und Ärzte nach der Akzeptanz chemotherapeutischer Behandlungen befragt werden. Danach seien Krebspatienten dazu bereit, eine nebenwirkungsreiche Therapie in Kauf zu nehmen, auch wenn diese nur mit einer geringen Heilungswahrscheinlichkeit verbunden ist. Die Ergebnisse dieser Untersuchung verdeutlichen die enorme Diskrepanz zwischen dem Therapiewunsch des Patienten und den Beurteilungen des Therapeuten (Slevin et al. 1990). Es kommt hinzu, dass der Therapiewunsch des Patienten im zeitlichen Verlauf unterschiedlich ausgeprägt sein kann (Hanratty und Lawlor 1999, Alt-Epping et al. 2006).

Frickhofen (2006) stellt die Frage nach dem idealen Zeitpunkt der Chemotherapie mit der Indikation zur Symptomkontrolle. Während zytostatische Chemotherapeutika erst nach ein bis zwei Monaten einen entsprechenden klinischen Effekt zeigen, können targeted therapies durch einen deutlich früheren Wirkungseintritt gekennzeichnet sein. Auch das Verkennen eines terminalen Stadiums unter Berücksichtigung des dynamischen Prozesses des Sterbens (Nauck 2001) stellt eine Schwierigkeit bei der Einschätzung der für den einzelnen Patienten adäquaten Therapie dar.

Die Kostenfrage darf hinsichtlich der Entscheidung für oder gegen eine TT ebenfalls nicht außer acht gelassen werden: der wirtschaftliche Druck zur Kosteneinsparung im Gesundheitswesen steht den vermeintlich kostenintensiven Chemotherapeutika gegenüber. Emanuel EJ und Emanuel LL (1994) setzen sich mit diesem ethischen Konflikt auseinander und warnen davor, sich irreführen zu lassen, dass weniger aggressive Behandlungen am Lebensende das finanzielle Problem des Gesundheitswesens lösen könnten. Diverse Chemotherapien - so belegen einige Studien - seien mit der Indikation zur Verbesserung der Lebensqualität bzw. Symptomkontrolle kosteneffektiver als BSC allein (Smith 1995, Klastersky und Paesmans 2001, Glimelius et al. 1996).

Welche Kriterien neben den oben genannten bei der Entscheidungsfindung eine Rolle spielen, kann in dieser Studie letztlich nicht ausreichend beantwortet werden.

Die weiterführende Untersuchung der Abteilung Palliativmedizin der UMG „Tumorspezifische Substanzen zur Symptomkontrolle in der Palliativmedizin Entscheidungsfindung und Anwendung“, in der prospektiv die konkreten Auswirkungen von Chemotherapeutika und ihren modernen Weiterentwicklungen auf die Symptomkontrolle und die vorangegangenen ärztlichen Entscheidungsfindungsprozesse analysiert werden, befindet sich derzeit im Abschluss. Letztlich muss eine Therapieentscheidung im Rahmen eines shared decision making gemeinsam gefällt werden. Die Aufklärung und Information durch den Arzt ist dabei entscheidend (Frickhofen 2006, Husebo und Klaschik 2003). 
In der vorliegenden Untersuchung lassen sich zwar Unterschiede in den Standpunkten bei der Therapieentscheidung und der Haltung gegenüber Tumortherapien bei Palliativpatienten in den verschiedenen Versorgungsbereichen feststellen, das praktische Vorgehen unterscheidet sich jedoch nicht wesentlich in palliativmedizinischen und onkologischen Versorgungsbereichen. Einschränkend muss an dieser Stelle auf die heterogenen Gruppenmerkmale onkologischer und palliativmedizinischer „Palliativpatienten“ hingewiesen werden. Die möglicherweise unterscheidbaren Patientengruppen deuten auf ein unterschiedliches Verständnis und (oder) eine unterschiedlich verstandene Definition vom Palliativpatienten hin. In diesem Zusammenhang sei jedoch auf die eingangs genannte geringe Anzahl teilnehmender onkologischer Einrichtungen sowie auf die Tatsache, dass der Dokumentation keine Patientenauswahl in den unterschiedlichen palliativmedizinischen Einrichtungen vorausging, hingewiesen.

Ein Ziel der Hospiz- und Palliativerhebung (HOPE) ist es, Palliativpatienten und palliativmedizinische Versorgungsstrukturen $\mathrm{zu}$ charakterisieren. Das unterschiedliche Verständnis kristallisiert sich an der Frage nach der Tumortherapie gut heraus. Voraussetzung für die HOPE-Dokumentation und die Teilnahme als „palliativmedizinische Einrichtung“ sollte nicht nur das Erkennen eines palliativmedizinischen Krankheitsstadiums sein, sondern auch der klar unterscheidbare therapeutische Ansatz: die Priorisierung des subjektiven Wohlergehens des Patienten (und seiner Angehörigen) vor den Belangen kausal gerichteter medizinischer Therapien.

\subsection{Palliativpatienten der UMG}

Die Daten der bundesweiten HOPE-Erhebung wurden mit den Krankheitsverläufen der Patienten, die auf der Palliativstation der Universitätsmedizin Göttingen eine Chemotherapie erhielten, verglichen. Hier konnten elf Therapieverläufe untersucht werden. Zwischen 1999 und Ende 2006 erhielten lediglich 1,4\% der stationären Palliativpatienten eine Chemotherapie auf der Palliativstation in Göttingen. Der Anteil männlicher Patienten (6) war geringfügig größer als der Anteil weiblicher Patienten (5). Das durchschnittliche Behandlungsalter lag bei 51 Jahren und war damit niedriger als das der PS-Patienten im TT-Modul (67,5 Jahre). Fünf der elf palliativmedizinisch betreuten Patienten wurden bis zu drei Wochen vor dem Versterben chemotherapeutisch behandelt (Patient: 1, 2, 3, 4, 9). Komplikationen traten bei insgesamt vier Patienten auf (Patient: 1, 2, 3, 8). Davon war eine Chemotherapiegabe mit einer letalen Komplikation (Patient 2) verbunden. In der Regel erfolgte eine 
chemotherapeutische Therapieeinleitung bzw. -fortsetzung auf Patientenwunsch und unter Rücksprache mit der Abteilung Hämatologie / Onkologie. Bei Patient 1 scheint eine Besserung der Dysphagie durch die Chemotherapie in der Vorgeschichte, sowie der beschriebenen Übelkeit und Leukozytopenie als Chemotherapieeffekt wahrscheinlich. Im zweiten Fall verstarb der Patient drei Wochen nach der letzten, auf der Palliativstation applizierten Chemotherapie infolge einer unter Aplasie entwickelten Pneumonie. Der dritte Patient klagte über Luftnot. Hier kommt neben einer psychogenen Ursache und einer Pneumonie auch eine nichtinfektiöse Nebenwirkung von Gemcitabin als Ursache in Frage. Der diagnostizierte paralytische Ileus könnte im Zusammenhang mit der Applikation von Vinca-Alkaloiden in Kombination mit Opioiden stehen. Der Patient verstarb fünf Tage nach der letzten Applikation der Chemotherapie: ein kausaler Zusammenhang erscheint nicht unwahrscheinlich.

Zwischen der letzten ambulanten Chemotherapiegabe und dem Versterben lagen beim vierten beschriebenen Therapieverlauf 17 Tage. Der Abstand zwischen der Chemotherapiegabe auf der Palliativstation und dem Tod des Patienten beträgt jedoch mehr als zwei Monate. Die Einleitung der Chemotherapie erfolgte durch die Palliativstation nach Rücksprache mit der Abteilung Hämatologie / Onkologie. Da die Patientin nach dem stationären Aufenthalt und der Chemotherapiegabe auf der Palliativstation in ihre häusliche Umgebung entlassen werden konnte, kann ein Benefit für die Patientin vermutet werden.

Auch im fünften beschriebenen Fall kann ein positiver Chemotherapieeffekt angenommen werden, da die Patientin nach Gabe der Chemotherapie auf der Palliativstation symptomkontrolliert in die häusliche Umgebung über mehrere Monate ohne einen zwischenzeitlichen Krankenhausaufenthalt entlassen werden konnte.

Kein nachvollziehbarer Chemotherapieeffekt konnte jedoch beim sechsten und siebten Patienten beobachtet werden. Bei Patient 8 erfolgte sowohl die Fortsetzung als auch der Abbruch der Chemotherapie auf der Palliativstation wegen der Tumorprogression und einer Verschlechterung des Allgemeinzustandes. Die Zeit zwischen den einzelnen Gaben der Chemotherapien (jeweils eine Woche) wurde dominiert von einer kurzzeitigen Verbesserung des Allgemeinzustandes (laut Dokumentation des Pflegepersonals), aber auch von Übelkeit, Erbrechen und Schwäche. Der Patient verstarb ca. vier Wochen nach der letzten Chemotherapie.

Die verabreichte Chemotherapie ist beim neunten Patienten als Ursache für die beschriebene Atemnot unwahrscheinlich. Da sich die Atemnot unter Furosemid bessert, kommt als Ursache für die Luftnot bei diesem Patienten mit oberer Einflussstauung eher ein Lungenödem in 
Frage. Andererseits spricht die Tatsache, dass der Patient nach der zweiten Chemotherapiegabe, die dosisreduziert verabreicht wurde, wie nach der ersten Gabe über Luftnot klagt, dafür, dass die Zytostatika bzw. deren Volumeneffekte als Ursache für die Atemnot wahrscheinlich sind (erneut Gemcitabin-Effekt).

Bei Patient 10 wurde auf der Palliativstation die Chemotherapie nach dem FOLFOX-Schema fortgesetzt. Eine Umstellung auf ein anderes Regime (laut interdisziplinärer Tumorkonferenz mit Vinorelbin oder Gemcitabin empfohlen) erfolgte jedoch nicht während des stationären Aufenthalts auf der Palliativstation. Der Grund hierfür lässt sich aus der Aktenlage nicht eruieren.

Im letzten (elften) untersuchten Fall erfolgte eine Fortsetzung der zuvor initiierten Tumortherapie durch die Palliativstation. Der Patient verstarb bei fortgeschrittener Tumorerkrankung und langjähriger Tumortherapie vier Wochen nach der letzten Zytostatikaapplikation.

Die Untersuchung dieser Krankheitsverläufe unter Berücksichtigung der verabreichten Chemotherapien auf der Palliativstation der Universitätsmedizin Göttingen stellt eine wichtige Bereicherung der HOPE-Ergebnisse dar, da sie eindrücklich die Komplexität der therapeutischen Entscheidungsfindung für oder gegen eine Chemotherapie im palliativmedizinischen Setting, die Wechselbeziehung onkologischer und palliativmedizinischer Therapieindikationsstellung und nicht zuletzt die ethischen Implikationen einer Therapieeinleitung beleuchtet.

\subsection{Schlussfolgerungen}

Sowohl aus den Daten der HOPE-Studie als auch aus den retrospektiv gewonnenen Daten der Palliativstation Göttingen können folgende Schlussfolgerungen gezogen werden:

- Tumorspezifische Therapien finden Eingang in palliativmedizinische Behandlungskonzepte, sowohl aus der Intention einer Tumorgrößenreduktion heraus als auch mit dem Ziel einer verbesserten Symptomkontrolle. Insofern ist die Palliativmedizin nicht mit einem Wegfall onkologischer, tumortherapeutischer Maßnahmen verbunden. Demzufolge ist ein „Palliativpatient“ nicht durch das Fehlen einer Tumortherapie charakterisiert.

- Es ist ein wesentlicher Überschneidungsbereich onkologischer und palliativmedizinischer Behandlungskonzepte zu sehen, welcher das interdisziplinär geprägte Selbstverständnis der Palliativmedizin unterstreicht. 
- In der konkreten klinischen Umsetzung kristallisiert sich zumindest im eigenen Patientenkollektiv die Notwendigkeit einer Einbindung onkologischer Expertise in derartige fachübergreifende palliativmedizinische Behandlungskonzepte (z.B. im Rahmen einer Zusammenarbeit mit fachonkologischen Abteilungen) heraus.

- Nach den vielerorts dokumentierten, vielschichtige Optionen aufgreifenden palliativmedizinischen Behandlungskonzepten finden sich jedoch Hinweise auf ein unterschiedliches Verständnis, unterschiedliche Voraussetzungen und unterschiedliche Standpunkte bei der Therapieentscheidung sowie unterschiedliche Haltungen bezüglich der dokumentierten Gruppe von „Palliativpatienten“ in onkologischen und palliativmedizinischen Versorgungseinrichtungen.

- Ob die sich vor dem Hintergrund neuer, zielgerichteter, tumorspezifischer Substanzen abzeichnenden Behandlungsoptionen diese Entwicklung weiter vorantreiben, wird derzeit in einem ergänzenden, prospektiven Projekt der Abteilung Palliativmedizin der Universitätsmedizin Göttingen untersucht. 


\section{Zusammenfassung}

Die vorliegende Untersuchung fand vor dem Hintergrund weitreichender Entwicklungen in der modernen Onkologie statt, die eine Erweiterung tumortherapeutischer Indikationsspektren hin zu genuin palliativmedizinischen Zielen der Symptomkontrolle nahe legen. Das Ziel der vorliegenden prospektiven Studie ist es, erstmalig einen Zustandsbericht über den systematischen Einsatz tumorspezifischer Therapien im palliativmedizinischen Setting zu generieren sowie Informationen zur Indikation und $\mathrm{zu}$ den Standpunkten bei der Therapieentscheidung zu gewinnen. Die Ergebnisse sollen somit Auskunft über den Stellenwert tumorspezifischer Therapien zur Symptomkontrolle bei Palliativpatienten geben und Unterschiede bzw. Gemeinsamkeiten zwischen stationärer Onkologie und stationärer Palliativversorgung aufzeigen. Bisher existieren hierzu keine anderen Untersuchungen in vergleichbarem Umfang.

Im Rahmen der Hospiz- und Palliativerhebung (HOPE) wurden im Erhebungszeitraum 36/2007 mit Hilfe eines neu entwickelten Moduls Tumortherapie (TT) in ambulanten und stationären bzw. in onkologischen, palliativmedizinischen und hospizlichen Einrichtungen die oben genannten Aspekte tumorspezifischer Therapien bei Palliativpatienten erhoben. Zudem wurden die Krankheitsverläufe aller Patienten, die in den Jahren 1999 bis Ende 2006 auf der Palliativstation der UMG eine tumorspezifische Therapie erhielten, unter klinischen Outcomekriterien untersucht.

Die Ergebnisse der Untersuchung zeigen, dass Tumortherapien (TT) altersunabhängig in allen Bereichen, die Palliativpatienten versorgen, (abgesehen von stationären Hospizen) fortgeführt und initiiert wurden. Patienten der betrachteten Palliativstationen waren insbesondere Tumorpatienten im metastasierten Tumorstadium (insbesondere Tumore des Gastrointestinaltraktes, des Respirationstraktes und der weiblichen Brustdrüse), die mit einem durchschnittlichen ECOG von 3,1 als pflegebedürftiger eingeschätzt wurden als Patienten onkologischer Stationen (2,4). Es zeigte sich, dass bei einigen Patienten (9) trotz schlechter Prognose im PPI (2, entspricht einem 3-Wochenüberleben von 20\%) eine TT neu begonnen wurde. 43,7\% der durchgeführten TT umfassten intravenöse zytotoxische Chemotherapien, insbesondere Antimetabolite. Auf Palliativstationen verstarben Patienten mit TT zwar seltener als andere PS-Patienten, jedoch deutlich häufiger als Patienten in onkologischen Einrichtungen. 24,0\% aller TT wurden auf Palliativstationen mit dem Ziel einer Tumorgrößenreduktion indiziert, 38,3\% der TT mit dem Ziel der Symptomkontrolle. Auf onkologischen Stationen findet sich mit 38,1\% (Tumorgrößenreduktion) bzw. 28,6\% (Symptomkontrolle) ein umgekehrtes Verhältnis. Die meisten Therapieentscheidungen 
wurden im klaren Konsens gefällt, die wenigen klaren Dissensentscheidungen (5,6\%) kumulieren bei der Indikation „Symptomkontrolle“. Der Therapieerfolg wurde auf einer Skala von 1-6 durch den Therapeuten mit durchschnittlich 2,68 angegeben. Für das Ausfüllen der TT-Fragebögen waren anteilig mehr Ärzte als Pflegekräfte verantwortlich, davon waren mit 30,4\% mehr Ärzte mit der Facharztbezeichnung Hämatologie / Onkologie vertreten, als mit anästhesiologischem Hintergrund (15,4\%). Insofern lassen sich zwar Unterschiede in den Standpunkten bei der Therapieentscheidung in den verschiedenen Versorgungsbereichen feststellen, das praktische Vorgehen unterscheidet sich jedoch nicht wesentlich in palliativmedizinischen und onkologischen Versorgungsbereichen.

Eine Chemotherapie erhielten elf (1,4\%) der 808 zwischen 1999 und Ende 2006 behandelten Patienten der Palliativstation in Göttingen. Therapieassoziierte Komplikationen traten möglicherweise in vier der elf untersuchten Krankheitsverläufe auf. In einer Situation musste das Versterben eines Patienten mit einer therapieassoziierten Komplikation in Verbindung gebracht werden. Fünf von elf Patienten erhielten noch bis drei Wochen vor dem Tod eine Chemotherapie. In bis zu vier Fällen kann von einem positiven Chemotherapieeffekt im Sinne einer Symptomlinderung bzw. Stabilisierung des Allgemeinzustandes und damit einhergehend einer verbesserten außerklinischen Versorgbarkeit gesprochen werden.

Die vorliegende Studie konnte zeigen, dass tumorspezifische Therapien mit dem Ziel einer verbesserten Symptomkontrolle im palliativmedizinischen Setting zum Einsatz kommen und als ein Bindeglied zwischen Palliativmedizin und Onkologie palliativmedizinische Behandlungsmöglichkeiten erweitern können. Es zeigen sich jedoch auch Unterschiede in den Voraussetzungen und Einschätzungen onkologischer und palliativmedizinischer Versorgungseinrichtungen, die auf heterogene Gruppenmerkmale in onkologischen und palliativmedizinischen Versorgungsstrukturen hinweisen. Es deutet sich an, dass die Definition des Begriffes „Palliativpatient“, die sich im palliativmedizinischen Selbstverständnis an medizinischen, pflegerischen, psychosozialen und spirituellen Bedürfnissen des Patienten orientiert, in onkologischen bzw. palliativmedizinischen Arbeitsbereichen unterschiedlich verstanden wird.

Ausgehend von den Ergebnissen der vorliegenden Studie sind weiterführende Untersuchungen notwendig, welche die konkreten Auswirkungen von Chemotherapeutika und ihren modernen Weiterentwicklungen auf die Symptomkontrolle und die vorangegangenen ärztlichen Entscheidungsfindungsprozesse analysieren. Außerdem ist die Schaffung eines einheitlichen Verständnisses vom „Palliativpatienten“ die Grundlage für eine zukünftige hochwertige palliativmedizinische Betreuung in verschiedenen Versorgungseinrichtungen. 


\section{Anhang}

\subsection{Fragebögen}

\subsubsection{Hospiz- und Palliativerhebung (HOPE) Basisbogen}

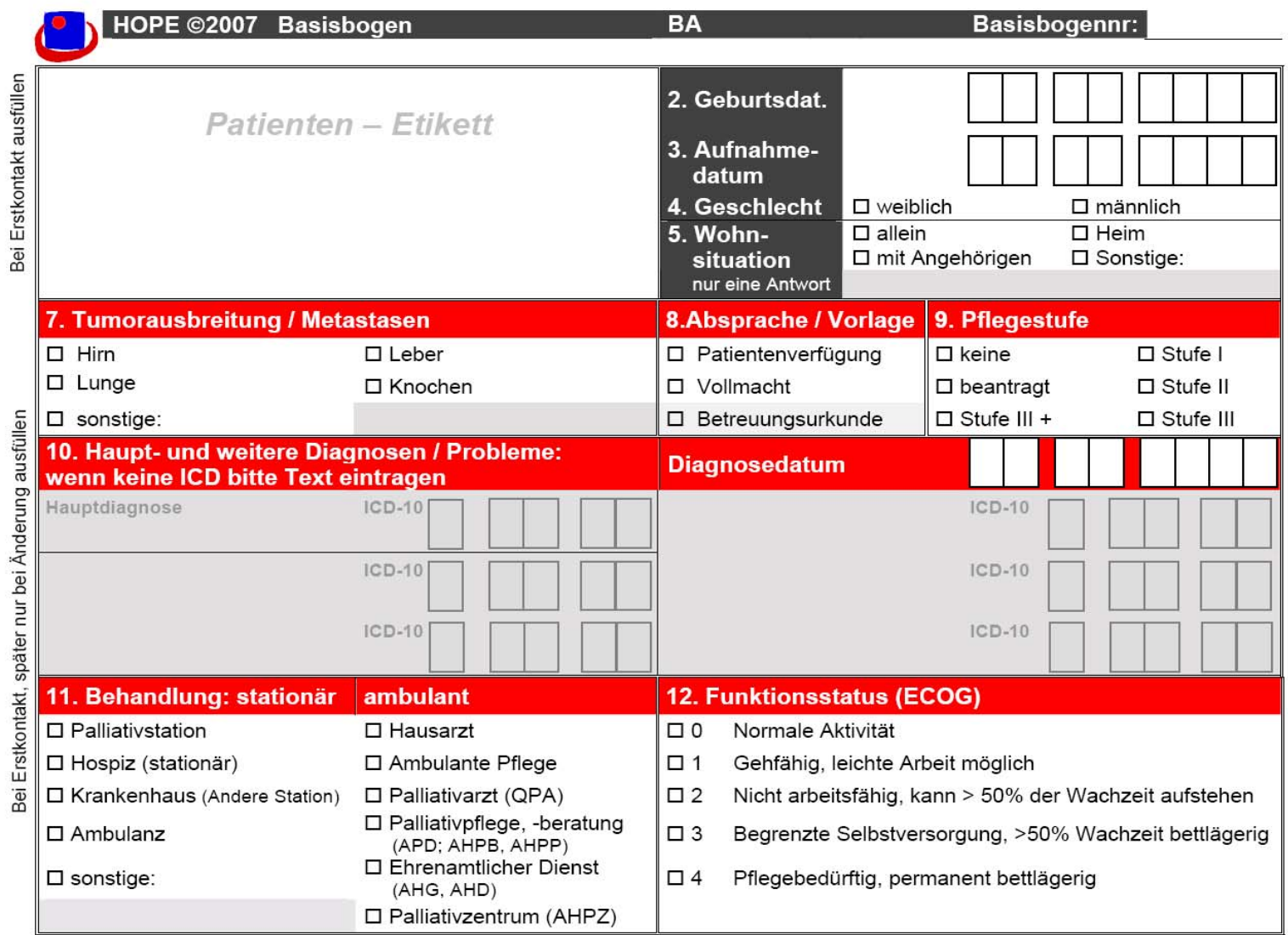

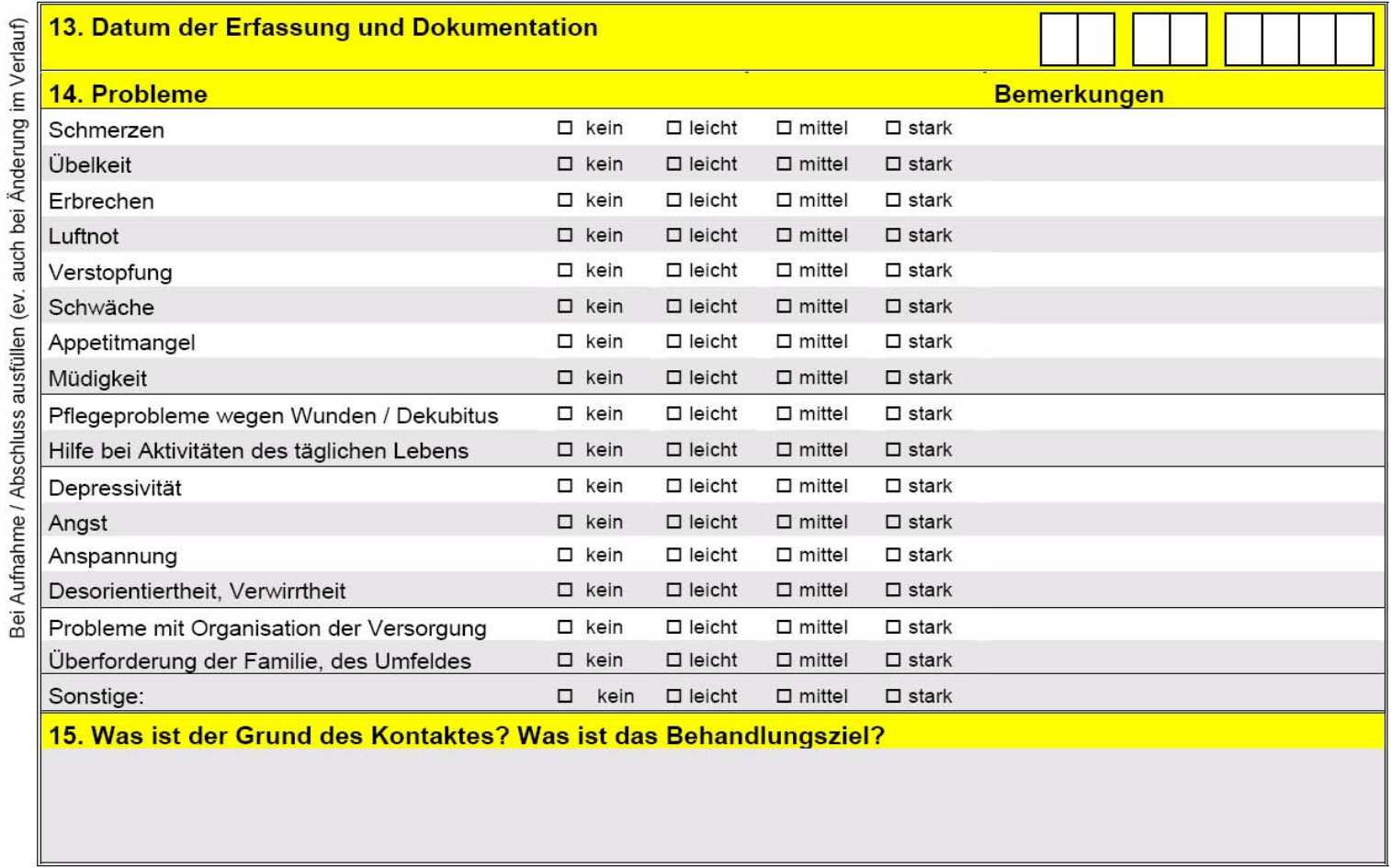




\subsubsection{Hospiz- und Palliativerhebung (HOPE) Modul Tumortherapie}

HOPE $\odot 2007$ Tumorspezifische Therapien in d. Palliativmedizin TT Basisbogennr.:

Dieser Fragebogen erfasst den Einsatz von tumorspezifischen Therapien während Ihrer Betreuung. Bitte füllen Sie im Falle einer fortgesetzten Vortherapie den Bogen bei Aufnahme aus, bei einer neu initiierten Tumortherapie zum Zeitpunkt der Therapieeinleitung. Bitte ergänzen Sie die Fragen 9-12 nach Therapieende.

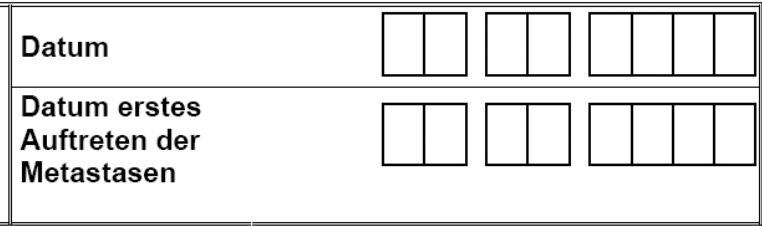

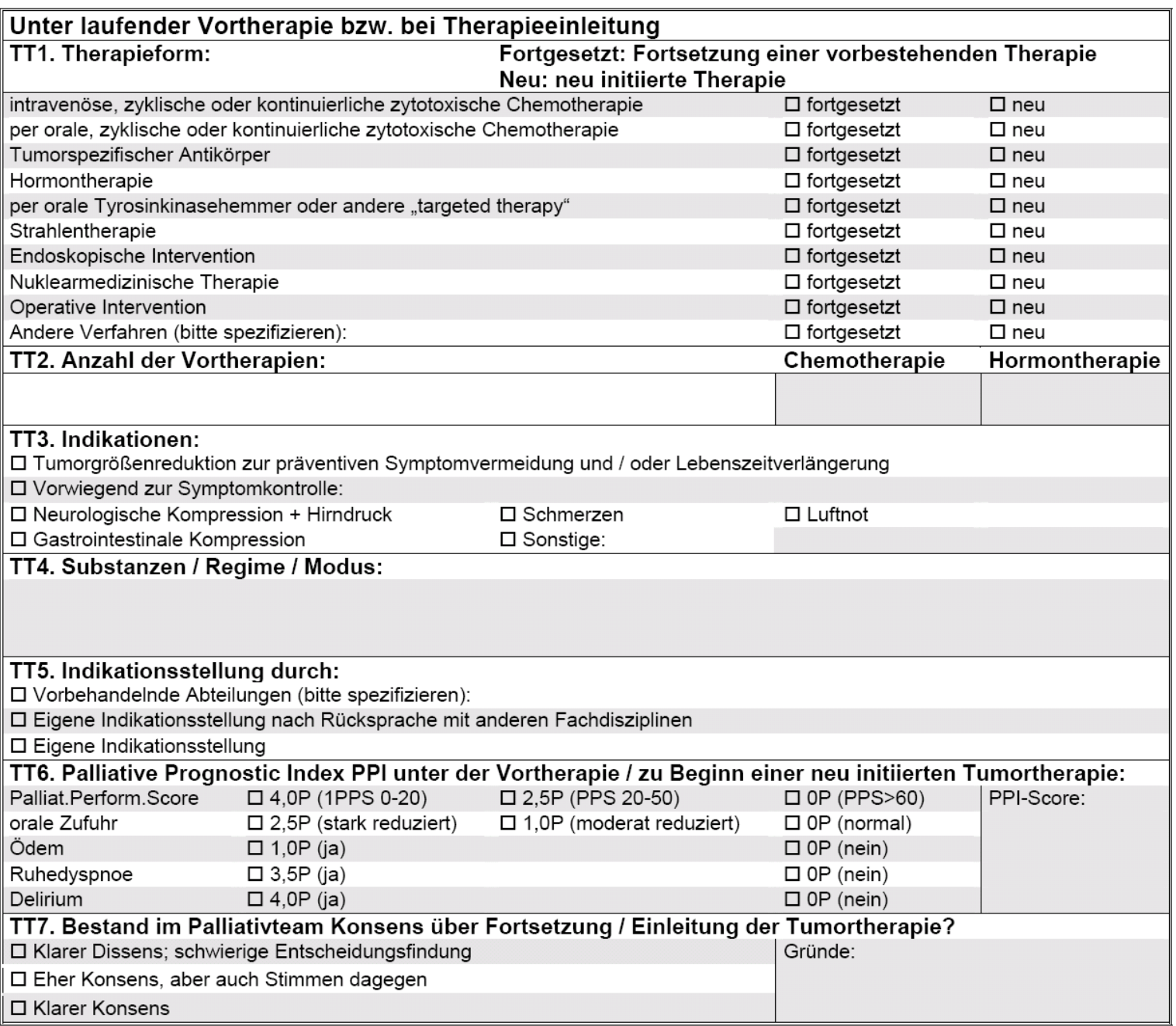

\section{Bei Beendigung der Tumortherapie}

TT8. Mit welchem subjektivem Erfolg wurde die Tumortherapie durchgeführt?
$\square$ sehr schlecht
$\square$ schlecht
$\square$ zufriedenstellend
$\square$ gut
TT9. Wurde die Tumortherapie vorzeitig abgebrochen?

$\square \mathrm{Ja}$

TT10. Wenn ja, welche Gründe lagen für den vorzeitigen Abbruch vor?

$\square$ Toxizitäten

$\square$ Ineffizienz der Therapie

$\square$ Verschlechterung des Allgemeinzustandes

$\square$ Wunsch des Patienten

TT11. Bestand im Palliativteam Konsens über Abbruch / Beendigung der Tumortherapie?

$\square$ Klarer Dissens; schwierige Entscheidungsfindung

$\square$ Eher Konsens, aber auch Stimmen dagegen

$\square$ Klarer Konsens

TT12. Wer füllt aus?

$\square$ Arzt / Ärztin

Fachrichtung

$\square$ Innere Medizin

Art der Toxizitäten / Nebenwirkungen:

$\square$ Pflegende

$\square$ Hämatologie/Onkologie 


\subsection{Hospiz- und Palliativerhebung (HOPE) Patienteninformation und}

\section{Einverständniserklärung}

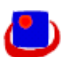

Sehr geehrte Patientinnen und Patienten,

Der Sie betreuende Pflegedienst beteiligt sich an einer Qualitätssicherungsmaßnahme. Dieses Projekt wird an mehr als 50 Palliativstationen und Hospizen, mit onkologischen Abteilungen sowie palliativärztlichen und pflegerischen ambulanten Diensten durchgeführt. Grundlage der Qualitätssicherung ist die Dokumentation von Symptomen und Problemen, deren Behandlung und den Erfolgen der Behandlung. Die Dokumentation geschieht in einem einheitlichen Formular (HOPE), das als neuer Standard für Palliativeinrichtungen entwickelt wurde und die wichtigsten Dinge erfasst. Das Formular besteht aus mehreren Teilen für die Ärzte und Schwestern und aus einem Fragebogen für Sie, die Patientinnen und Patienten. In diesem Fragebogen sollen Sie selber über Ihre Beschwerden (z. B. Schmerzen) und Ihr Befinden Auskunft geben. Denn niemand kennt Ihre Beschwerden und Inre Situation so gut wie Sie selbst.
Der Fragebogen wurde für die speziellen Belange der Palliativmedizin entwickelt. Wir möchten Sie bitten, den Fragebogen so sorgfältig und vollständig wie möglich auszufüllen, auch wenn einzelne Fragen für Ihre Situation eventuell nicht zutreffend sind. Wenn Sie einzelne Fragen oder den ganzen Fragebogen nicht beantworten, wird das natürlich keine Nachteile für Sie oder für Ihre weitere Behandlung haben.

Die in diesem Fragebogen erhobenen Daten werden mittels eines EDV-Systems gespeichert und anonym (also ohne Namen) ausgewertet. Alle Daten unterliegen selbstverständlich der ärztlichen Schweigepflicht gemäß § 203 StGB und werden nach den Bestimmungen des Bundesdatenschutzes vor jedem Missbrauch geschützt.

Wir danken Innen für Ihre Mitarbeit!

Die Koordinationsgruppe von HOPE 2007
Einverständniserklärung

Ich bin durch die betreuende Person über die

Fragebogenerhebung aufgeklärt worden und habe keine weiteren Fragen.

Ich bin mit der Speicherung der in diesem Fragebogen erhobenen Daten in anonymisierter Form in einem EDV-Dokumentationssystem einverstanden. Sollte ich zu irgendeinem Zeitpunkt mein Einverständnis zurückziehen, werden meine Daten gelöscht.

Datum:

Unterschrift des Patienten: 


\subsection{Tabellen}

Tabelle 23: Teilnehmende Einrichtungen und Anzahl der dokumentierten Patienten zwischen 1999 und 2007

\begin{tabular}{|c|c|c|c|c|}
\hline \multirow[t]{2}{*}{ Jahr } & \multicolumn{2}{|c|}{ Einrichtungen } & \multirow{2}{*}{\multicolumn{2}{|c|}{$\begin{array}{l}\text { Patienten- } \\
\text { dokumentationen }\end{array}$}} \\
\hline & \multicolumn{2}{|c|}{\begin{tabular}{l|l} 
Art & Anzahl
\end{tabular}} & & \\
\hline 1999 & PS & 33 & 757 & 757 \\
\hline 2000 & PS & 44 & 1.086 & 1.086 \\
\hline 2001 & PS & 57 & 1.304 & 1.304 \\
\hline \multirow[t]{4}{*}{2002} & PS & 54 & 1.230 & \multirow[b]{4}{*}{1.546} \\
\hline & OS & 5 & 110 & \\
\hline & G & 2 & 49 & \\
\hline & $\mathrm{H}$ & 8 & 157 & \\
\hline \multirow[t]{5}{*}{2004} & PS & 68 & 1.665 & \multirow[b]{5}{*}{2.214} \\
\hline & OS & 3 & 85 & \\
\hline & $\mathrm{H}$ & 12 & 224 & \\
\hline & AA & 7 & 162 & \\
\hline & AP & 4 & 78 & \\
\hline \multirow[t]{5}{*}{2005} & PS & 53 & 1.268 & \multirow[b]{5}{*}{1.903} \\
\hline & OS & 6 & 82 & \\
\hline & $\mathrm{H}$ & 12 & 274 & \\
\hline & AA & 8 & 169 & \\
\hline & AP & 5 & 110 & \\
\hline \multirow[t]{5}{*}{2006} & PS & 58 & 1.472 & \multirow[b]{5}{*}{2.841} \\
\hline & OS & 7 & 187 & \\
\hline & $\mathrm{H}$ & 22 & 457 & \\
\hline & AA & 29 & 474 & \\
\hline & AP & 15 & 251 & \\
\hline \multirow[t]{5}{*}{2007} & PS & 67 & 1.663 & \multirow{6}{*}{$\begin{array}{r}3.184 \\
15025\end{array}$} \\
\hline & OS & 8 & 143 & \\
\hline & $\mathrm{H}$ & 24 & 498 & \\
\hline & AA & 28 & 435 & \\
\hline & AP & 22 & 445 & \\
\hline Gesamt & & & & \\
\hline
\end{tabular}

$\mathrm{PS}=$ Palliativstation, $\mathrm{OS}=$ Onkologische Station, $\mathrm{G}=$ Geriatrische Station, $\mathrm{H}=$ stationäres Hospiz,AA = ambulanter Arzt, AP = ambulante Pflege 


\section{Literaturverzeichnis}

Adelstein DJ (1995): Palliative chemotherapy for non-small cell lung cancer. Semin Oncol, $\underline{2}$ (Suppl 3), 22: 35-39

Aichmüller-Lietzmann G: Palliativmedizin in der Praxis - dargestellt am Johannes- Hospiz in München, LIT Verlag, Münster 1998, S. 34.f

Alt-Epping B, Nauck F (2007): Palliativmedizin in der Onkologie - Onkologie in der Palliativmedizin. Forum DKG, 3/2007: 42-44

Alt-Epping B, Jung W, Trümper L (2006): Tumorspezifische Therapien auch auf der Palliativstation? - Eine alte Frage neu beleuchtet. Z Palliativmed, 7: 19-24

Alt-Epping B, Jung W, Nauck F (2007): Symptomkontrollierende Effekte der Chemotherapie - Ergänzung palliativer Therapiekonzepte? Onkologe, 13: 619-624

Anderson F, Downing GM, Hill J, Carsorso L, Lerch N (1996): Palliative performance scale (PPS): a new tool. J Palliat Care, 12(1): 5-11

Anderson H, Hopwood P, Stephens RJ, Thatcher N, Cottier B, Nicholson N, Milroy R, Maughan TS, Falk SJ, Bond MG et al. (2000): Gemcitabine plus best supportive care (BSC) vs. BSC in inoperable non-small cell lung cancer - a randomized trial with quality of life as the primary outcome. Br J Cancer, 83(4): 447-453

Bausewein C, Fegg M, Radbruch L, Nauck F, von Mackensen S, Borasio GD, Higginson IJ (2005): Validation and Clinical Application of the German Version of the Palliative Care Outcome Scale. J Pain Symptom Manage, 30(1): 51-62

Beck C, Kneba M (2004): Designermedikamente in der Tumortherapie. Internist, Suppl 1: $38-47$

Beck D, Kettler D (2001): Symptomkontrolle in der Palliativmedizin. Schmerz, 15: 320-332 Berry DL, Moinpour CM, Jiang CS, Ankerst DP, Petrylak DP, Vinson LV, Lara PN, Jones S, Taplin ME, Burch PA et al. (2006): Quality of life and pain in advanced stage prostate cancer: results of a Southwest Oncology Group randomized trial comparing docetaxel and estramustine to mitoxantrone and prednisone. J Clin Oncol, 24(18): 2828-2835

Bezjak A, Ng P, Skeel R, DePetrillo AD, Comis R, Taylor KM (2001): Oncologists' use of quality-of-life information: Results of a survey of Eastern Co-operative Group (ECOG) physicians. Qual Life Res, 10:1-13

Bezjak A, Tu D, Seymour L, Clark G, Trajkovic A, Zukin M, Ayoub J, Jago S, de Albuquerque R, Gerogianni A et al. (2006): Symptom improvement in lung cancer patients treated with erlotinib: quality of life analysis of the National Cancer Institute of Canada clinical trials group study BR.21. J Clin Oncol, 24(24): 3831-3837 
Burris H, Storniolo AM (1997): Assessing clinical benefit in the treatment of pancreas cancer: gemcitabine compared to 5-fluorouracil. Eur J Cancer, 33(Suppl 1): 18-22

Cardoso F, Di Leo A, Lohrisch C, Bernard C, Ferreira F, Piccart MJ (2002): Second and subsequent lines of chemotherapy for metastatic breast cancer: what did we learn in the last two decades? Ann Oncol, 13: 197-207

Detmar SB, Muller MJ, Schornagel JH, Wever LDV, Aaronson NK (2002): Role of health-related quality of life in palliative chemotherapy treatment decisions. J Clin Oncol, 20(4): 1056-1062

DGP= Deutsche Gesellschaft für Palliativmedizin (2003): Definition Palliativmedizin 31.10.2003, www.dgpalliativmedizin.de

DGP = Deutsche Gesellschaft für Palliativmedizin (2007): Stand 2/2007, www.dgpalliativmedizin.de

Doyle C, Crump M, Pintilie M, Oza AM (2001): Does chemotherapy palliate? Evaluation of expectations, outcomes, and costs in women receiving chemotherapy for advanced ovarian cancer. J Clin Oncol, 19(5): 1266-1274

Ellershaw J (2002): Clinical pathways for care of the dying: an innovation to disseminate clinical excellence. J Palliat Med (United States), 5(4): 617-621

Ellershaw J (2007): Care of the dying: what a difference an LCP makes! Palliat Med (England), 21(5): 365-368

Ellis PA, Smith IE, Hardy JR, Nicolson MC, Talbot DC, Ashley SE, Priest K (1995): Symptom relief with MVP (mitomycin C, vinblastine and cisplatin) chemotherapy in advanced non-small cell lung cancer. Br J Cancer, 71(2): 366-370

Emanuel EJ, Emanuel LL (1994): The Economics of Dying- The Illusion of Cost Saving at the End of Life. New Engl J Med, 330(8): 540-544

Escudier B, Eisen T, Stadler WM, Szczylik C, Oudard S, Siebels M, Negrier S, Chevreau C, Solska E, Desai AA et al. (2007): Sorafenib in advanced clear-cell renal- cell carcinoma. N Eng J Med, 356(2): 125-134

Fölsch UR, Schreiber S (2004): Therapiewandel in der Inneren Medizin. Internist, 45(Suppl 1): 5

Frickhofen N (2006): Entscheidungswege zum Umgang mit Chemotherapie am Lebensende Palliativmedizin. abstract / Vortrag V4_1, 6. Kongress der DGP, September 2006, www.thieme-connect.com/ejournals

Fukuoka M, Yano S, Giaccone G, Tamura T, Nakagawa K, Douillard JY, Nishiwaki Y, Vansteenkiste J, Kudoh S, Rischin D et al. (2003): Multi-institutional randomized phase II 
trial of gefitinib for previously treated patients with advanced non-small cell lung cancer (The IDEAL 1 Trial). J Clin Oncol, 21(12): 2237-2246

Fuster LM, Sandler AB (2004): Select clinical trials of erlotinib (OSI-774) in non-small cell lung cancer with emphasis on phase III outcomes. Clin Lung Cancer, 6 (Suppl 1): 24-29

Geyer CE, Forster J, Lindquist D, Chan S, Romieu GC, Pienkowski T, JagielloGruszfeld A, Crown J, Chan A, Kaufman B et al. (2006): Lapatinib plus capecitabine for HER2-positive advanced breast cancer. N Engl J Med, 355(26): 2733-2743

Glimelius B, Hoffman K, Sjöden PO, Jacobsson G, Sellström H, Enander LK, Linne T, Svensson C (1996): Chemotherapy improves survival and quality of life in advanced pancreatic and biliary cancer. Ann Oncol, 7: 593-600

Gralla RJ, Hollen PJ, Liepa AM, Symanowski JT, Boyer MJ, Abraham R, Rusthoven JJ, Paz-Ares L, Vogelzang NJ (2003): Improving quality of life in patients with malignant pleural mesothelioma; results of the randomized premetrexed + cisplatin vs cisplatin trial using the LCSS- meso instrument. Proc Am Soc Clin Oncol, 22; abstr 2496

Gridelli C, Gallo C, Shepherd FA, Illiano A, Piatedosi F, Robbiati SF, Manzione L, Barbera S, Frontini L, Veltri E (2003): Gemcitabine plus vinorelbin compared with cisplatin plus vinorelbine or cisplatin plus gemcitabine for advanced non-small cell lung cancer: a phase III trial of the Italian GEMVIN investigators and the National Cancer Institute of Canada Clinical Trials Group. J Clin Oncol, 21(16): 3025- 3034

Grossenbacher-Gschwend B, Eychmüller S (2007): The Liverpool Care Pathway for the dying - Gemeinsam für eine gute Qualität in der Betreuung am Lebensende. Onkologe, 13(4): 343-348

Hanekop GG, Ensink FBM, Bautz MT, Kettler D (2000): Schmerztherapie in der Palliativmedizin. Internist, $\underline{41}$ : 633-640

Hanratty B, Lawlor DA (1999): Will to live in the terminal ill. Lancet, 354: 2084

Hartenstein R (2002): Stellenwert der Palliativmedizin in der Onkologie. Onkologie, $\underline{25}$ (Suppl 1): 60-64

Hearn J, Higginson IJ (1999): Development and validation of a core outcome measure for palliative care: the palliative care outcome scale. Qual Health Care, $\underline{8}$ : 219-227

Herschbach P, Brandl T, Knight L, Keller M (2004): Einheitliche Beschreibung des subjektiven Befindens von Krebspatienten: Entwicklung einer psychoonkologischen Basisdokumentation (PO-Bado). Dtsch Arztebl, Heft 12, 101: A 799-802

Hiddemann W (2000): Palliativmedizin. Internist, 41: 605 
Hurwitz H, Fehrenbacher L, Novotny W, Cartwright T, Hainsworth J, Heim W, Berlin J, Baron A, Griffing S, Holmgren E et al. (2004): Bevacizumab plus Irinotecan, fluorouracil and leucovorin for metastatic colorectal cancer. N Engl J Med, 350(23): 23352342

Husebo S, Klaschik E: Palliativmedizin, Auflage 3, Springer Verlag, Berlin 2003, S. 296302

Jochims C, Mazitschek U, Jäger D, Goldschmidt H (2006): Zielgerichtete Therapie bei soliden Tumoren und in der Hämatoonkologie. Internist, 47: 633-641

Junker A (2002): Onkologische Therapie: Auf einzelne Moleküle zielen. Dtsch Arztebl, Heft 6, 99: 339-340

Kabbinavar FF, Schulz J, McCleod M, Patel T, Hamm JT, Hecht JR, Mass R, Perrou B, Nelson B, Novotny WF (2005): Addition of bevacizumab to bolus fluorouracil and leucovorin in first-line metastatic colorectal cancer: results of a randomized phase II trial. J Clin Oncol, 16(23): 3697-3705

Klaschik E, Husebo S (1997): Palliativmedizin. Anaesthesist, 46: 177-185

Klaschik E, Nauck F, Kern M (1998): Palliativmedizin. Z Arztl Fortbild Qualitatssich, $\underline{92}$ : 53

Klaschik E, Nauck F, Radbruch L, Sabatowski R (2000): Palliativmedizin - Definition und Grundzüge. Internist, $\underline{\text { 41: 606- } 611}$

Klaschik E, Ostgathe C, Nauck F (2001): Grundlagen und Selbstverständnis der Palliativmedizin. Z Palliativmed, 2: 71-75

Klastersky J (1995): Therapy of non-small cell lung cancer. Lung Cancer, 12(Suppl 1): 133145

Klastersky J, Paesmans M (2001): Response to chemotherapy, quality of life benefits and survival in advanced non small cell lung cancer: Review of literature results. Lung Cancer, $\underline{34}$ (Suppl 4): 95- 101

Klinkhammer G (2007): Palliativmedizin: Junge Disziplin mit großem Potential. Dtsch Arztebl, Heft 5: 217-220

Koedoot CG, de Haan RJ, Stiggelbout AM, Stalmeier PFM, de Graeff A, Bakker PJM, de Haes JCJM (2003): Palliative chemotherapy or best supportive care? A prospective study explaining patient’s treatment preference and choice. Br J Cancer, 89: 2219- 2226

Kornblith AB (2001): Does palliative care palliate? J Clin Oncol, 19(8): 2111-2113

Kris MG, Natale RB, Herbst RS, Lynch TJ, Prager D, Belani CP, Schiller JH, Kelly K, Spiridonidis H, Albain KS et al. (2002): A phase II trial of ZD 1839 (Iressa) in advanced 
non-small cell lung cancer in patients who have failed platinum- and docetaxel based regimens (IDEAL2). Proc Am Soc Clin Oncol, 21: abstr 1166

Kris MG, Natale RB, Herbst RS, Lynch TJ, Prager D, Belani CP, Schiller JH, Kelly K, Spiridonidis H, Sandler A et al. (2003): Efficacy of gefitinib, an inhibitor of the epidermal growth factor receptor tyrosine kinase, in symptomatic patients with non-small cell lung cancer: a randomised trial. JAMA, 290(16): 2149-2158

Krumm N, Stiel S, Ostgathe C, Lindena G, Nauck F, Eisner F, Radbruch L (2008): Subjektives Befinden bei Palliativpatienten-Ergebnisse der Hospiz- und Palliativerhebung (HOPE), Palliativmedizin, 9: 132-138

Laske A, Pollkläsener I, Dietz I (2008): Entwicklung der Palliativmedizinischen Lehre in Deutschland 2008, Poster 7. Kongress der DGP, September 2008, AG Palliativmedizin www.pallmed.de

Lin NU, Carey LA, Liu MC, Younger J, Come SE, Ewend M, Harris GJ, Bullitt E, Van den Abbeele AD, Henson JW et al. (2006): Phase II trial of lapatinib for brain metastases in patients with HER2+ breast cancer. Proc Am Soc Clin Oncol 23: 3 (abstr)

Maltoni M, Nanni O, Pirovano M, Scarpi E, Indelli M, Martini C, Monti M, Arnoldi E, Piva L, Ravaioli A et al. (1999): Successful validation of the palliative prognostic score in terminally ill cancer patients. Italian Multicenter Study Group on Palliative Care. J Pain Symptom Manage, 17(4): 240-247

Maughan TS, James RD, Kerr DJ, Ledermann JA, Seymour MT, Topham C, McArdle C, Cain D, Stephens RJ (2003): Comparison of intermittent and continuous palliative chemotherapy for advanced colorectal cancer. Lancet, 361: 457-464

Middleton GW, Smith IE, O’Brien MER, Norton A, Hickish T, Priest K, Spencer L, Ashley S (1998): Good symptom relief with palliative MVP (mitomycin C, vinblastine and cisplatin) chemotherapy in malignant mesothelioma. Ann Oncol, 9(3): 269-273

Morita T, Tsunoda J, Inoue S, Chihara S (1999): The Palliative Prognostic Index: a scoring system for survival prediction of terminally ill cancer patients. Support Care Cancer, 7: $128-133$

Motzer RJ, Hutson TE, Tomczak P, Michgelson MD, Bukowski RM, Rixe O, Oudard S, Negrier S, Szczylik C, Kim ST et al. (2007): Sunitinib versus interferon alfa in metastatic renal-cell carcinoma. N Engl J Med, 356: 115-124

Natale RB, Skarin AT, Maddox AM, Hammond LA, Thomas R, Gandara DR, Gerstein H, Panella TJ, Cole J, Jahanzeb M et al. (2002): Improvement in symptoms and quality of 
life for advanced non-small cell lung cancer patients receiving ZD 1839 ('Iressa') in IDEAL 2. Proc Am Soc Clin Oncol, 21: abstr 1167

Nauck F, Ostgathe C, Radbruch L, Bausewein C, Fuchs M, Lindena G, Neuwöhner K, Schulenberg D, Klaschik E, and the Working Group on the Core Documentation for Palliative Care Units in Germany (2004): Drugs in Palliative Care. Results from a representative survey in Germany. Palliat Med; 18: 100-107

Nauck F (2001): Symptomkontrolle in der Finalphase. Schmerz, 15: 362-369

O`Brien M, Ciuleanu T, Tsekov H, Shparyk Y, Cucevic B, Juhasz G, Ross G, Dane G, Crofts T (2005): Survival benefit of oral topotecan plus supportive care versus supportive care alone in relapsed, resistant SCLC. Lung Cancer, 49(Suppl 2): 54

O`Brien M, Ciuleanu TE, Tsekov H, Shparyk Y, Cucevia B, Juhasz G, Thatcher N, Ross GA, Dane GC, Crofts T (2006): Phase III trial comparing supportive care alone with supportive care with oral topotecan in patients with relapsed small cell lung cancer. J Clin Oncol, 24(34): 5441-5447

Ostgathe C, Voltz R, Nauck F, Klaschik E (2007): Undergraduate training in palliative medicine in Germany: what effect does a curriculum without compulsory palliative care have on medical students' knowledge, skills and attitudes? Palliat Med, 21(2):155-156

Pawel J, Schiller JH, Shepherd FA, Fields SZ, Kleisbauer JP, Chrysson NG, Stewart DJ, Clark PI, Palmer MC, Depierre A et al. (1999): Topotecan versus cyclophosphamide, doxorubicin and vincristine for the treatment of recurrent small cell lung cancer. J Clin Oncol, 17(2): 658-667

Pirovano M, Maltoni M, Nanni O, Marinari M, Indelli M, Zaninetta G, Petrella V, Barni S, Zecca E, Scarpi E et al. (1999): A new palliative prognostic score: a first step for the staging of terminally ill cancer patients. Italian Multicenter and Study Group on Palliative Care. J Pain Symptom Manage, 17(4): 231-239

Portenoy RK, Lesage P (1999): Management of cancer pain. Lancet, 353: 1695-1700

Pott G: Ethik am Lebensende, 1. Auflage, Schattauer Verlag, Stuttgart 2007, S. $53 \mathrm{f}$

Radbruch L, Sabatowski R, Loick G, Jonen-Thielemann I, Elsner F, Hörmann E (2000): MIDOS - Validierung eines minimalen Dokumentationssystems für die Palliativmedizin. Schmerz, 14: 231-239

Radbruch L, Nauck F, Fuchs M, Neuwöhner K, Schulenberg D, Lindena G (2002): What is palliative care in Germany? Results from a representative survey, J Pain Symptom Manage, 23(6): 471-483 
Radbruch L, Nauck F, Ostgathe C, Elsner F, Bausewein C, Fuchs M, Lindena G, Neuwöhner K, Schulenberg D (2003): What are the problems in palliative care? Results from a representative survey. Support Care Cancer, 11: 442-451

Reck M, Kranich AL, Steinbach AK, Gatzemeier U (2005): Neue molekulare Therapien beim nichtkleinzelligen Lungenkarzinom am Beispiel der EGFR/HER1-Inhibition. Med Klin, 100(12): 785-793

RKI= Robert-Koch-Institut: Krebshäufigkeiten Deutschland 2004, www.rki.de (2004)

Sabatowski R, Graf G: Stationäre Einrichtungen, ambulante Palliativ- und Hospizdienste, in: Lehrbuch für Palliativmedizin. Aulbert E, Nauck F, Radbruch L, 2. Auflage, Schattauer Verlag, Stuttgart 2007, S. 108-123

Sabatowski R, Radbruch L, Nauck F, Loick G, Meuser T, Lehmann KA (2001): Entwicklung und Stand der stationären palliativmedizinischen Einrichtungen in Deutschland. Schmerz, 15: 312- 319

Sabatowski R, Radbruch L, Nauck F, Roß J, Zernikow B: Wegweiser Hospiz und Palliativmedizin Deutschland 2005. Der Hospiz Verlag, Wuppertal 2005

Saltz LB, Metropol NJ, Loehrer PJ, Needle MN, Kopit J, Mayer RJ (2004): Phase II trial of cetuximab in patients with refractory colorectal cancer that express the epidermal growth factor receptor by immunohistochemistry. J Clin Oncol, 22(7): 1201-1208

Schöffski P, Dumez H, Clement P, Hoeben A, Prenen H, Wolter P, Joniau S, Roskams T, Van Poppel H (2006): Emerging role of tyrosine kinase inhibitors in the treatment of advanced renal cell cancer: a review. Ann Oncol, 17(8): 1185-1196

Sepulveda C, Marlin A, Yoshida T, Ullrich A (2002): Palliative care: the world health organization’s global perspective. J Pain Symptom Manage, 24(2): 91-96

Shepherd FA, Dancey J, Ramlau R, Mattson K, Gralla R, O'Rourke M, Levitan N, Gressot L, Vincent M, Burkes R et al. (2000): Prospective randomized trial of docetaxel versus best supportive care in patients with non-small cell lung cancer previously treated with platinum-based chemotherapy. J Clin Oncol, 18(10): 2095-2103

Shepherd FA, Pereira JR, Ciuleanu T, Tan EH, Hirsh V, Thongprasert S, Campos D, Maoleekoonpiroj S, Smylie M, Martins R et al. (2005): Erlotinib in previously treated nonsmall cell lung cancer. N Engl J Med, 353(2): 123-132

Slevin ML, Stubbs L, Plant HJ, Wilson P, Gregory WM, Armes PJ, Downer SM (1990): Attitudes to chemotherapy: comparing views of patients with cancer with those of doctors, nurses and general public. Br Med J, 300: 1458-1460 
Smith IE (1995): Medical management of non-small cell lung cancer. Eur J Cancer 31 A (5): 818-819

Statistisches Bundesamt Deutschland (2007): Todesursachen 2007, www.destatis.de Steele JPC, Klabatsa A (2005): Chemotherapy options and new advances in malignant pleural mesothelioma. Ann Oncol, 16: 345-351

Strumpf M, Zenz M, Donner B (1996): Germany: Status of cancer pain and palliative care. J Pain Symptom Manage, 12(2): 109-111

Tannock IF, de Wit R, Berry WR, Horti J, Pluzanska A, Chi KM, Oudard S, Theodore C, James D, Turesson I et al. (2004): Docetaxel plus prednisone or mitoxantrone plus prednisone for advanced prostate cancer. N Engl J Med, 351(15): 1502-1512

Taylor KM, Ng P, Bezjak A, Skeel RT, DePetrillo A (1997): Predicting Oncologists' use of quality of life (QOL) data: results of a survey of Eastern Cooperation Group (ECOG) physicians. ASCO Annual Meeting 1997, abstr 186

Tummarello D, Graziono F, Isidori P, Cellerino R (1995): Symptomatic, stage IV, nonsmall cell lung cancer (NSCLC): response, toxity, performance status change and symptom relief in patients treated with cisplatin, vinblastine and mitomycin-C. Cancer Chemother Pharmacol, 35: 249- 253

WHO= World Health Organisation: Cancer pain relief and palliative care. Report of a WHO Expert Committee (WHO Technical Report Series, No. 804), World Health Organisation, Geneva 1990 


\section{Veröffentlichungen}

Teile der Ergebnisse dieser Dissertation wurden auf folgenden medizinischwissenschaftlichen Fachkongressen vorgestellt:

Als Vortrag: 28. Deutscher Krebskongress vom 20.-23. Februar 2008 in Berlin im Rahmen des HOPE- Arbeitsgruppentreffens, am 23.02.2008: Tumortherapien in der Palliativmedizin (Autor: Pache S)

Als Vortrag: 7. Kongress der Deutschen Gesellschaft für Palliativmedizin vom 25.27.September 2008 in Wiesbaden, am 26.09.2008: Forschung im Verbund: Tumordiagnostik und -therapie auf der Palliativstation (Autor: Alt-Epping B)

Als Abstract: Alt-Epping B, Pache S, Lindena G, Nauck F (2008): Tumorspezifische

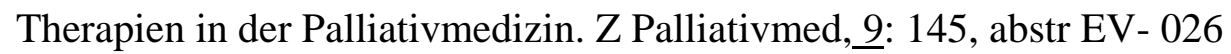

Als Poster: Jahrestag der DGHO, ÖGHO, SGMO 10.-14.10.2008 in Wien: Alt-Epping B, Pache S, Lindena G, Nauck F (2008): Anticancer therapies in palliative care setting? Multicenter evaluation and review of cases 


\section{Danksagung}

Zum Abschluss dieser Arbeit möchte ich mich ganz besonders herzlich bei Herrn Professor Dr. med. Friedemann Nauck und Herrn Dr. med. Bernd Alt-Epping für das Thema meiner Doktorarbeit und für das Ermöglichen dieser wissenschaftlichen Arbeit bedanken. Beide haben diese Arbeit mit ihren Ideen, ihrer Geduld und ihrer Erfahrung und vielen wegweisenden und ermutigenden Gesprächen und Anregungen immer wieder vorangetrieben. Des Weiteren möchte ich meinen besonderen Dank gegenüber Frau Dr. Gabriele Lindena von CLARA (Clinical Analysis, Research and Application) aussprechen, die mir mit wertvollen Ratschlägen bei der Interpretation und Erarbeitung der Daten sehr geholfen hat.

Nicht unerwähnt lassen möchte ich auch meinen Dank an alle Einrichtungen, die an HOPE 2007 teilgenommen haben, an der Apotheke und Abteilung Medizinische Statistik / Epidemiologie der UMG sowie an Dr. rer. nat. Thomas Hotz vom Institut für Mathematische Stochastik. 


\section{Lebenslauf}

Mein Name ist Sabrina Pache. Ich wohne in der Grafenberger Allee 43 in 40237 Düsseldorf. Am 14. Juli 1983 wurde ich in Nordhorn geboren. Nach meiner Schulzeit, die ich Sommer 2003 mit dem Abitur abschloss, absolvierte ich den Lehrgang für Rettungssanitäter/ innen an der Alten Michaelschule am Mathias-Spital in Rheine. Im Sommersemester 2004 begann ich mein Medizinstudium an der Georg-August-Universität in Göttingen, welches ich voraussichtlich im Juni 2010 mit dem zweiten Staatsexamen abschließen werde. Von Februar 2009 bis Januar 2010 leistete ich mein praktisches Jahr im Diakoniekrankenhaus in Rotenburg (Wümme) mit dem Wahlfach Gynäkologie. 